\title{
Paving the road for early breast cancer presentation
}

\author{
Citation for published version (APA):
}

Dewi, T. K. (2021). Paving the road for early breast cancer presentation: investigating the psychosocial determinants of breast self-examination in Surabaya, Indonesia. [Doctoral Thesis, Maastricht University]. Proefschriftenprinten.nl. https://doi.org/10.26481/dis.20211117td

Document status and date:

Published: 01/01/2021

DOI:

10.26481/dis.20211117td

Document Version:

Publisher's PDF, also known as Version of record

\section{Please check the document version of this publication:}

- A submitted manuscript is the version of the article upon submission and before peer-review. There can be important differences between the submitted version and the official published version of record.

People interested in the research are advised to contact the author for the final version of the publication, or visit the DOI to the publisher's website.

- The final author version and the galley proof are versions of the publication after peer review.

- The final published version features the final layout of the paper including the volume, issue and page numbers.

Link to publication

\footnotetext{
General rights rights.

- You may freely distribute the URL identifying the publication in the public portal. please follow below link for the End User Agreement:

www.umlib.nl/taverne-license

Take down policy

If you believe that this document breaches copyright please contact us at:

repository@maastrichtuniversity.nl

providing details and we will investigate your claim.
}

Copyright and moral rights for the publications made accessible in the public portal are retained by the authors and/or other copyright owners and it is a condition of accessing publications that users recognise and abide by the legal requirements associated with these

- Users may download and print one copy of any publication from the public portal for the purpose of private study or research.

- You may not further distribute the material or use it for any profit-making activity or commercial gain

If the publication is distributed under the terms of Article $25 \mathrm{fa}$ of the Dutch Copyright Act, indicated by the "Taverne" license above, 
Paving the Road for Early Breast Cancer Presentation: Investigating the psychosocial determinants of breast self-examination in Surabaya, Indonesia

Triana Kesuma Dewi 
(C) Triana Kesuma Dewi, 2021

Cover design by: Bivita Brata Riko

Printed by: proefschriftenprinten.nl

ISBN/EAN: 978-90-831893-1-4

The research presented in this dissertation was conducted at the department of Work and Social Psychology, Maastricht University.

All rights are reserved. No part of this book may be reproduced, distributed, or transmitted in any form or by any means, without prior written permission of the author. 


\title{
Paving the Road for Early Breast Cancer Presentation:
}

\author{
Investigating the psychosocial determinants \\ of breast self-examination in Surabaya, Indonesia
}

\section{DISSERTATION}

to obtain the degree of Doctor at the Maastricht University, on the authority of the Rector Magnificus, Prof. dr. Rianne M. Letschert, in accordance with the decision of the Board of Deans, to be defended in public on Wednesday 17 November 2021, at 10.00 hours

by

Triana Kesuma Dewi 


\section{Supervisor:}

Prof. dr. R. A. C. Ruiter

\section{Co-supervisors:}

Dr. K. Massar

Dr. R. Ardi, Universitas Airlangga, Indonesia

\section{Assessment committee:}

Em. Prof. dr. G. Kok (Chair)

Em. Prof. dr. H. W. van den Borne

Dr. G. A. ten Hoor

Prof. dr. E. H. S. Lechner, OU Heerlen

Prof. dr. J. Prawitasari, Krida Wacana Christian University, Indonesia 


\section{This dissertation is dedicated to}

My husband, Bandono - the backbone, for making the impossible, possible.

Our beloved children, Bima, Indra, Zahra, and Fatimah - the future.

My parents, Bapak and Mami - the first love. 



\section{Table of contents}

Chapter 1. General Introduction

Chapter 2. Determinants of breast self-examination practice among women in 29 Surabaya, Indonesia: An application of the health belief model

Chapter 3. Determinants of early breast cancer presentation: a qualitative exploration among female survivors in Indonesia

Chapter 4. The role of psychosocial variables in breast self-examination practice: Results from focused group discussion in Surabaya, Indonesia

Chapter 5. Breast self-examination as a route to early detection in a lower middle-income country: Assessing psychosocial determinants among women in Surabaya, Indonesia

Chapter 6. General Discussion 

Chapter 1.

General Introduction 


\section{Breast cancer}

Breast cancer is a disease marked with malignant (cancer) cells that form in breast tissue. These cells can subsequently spread through the blood or lymph system to other parts of the body, resulting in metastatic breast cancer (American Cancer Society, 2021). Metastatic breast cancer is marked by any spread of cancer cells that originated in the breast to another part of the body, most commonly the liver, brain, bones, or lungs (Breastcancer.org, 2021a). The American Cancer Society (ACS; 2021) described that the most common symptom of breast cancer is the detection of a lump or mass in the breast tissue, which can be either painless or painful; swelling of the whole or part of the breast; breast skin dimpling; breast or nipple pain; nipple retraction; red, dry flaking or thickened nipple or skin; nipple discharge (other than breast milk); or swollen lymph nodes. The breast cancer staging system generally classifies breast cancer into stages 0 to IV, in which the higher the stage indicates the larger tumor size, higher degree of tumors differentiation, and the presence of axillary metastases (Breastcancer.org, 2021b).

\section{Breast cancer incidence, prevalence, and mortality}

Breast cancer is the most frequently reported malignancy among women globally, accounting for $11.7 \%$ of all types of cancer (IARC, 2020a). In Indonesia, as elsewhere, breast cancer is of great concern. Particularly, breast cancer mortality in Indonesia is among the highest in Asia, i.e., together with India, China, Pakistan, and Japan, these 5 countries contribute to $73.4 \%$ of breast cancer mortality in Asia (Ghoncheh et al., 2016). Indeed, the World Health Organization (WHO) noted that breast cancer has the highest incidence of all cancer in Indonesia, representing $30.8 \%$ of all new cancer diagnoses among women, and it is the second-highest cause of death in the country after lung cancer, constituting $9.6 \%$ of all 
cancer-related deaths (IARC, 2020b). Overall, the demographic characteristics of cancer patients in Indonesia are being aged 35 years or older with diverse socio-economic backgrounds, and mostly living in urban areas (Ministry of Health RI, 2019).

The high number of breast cancer mortality in Indonesia is mostly the result of the delayed presentation, i.e., the disease is diagnosed in advanced stages (Stage III and IV) where the curative treatment is no longer effective (Caplan, 2014). Previous studies in lowand-middle-income countries (LMICs) indicated that approximately $77 \%$ of patients with breast cancer were diagnosed at an advanced stage (Jedy-Agba et al., 2016; Lopes et al., 2015). Similarly, breast cancer in Indonesia is in approximately $60 \%-70 \%$ of cases detected in an advanced stage, with 35\% of the cases metastasized (Anwar et al, 2019; Ministry of Health RI, 2018; Ng et al., 2011; Irwan et al., 2008). According to ACS (2021), the 5-year survival rate (i.e., the percentage of people with the same type and stage of cancer who are still alive at least 5 years after being diagnosed) of women diagnosed with breast cancer between 2010 and 2016 is $90 \%$. Specifically, the 5-year survival rate of breast cancer among patients without any sign of cancer spreading outside the breast is $99 \%$, whereas it decreases to $86 \%$ when cancer has spread outside the breast to nearby structures or lymph nodes and reduces further to only $28 \%$ when cancer has spread to distant parts of the body such as lungs, liver or bones. Globally, breast cancer mortality rates have been declining for past decades (Autier et al., 2011; Narod et al., 2015), and current literature confirms that the mortality reduction is mostly due to effective breast cancer screening - followed by timely treatment (Hofvind et al., 2013; Broeders et al., 2012; Njor et al., 2012; van Schoor et al., 2011). Therefore, strategies for improving early diagnosis should be regarded as a major priority in breast cancer control. 


\section{Psychosocial issues in breast cancer}

Being diagnosed with breast cancer is an immensely stressful experience for a woman, which may compromise their quality of life, life purpose, career, and family life (Khazaee-Pool et al., 2014; Schmidt et al., 2018). Nowadays, cancer treatments lead to better survival, however, women diagnosed with breast cancer may still experience physical and emotional distress related to the disease course, and adverse effects of treatment. For example, women who are treated with radiation therapy or chemotherapy may experience nausea or vomiting, chronic diarrhea, hair loss, fatigue, and loss of energy (Taylor, 2020). Additionally, breast cancer poses a threat to the breast, which symbolizes femininity and sexuality, and thus women also report a loss of self-perceived attractiveness, and changes in female identity, body image, and sexuality (Ganz, 2008; İzci et al., 2016; Khazaee-Pool et al., 2014; Schmid-Büchi et al., 2008). Furthermore, commonly reported experiences resulting from a breast cancer diagnosis are feeling uncertain about the treatment, occurrence of physical symptoms, fear of recurrence of cancer, intrusive thoughts about the illness and existential concerns about death, difficulties in adjusting daily life activities, family related problems, and lack of emotional support (Ganz, 2008; Schmid-Büchi et al., 2008). Previous systematic reviews and meta-analyses indicated that being diagnosed with cancer may lead to mental health problems, such as major depressive disorder with a global prevalence of 32.2\% (Pilevarzadeh et al., 2019). Physical and emotional issues related to breast cancer may interfere with women's perceptions towards the disease as well as its screening and treatment procedures, and these could subsequently influence their decision to engage in such procedures - causing screening absenteeism due to fear of positive diagnosis (see Al-Naggar \& Bobryshev, 2012). 


\section{Breast cancer early detection and treatment modalities}

Early detection refers to the effort to find and diagnose breast cancer early, preferably before a person has symptoms (American Cancer Society, 2021). According to the National Cancer Institute (NCI; PDQ ${ }^{\circledR}$ Screening and Prevention Editorial Board, 2020) the procedures or tests used to detect and diagnose breast cancer by health professionals are sevenfold: 1) Physical exam and health history - a procedure to check general signs of health including sign of a disease such us lumps or anything that seems unusual, and explore the patients' history of health habits, and past illness and treatment, 2) Clinical Breast Exam (CBE) performed by a health professional who will carefully feel the breast and under arms for lumps or anything else that seems unusual, 3) Mammogram - is an x-ray picture of the breast, 4) Ultrasound exam - a procedure to use high-energy sound waves (ultrasound) to make a picture of breast, 5) Magnetic Resonance Imaging (MRI) - a procedure that uses a magnet, radio waves, and a computer to make series of specified pictures of breast, 6) Blood chemistry studies - a blood sample examination to measure amounts of certain substance released into the blood by organs and tissues as the sign of a disease, and 7) Biopsy - a procedure to take cells from breast tissue to check for sign of cancer under a microscope by a pathologist.

The NCI describes different types of treatment are available for patients with breast cancer (PDQ ${ }^{\circledR}$ Adult Treatment Editorial Board, 2021): 1) Surgery to remove cancer, 2) Radiation therapy that uses high-energy x-rays or other types of radiation to kill cancer cells or stop them from growing, 3) Chemotherapy that uses drugs to stop the cancer cell from growing by killing the cells or stopping them from dividing, 4) Hormone therapy by removing hormones or blocks their action and stops cancer cells from growing, 5) Targeted therapy uses drugs to identify and attack specifics cancer cells which cause less harm to normal cells than chemotherapy or radiotherapy, and 6) Immunotherapy that uses the patients' 
immune system to fight cancer. The treatment plan can comprise individual treatment or a combination of several treatment types, depending on the tumor size and the presence of metastases.

\section{Breast cancer screening in Indonesia}

Mammography is the most universally accepted method and is the golden standard for breast cancer screening (American Cancer Society, 2021; PDQ ${ }^{\circledR}$ Screening and Prevention Editorial Board, 2020). However, in Indonesia, there is limited access to it. Mammography has not been designated as an organized national screening program and is not covered by Badan Penyelenggara Jaminan Sosial Kesehatan (BPJS Kesehatan) - Indonesian national health insurance, therefore, it is costly and individuals have limited access to this procedure (Choridah et al., 2019). A substantial effort is being made to establish an organized breast screening program through the National Movement of Breast and Cervical Cancer Screening, by promoting regular BSE at least monthly, as a breast cancer screening modality besides regular CBE in the Community Healthcare Centers (CHCs, Indonesian: Pusat Kesehatan Masyarakat-Puskesmas; Ministry of Health RI, 2015a). As a result of this program, up to 2017, early detection for cervical cancer and breast cancer has been done for 3,040,116 (2.98\%) women aged 30-50 years throughout Indonesia, with breast cancer examination was carried out using CBE (Ministry of Health RI, 2018).

There is ongoing debate regarding the efficacy of BSE and CBE in terms of mortality reduction. The ACS no longer recommends BSE to detect breast cancer in its early stages because it is not significantly associated with survival rates when at the same time the women also tested for mammography (American Cancer Society, 2017). However, in technically less developed countries where women are usually diagnosed with breast cancer at advanced stages and there is limited health care access, as is the case in Indonesia, the benefits of BSE 
and $\mathrm{CBE}$ (i.e., raise awareness, decrease tumor size, and earlier stage at diagnosis) might outweigh the disadvantages and facilitate early detection of breast cancer (Albeshan et al., 2020; Corbex et al., 2012). Furthermore, as argued by Gyawali et al. (2016), implementing a more cost-effective screening program in LMICs (e.g., breast awareness followed by timely diagnosis and treatment) is more feasible than implementing mammography-based screening, particularly since mammography has not shown to decrease breast cancer mortality in younger women. The International Agency of Research Cancer (IARC) recorded that mammography effectively reduces mortality in women aged 50-74 but there is limited evidence for its effectiveness for women of a younger age (Lauby-Secretan et al., 2015) while most women in LIMCs are diagnosed with breast cancer precisely at these younger ages (Ministry of Health RI, 2019, Bhoo Pathy et al., 2011; Ng et al., 2011; Najjar \& Easson, 2010).

\section{Promoting breast cancer early detection}

Understanding and promoting breast cancer early detection may involve a multidimensional and complex approach. The ecological model of health and health behavior suggests that all parts of the health system have an important role in promoting health behavior (see Bartholomew Eldredge et al., 2016). Specifically, this approach targets five levels of influence for health behavior: individual factors, interpersonal process, organizational factors, community factors, and public policy (McLeroy et al., 1988). In addition, the psychosocial factors underlying health behavior are both powerful and malleable, making them ideal targets for interventions to change health behaviors. A conceptual review and synthesis about common psychosocial factors underlying breast cancer screening adherence differentiated 
three domains, i.e., demographic and structural factors, cognitive variables, and socioemotional variables (Magai et al., 2007), which are elaborated below:

\section{Demographic and structural factors}

Demographic variables. Numerous previous studies on breast cancer screening documented the association between demographic variables and screening behavior. For example, younger age is positively associated with screening: Research in China, India, and Turkey indicated that women aged 59 and younger were more likely to report breast cancer screening adherence than older women (Frie et al., 2013; Gang et al., 2013; Gürsoy et al., 2011; Sreedevi et al., 2014). Another factor is education, which seems to have a conflicting association with breast cancer screening. Having a higher education was significantly and positively correlated with breast cancer screening uptake in Brazil, Nigeria, and India. In contrast, screening adherence among women in China was associated with lower education (Gang et al., 2013). Other demographic variables associated with breast cancer screening uptake found in previous studies are higher income or social status, being married, and being from an urban area (Dundar et al., 2012; Frie et al., 2013; Gang et al., 2013; Gürsoy et al., 2011; Sreedevi et al., 2014).

Structural factors. Healthcare access and availability, and cost of screening and treatment are among the variables related to breast cancer screening, especially in LIMCs. For example, limited utilization of breast cancer screening modalities (i.e., mammography) in India was reported, due to lack of health insurance and financial restraints (Sreedevi et al., 2014; Frie et al., 2013). Other barriers identified for screening absenteeism are a lack of access to healthcare providers, for example, due to long waiting hours and overcrowded clinics, lack of a physician's recommendation to have a breast cancer screening, difficulty in making an appointment, and lack of facilities in nearby clinics resulting in extra travel costs to travel to 
clinics further from home (Iskandarsyah et al., 2014; Kissal \& Beşer, 2011; Sreedevi et al., 2014). Additionally, less communicative healthcare professionals were also regarded as barriers to breast cancer screening (Kissal \& Beşer, 2011).

\section{Cognitive variables}

Knowledge. The women's knowledge about breast cancer and its screening and treatment modalities is assumed to influence their decision to engage in their screening behavior. A systematic review of 22 breast cancer screening studies in LIMCs documented that lack of knowledge and awareness were key barriers to breast cancer screening. Women had poor knowledge about the nature of the disease (early signs and symptoms) and about possible screening methods, which leads to screening absenteeism since they were asymptomatic, did not know that screening was necessary, did not know where to go for screening, did not know about BSE, and did not know how to perform BSE (Islam et al., 2017).

Risk perception. Risk perception refers to the individual's perceived susceptibility to a threat, which is regarded as a key motivator for preventive action (Janz \& Becker, 1984; Leventhal \& Brissette, 2012; Vernon, 1999; Weinstein, 1988). The perception that one is not at risk for breast cancer may lead to breast cancer screening absenteeism. For example, previous studies in Nigeria, Turkey, and Malaysia indicated that women did not check their breasts since they perceived that they were not at risk, i.e. they experienced no physical symptoms, felt well, had no history of breast cancer in their family, and perceived themselves as among the low-risk group (Amoran \& Toyobo, 2015; Hassan, 2015; Kissal \& Beşer, 2011).

Attitudes towards screening. Attitudes towards a health behavior are generally considered as a major determinant of intention for screening behavior (Cooke \& French, 2008). When one 
regards breast cancer screening as necessary, important, and beneficial, the intention to engage in such screening will be higher. For example, studies among women in China, Iran, and Turkey indicated women's perceived benefits of uptaking a breast cancer screening were a significant predictor of their mammography adherence (Dundar et al., 2012; Gang et al., 2013; Hajian Tilaki \& Auladi, 2015). Conversely, when women regarded breast cancer screening as not interesting and expressed negative attitudes about it, they were less likely to perform the procedures (Ferrat et al., 2013; Frie et al., 2013).

\section{Socioemotional variables}

Social networks. Social network characteristics that influence screening behaviors include network size (i.e., the number of connections within a network), social support (i.e., perceived availability of general emotional, instrumental, and informational support provided by network members), and social influence, generally distinguished into two components: injunctive norms (i.e., what do important others think) and descriptive norms (i.e., what do important others do). All these elements are positively associated with breast cancer screening (Allen et al., 1999; Latkin \& Knowlton, 2015). For example, numerous studies in both developed and developing countries documented that greater social support promotes breast cancer screening adherence (Smalls et al., 2018; Documet et al., 2015; Leyva et al., 2015; Donnelly et al., 2013; Ma et al., 2012). Additionally, a systematic review and meta-analysis indicate that injunctive norms (i.e., physician recommendation, and family and friends recommendation) increased the motivation to undergo cancer screening among cancer patients' first-degree relatives (Fattahi Ardakani et al., 2020).

Emotion. Emotions have a motivational function for the occurrence of a behavior (Consedine et al., 2003; Mayne, 1999), often causing avoidance or approach tendencies. Thus, the 
experience of negative emotion, for example, fear or embarrassment, exerts an important influence on breast cancer screening uptake. Previous literature indicated that fear, in particular, may promote or prevent precautionary motivation and self-protective actions (Rogers \& Deckner, 1975; Ruiter et al., 2014). For example, a qualitative study among elderly women in Turkey indicated that fear of having breast cancer and metastasis to other organs, and a fear of needing others' assistance for self-care, facilitated breast cancer screening (Kissal \& Beşer, 2011). In contrast, a systematic review in LMICs indicated that fear and anxiety of being diagnosed with breast cancer, fear of painful mammography or screening discomfort, fear of breast removal, and fear of treatment (e.g., surgery, radiation therapy) limited the utilization of breast cancer screening (Islam et al., 2017). While fear appears to have a conflicting result on breast cancer screening uptake, previous studies found that embarrassment has been negatively associated with screening (Frie et al., 2013; Khazaee-Pool et al., 2014; Kissal \& Beşer, 2011; Sreedevi et al., 2014).

\section{The current project: Promoting BSE in the Indonesian context}

Previous research has shown that BSE is associated with increased health-seeking behavior and undergoing biopsies (Hackshaw \& Paul, 2003), which are positively associated with earlier diagnosis and more enhanced treatment outcomes (Miller \& Baines, 2011). Nevertheless, the practice of BSE among Indonesian women is still low (Ministry of Health RI, 2018; Pengpid \& Karl, 2018). Therefore, the development of effective strategies to promote BSE practice among Indonesian women is imperative. To be able to develop a culturally sensitive and theory-based program to promote BSE, it is necessary to first identify the target population's needs and describe the problem. To the best of our knowledge, there 
are limited published empirical studies about multidimensional factors that determine BSE practice among women in Indonesia. The current project aims to fill this gap.

The studies that are featured in this dissertation were conducted in Surabaya, the capital city of East Java province, Indonesia. Surabaya is the second-largest city in Indonesia after Jakarta and is the center of the regional economy in eastern Indonesia. The city is located on the north-eastern border of Java island and covers 31 sub-districts and 154 administrative villages, in an area of $326.36 \mathrm{~km}^{2}$, with a total population of 3,094,732 (Statistics of Surabaya, 2019). The majority of the Surabaya population is Muslim. Although most inhabitants are Javanese, other ethnicities in Surabaya are Madurese, Sundanese, Minangkabau, Batak, Banjar, Balinese, Bugis, Malay, Chinese, Arabs, and Indians. These diverse groups and the coastal geographical nature create unique characteristics of Javanese culture in Surabaya (i.e., Arek culture), which is considered as egalitarian, open, and having high solidarity, while at the same time it is rooted in traditional and religious values (see Cholil, 2017; Sa'ir et al., 2020). As the capital city of East Java province, Surabaya is facilitated with several hospitals, including five top referral hospitals and Puskesmas in each sub-district. Specifically, as of 2018, there are 37 general hospitals, 14 maternity hospitals, and one cancer hospital among others (Statistics of Surabaya, 2019), which would support breast cancer early detection and/or treatment in Surabaya. The Ministry of Health (2018) reported that the cancer prevalence in East Java is $2.17 \%$, which is higher than the national prevalence. However, breast cancer early detection practice conducted with CBE in East Java is above the national rate, accounting for $3.81 \%$ of women aged $30-50$ years (Ministry of Health RI, 2018). 


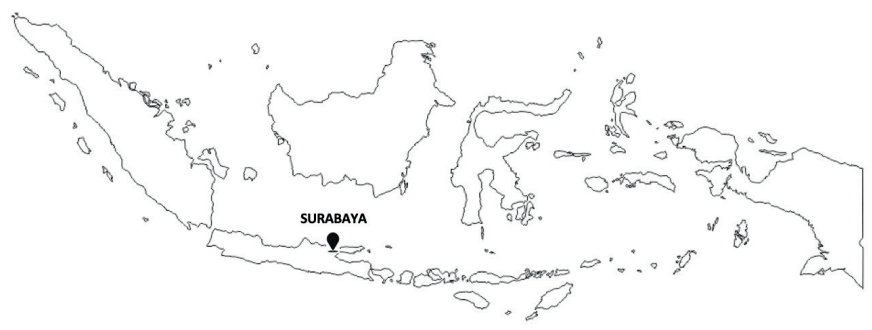

Figure 1. Map of Indonesia

\section{Theoretical frameworks}

Identifying the underlying factors that influence Indonesian women's decision to engage or not to engage in BSE practice is the first step to inform future breast cancer awareness interventions. In the studies reported in this dissertation, we will explore which determinants influence breast cancer screening practice, particularly BSE, combining the socio-ecological model (McLeroy, et al., 1988) and psychosocial factors (i.e., structural, cognitive, and socioemotional; Magai et al., 2007) that are part of the Health Belief Model (HBM), the Theory of Planned Behavior (TPB) and the Reasoned Action Approach (RAA). These three theoretical frameworks have been used in previous research, and can successfully predict a wide-range of health behaviors, including cancer screening (see Armitage \& Conner, 2001; McEachan et al., 2016; Ritchie et al., 2021).

Health Belief Model. The HBM, first introduced by Rosenstock (1966), proposes that health behavior is determined by individual beliefs or perceptions about a disease, and the strategies available to reduce the likelihood of that disease occurring. According to HBM, the constructs that influence the decision to engage in health behavior are: 1) perceived susceptibility perceived personal vulnerability to the risk of developing a disease, 2) perceived severity beliefs about the seriousness of the disease and its consequences, 3) perceived benefits beliefs about the advantageous of performing a health behavior, 4) perceived barriers - 
perceived personal costs or negative attributes of performing a health behavior, 5) cues to action - the internal or external triggers that encourage the performance of health behavior, and 6) self-efficacy - an individual's beliefs regarding their ability to perform a health behavior. Perceived susceptibility and perceived severity together form the perceived threat of a disease, while perceived benefits and perceived barriers represent the evaluation of the health behavior targeted to reduce the threat. While perceived barriers will reduce the likelihood to perform the health behavior, the other HBM components are positively associated with the behavior occurrence. Skinner et al. (2015) added that demographic variables (e.g., age, gender, etc.) and psychosocial factors (e.g., personality, peer pressure, etc.) may also influence the relationship between the main constructs and the performance of health behaviors.

Previous research indicated that HBM could be used to predict a wide range of healthrelated behavior, including breast cancer screening practice. For example, a study among Iranian students indicated that HBM constructs can predict BSE behavior (Didarloo et al., 2017). This study indicated that participants who scored high on perceived severity, perceived barriers, and self-efficacy were more likely to perform BSE behavior. Similarly, another study among female teachers in Ethiopia also documented the applicability of HBM to predict BSE behavior, with perceived susceptibility, perceived severity, and perceived benefits found to be the major predictor of BSE behavior (Birhane et al., 2015). Other studies among Saudi Arabia, Iranian, and China women also documented the significance of HBM constructs to predict BSE behavior (Abolfotouh et al., 2015; Noroozi et al., 2011a; Wang et al., 2019).

Theory of Planned Behavior and Reasoned Action Approach. The TPB (Ajzen, 1991) and the RAA (Fishbein \& Ajzen, 2010) state that the most proximal determinant of health-related behavior is the intention to engage in the behavior. This behavioral intention is further 
determined by the attitudes towards behavior, subjective norms, and perceived behavioral control. The RAA is the extended version of the TPB, which differentiates those three TPB subcomponents. In more detail, the RAA states that the decision to perform or not perform a health behavior is guided by beliefs associated with the behavior, distinguished into three kinds of beliefs. First, behavioral beliefs about consequences that one may experience if they perform a health behavior. These beliefs or outcome expectancies will determine the individual's attitude - positive or negative evaluation - towards a health behavior. Further, attitude is differentiated into instrumental attitude - which refers to the cognitive evaluation of behavior in the context of useful or rewarding, and experiential attitude - which is the affective component of attitude. Second, normative beliefs whether important others in one live would approve or disapprove of their performing a health behavior (injunctive normative beliefs), as well as to perform or not to perform the behavior (descriptive normative beliefs). These normative beliefs produce a perceived norm, which is perceived social pressure to engage or not to engage in a behavior. Finally, control beliefs refer to personal and environmental factors that can help or impede one's attempts to perform the behavior. These beliefs will result in a sense of self-efficacy (Bandura, 1977) or perceived behavioral control $(P B C)$ towards the behavior. $\mathrm{PBC}$ is further categorized into perceived capacity - judgments of the perceived capability of performing the behavior, and perceived autonomy - refers to the degree of control over a behavior. Generally, when an individual perceives that the performance of a behavior results in more positive than negative outcomes, the attitude towards the behavior should be favorable. If a person perceives that more significant others approve than disapprove of the behavior, and if the majority of important others perform the behavior, they are likely to perceive social pressure to engage in the behavior. And finally, when control beliefs identify more facilitating factors than inhibiting factors, PBC would be high. In combination, attitudes, perceived norms and PBC would lead to the formation of a 
behavioral intention - readiness to perform the behavior. Finally, the intention would further predict the occurrence of the health behavior.

A meta-analysis on the efficacy of the TPB reported that TPB components significantly predicted a wide-range of health-related behavior, including cancer screening (McEachan et al., 2011). In addition, a meta-analysis on RAA subcomponents found that all constructs except autonomy were significant predictors of intention, while intention, capacity, experiential attitude, and descriptive norms were significant predictors of varied health behavior (McEachan et al., 2016). Additionally, a meta-analysis across 33 studies to predict intention and attendance on screening programs reported that attitudes had a large-sized relationship with intention, while subjective norms and $\mathrm{PBC}$ possessed medium-sized relationship with intention; whereas, attendance was highly correlated with intention and medium-sized relation with PBC (Cooke \& French, 2008). Further, previous studies also documented the applicability of the TPB/RAA components to predict breast cancer screening. For example, breast cancer screening intention was predicted by subjective norms in an Iranian population (Firouzbakht et al., 2020); whereas a study in Australia indicated that attitude, subjective norms, and PBC predicted BSE intention, while intention and PBC significantly predict BSE behavior (Mason \& White, 2008). Drossaert et al. (2003) added that TPB variables were more related to the initiation of screening behavior (consistent refusal $v s$. delayed attendance) than to the maintenance of screening behaviors (consistent attendance $v s$. dropout). Additionally, Norman and Cooper (2011) found that subjective norms and PBC were significant predictors of BSE intention; and their study also reported that both frequency of past behavior and context stability in which the behavior is performed moderates the habit strength and behavior relationship. 


\section{Project overview}

The overall aim of this dissertation is to understand the relevant and changeable determinants of BSE behavior in the Indonesian context because systematic research is lacking for this context. The findings will further inform the key targets for future tailored breast awareness education aimed at stimulating regular BSE and other screening behaviors among Indonesian women. Therefore, the objectives of this dissertation are twofold:

1) To explore psychosocial determinants of BSE quantitatively according to HBM among the general population (Chapter 2), and qualitatively according to TPB/RAA among breast cancer survivors (semi-structured interviews, Chapter 3) and women from the general population (focus group discussions, Chapter 4) in Surabaya, Indonesia.

2) To quantitatively confirm and assess psychosocial determinants of BSE among women in Surabaya, Indonesia - Chapter 5.

Specifically, we conducted four empirical studies - using both quantitative and qualitative methodology - which are documented in the chapters of this dissertation:

Chapter 2 is a cross-sectional study exploring the determinants of BSE based on the HBM among the general population in Surabaya, Indonesia $(n=1,967)$. This chapter specifically investigating to what extent HBM components (perceived susceptibility, perceived severity, self-efficacy, perceived barriers, perceived benefits, and cues to action) could predict women's intention to and actual performance of BSE. In Chapter 3, we report on semistructured interviews exploring the determinants of breast cancer early presentation among breast cancer survivors in Surabaya $(n=23)$. This study focuses on internal (i.e., lack of knowledge, perceived behavioral control, previous health-related experiences and risk perceptions, and attitudes and beliefs) and external (i.e., norms, competing priorities, financial issues, instrumental factors, and health provider factors) factors that promote earlier 
presentation. In Chapter 4, we report on focus group discussions (FGDs) among women from the general population in Surabaya, who never or rarely perform BSE $(n=62)$ to explore the determinants which would motivate BSE behavior. In this chapter, we examine the applicability of the RAA for BSE, whether knowledge, attitude and beliefs, risk perception, norms, and perceived behavior control would predict women's intention to and actual performance of BSE. Additionally, we also explore the effective approach work best to improve breast awareness in the women's social network. Lastly, we confirmed and assessed the determinants related to BSE behavior that we identified in Chapter 2-4 in Chapter 5. In this study $(n=204)$, we investigate whether the intention and performance of BSE were determined by knowledge, HBM components, and TPB/RAA components. Finally, Chapter 6 covers the general discussion of the projects. 



\section{Chapter 2.}

\section{Determinants of breast self-examination practice among women} in Surabaya, Indonesia: An application of the health belief model

\section{Published as:}

Dewi, T. K., Massar, K., Ruiter, R. A. C., \& Leonardi, T. (2019). Determinants of breast selfexamination practice among women in Surabaya, Indonesia: an application of the health belief model. BMC Public Health, 19(1), 1-8. 


\section{Abstract}

Breast cancer has become one of the most common causes of mortality among Indonesian women. Many women in Indonesia present with late-stage breast cancer, negatively affecting prognosis and treatment outcomes. Better prognosis of breast cancer will be achieved if it is diagnosed in an earlier stage, thus efforts to detect breast cancer earlier are important. Breast self-examination (BSE) is considered as an important first step to encourage women to actively be responsible for their own health, especially for women in low-and middle-income countries (LMICs) with limited resources and access to other forms of preventive healthcare (e.g., screening programs). The present study aimed to predict BSE practice among women in Surabaya, Indonesia using the Health Belief Model (HBM). This investigation was a crosssectional survey which was distributed among 1,967 women aged $20-60$ years. The Indonesian version of Champion's Health Belief Model Scale (I-CHBMS) was used to explain self-reported BSE practice. Logistic regression analysis was used to examine the association of HBM variables with BSE practice. $44.4 \%$ of the respondents indicated they had performed BSE. Further, the results indicated that the HBM variables were significantly associated with BSE practice. Specifically, higher perceived benefits and self-efficacy, lower perceived barriers and less cues to action were unique correlates of BSE practice. The result also showed that perceived severity and susceptibility were not associated with BSE practice. To conclude, this study indicated that several HBM constructs significantly associated with BSE practice among Indonesian women, suggesting that BSE health education programs should emphasize the perceived benefits of BSE, focus on increasing women's self-efficacy to address and overcome perceived barriers in performing BSE, and help them in identifying personally relevant cues to action. 


\section{Introduction}

Globally, breast cancer is the most common type of cancer, especially in low-and middle-income countries (LMICs; American Cancer Society, 2011). For example, as of 2012, Indonesia had a breast cancer incidence rate of 40.3 per 100,000 population and a mortality rate of 16.6 per 100,000 (Ghoncheh et al., 2015). Breast cancer accounted for $16.7 \%$ of all cancer cases (ranking first among types of cancer) and $11 \%$ of all cancer-related deaths (ranking second after lung cancer; IARC, 2018a).

In Indonesia, most cancer patients are age 35 years or older; they come from diverse socio-economic backgrounds, but mostly live in urban areas (Ministry of Health RI, 2013). The medical costs of managing, ranging from diagnosis to various treatments such as chemotherapy and radiotherapy, are high and are increasing every year (Lauver, 1987; Ministry of Health RI, 2015a). One factor that greatly increases the cost of cancer treatment is that most patients are already at an advanced stage of the disease when they first seek healthcare. Therefore, early cancer detection programs are important in Indonesia; even though early detection would not decrease the incidence of breast cancer, it would help improve the prognosis and treatment outcomes, which could ultimately reduce mortality rates (McPherson et al., 2000), while also reducing the cost of treatments.

Regular breast self-examination (BSE), combined with breast self-awareness, is one of strategy aimed at achieving early breast cancer detection, especially in LMICs where access to other early detection methods, such as mammography and ultrasonography, is limited. BSE is uniquely suited for populations with limited access to formal healthcare: it is inexpensive, non-invasive, simple to perform, and does not depend on a health practitioner's assistance. Furthermore, performing regular BSE enhance breast awareness and encourage women to take more active responsibility for their own health (Lauver, 1987; Narimah et al., 1999). 
The Indonesian Ministry of Health launched its 'National Movement for Prevention and Early Detection of Breast and Cervical Cancer' program in 2015. This program sought to encourage women age 20 and older to go to a primary healthcare center (PHC) for regular clinical breast examinations (CBEs). It is also provided BSE education and encouraged women to practice BSE at least monthly (Ministry of Health RI, 2015a). The effort to increase the use of BSE as an early home-based screening for breast cancer constitutes a critical part of early detection activity.

Research in LMICs has indicated that regular BSE is associated with the identification of breast cancer in an earlier stage, and thereby with reduced mortality (Lam et al., 2008). However, early detection, whether through BSE or by other means, must be followed up with prompt diagnosis and effective treatment (Anderson et al., 2008). In LMICs, as is the case in Indonesia where most cancers are diagnosed at a relatively late stage, BSE, followed up by CBE at a healthcare facility, could be effective in increasing early detection of breast cancer and in improving treatment outcomes (Miller \& Baines, 2011).

Although exact numbers on BSE practice among Indonesian women are lacking, a study conducted among university students from low and middle income, and emerging economy countries indicated that BSE practice among Indonesian students was higher (64.5\%) compared to other South East Asian countries, i.e., Laos, Philippines, Singapore and Thailand, where BSE practice ranged between 19.7\%-58.2\% (Pengpid \& Peltzer, 2018). Moreover, studies in Muslim samples indicated that BSE practice among Saudi, Turkish, and Iranian women was 41.6\%, 39.5\% and 41.9\% respectively (Abolfotouh et al., 2015; Noroozi et al., 2011; Secginli \& Nahcivan, 2006).

Several studies have shown show positive associations between cancer screening behaviors (including BSE) and psychological variables such as self-efficacy and attitudes, and the Health Belief Model (HBM) in particular has proven to be a valid tool to predict such 
screening behaviors among women in LMICs (Birhane et al., 2015; Nahcivan \& Secginli, 2007; Noroozi et al., 2011). The HBM (Rosenstock, 1966) explains health behavior as being determined by personal beliefs or perceptions about a disease, as well as by the strategies available to an individual to reduce the occurrence of the disease (Sheeran \& Abraham, 2003). Specifically, according to this model, people's beliefs and perceptions influence their health behavior, such that when individuals perceive that they are at risk for the disease they will perform the health behaviors necessary to prevent it, if they are reminded of these behaviors and expect anticipated positive health outcomes from performing them (Rosenstock, 1966).

The most recent conceptualization of the HBM (Carpenter, 2010) includes the following components: perceived susceptibility, or one's perceived personal vulnerability to the risk of incurring the health condition in question; perceived severity, or the degree of personal harm expected if one were to incur the health condition; perceived benefits, or the positive results expected from performing a certain health behavior; perceived barriers, meaning the perceived costs or negative attributes of performing a health behavior; cues to action, or the internal or external triggers that encourage the performance of the health behavior; and selfefficacy, or one's confidence in his or her ability to perform the health behavior.

Champion (1984) was the first to apply the HBM framework to investigating women's beliefs regarding breast cancer and breast screening behavior, including BSE and mammography, resulting in the development of Champion's Health Belief Model Scale (CHBMS; Champion \& Scott, 1997; Champion, 1999). This scale has been widely used to predict breast cancer screening rates, and has been adapted to many languages and cultural settings such as Iran (Tavafian et al., 2009), Taiwan (Wang et al., 2014), and Turkey (Karayurt \& Dramal, 2007). The present study's aim was to investigate whether the HBM variables are correlates of BSE practice among Indonesian women. 
Previous research demonstrated the ability of HBM to predict a range of health-related behavior, including breast cancer screening practice (Sheeran \& Abraham, 2003). Various results related to the significance and magnitude of HBM factors in predicting BSE practice have also been reported (Guilford et al., 2017; Oh et al., 2017; Shin et al., 2012). However, due to specific characteristics of the Indonesian population, further exploration of the relationship between HBM and BSE practice among Indonesian women is needed. This population is characterized by limited health care resources - for example, only $7.6 \%$ of all PHCs in Indonesia that provided early detection services for breast and cervical cancer (Ministry of Health RI, 2015b) - and certain psycho-socio-cultural characteristics, such as fatalistic beliefs about health and illness, along with embarrassment about discussing or performing breast examinations. Knowledge about the determinants of BSE could inform health education programs designed to create breast cancer awareness and could stimulate regular BSE among Indonesian women.

\section{Methods}

\section{Study design and participants}

A cross-sectional study was conducted in Surabaya, the capital of East Java and the second largest city in Indonesia. Surabaya has 31 sub-districts, each of which comprises 3 to 8 villages. In the 2010 census, the total population of Surabaya was 2,599,796; women age 20 to 60 represented $30 \%$ of the population (Statistics of Surabaya, 2016).

To obtain representative data, we randomly selected 76 villages of the total of 165 villages in Surabaya, including both rural and urban areas. Participants were recruited by trained research assistants, and the monthly meetings of PKK ('Women's Family 
Welfare Movement', a nation-wide women's NGO that seeks to reach every wife in a certain geographic area), were used to recruit female participants. Research assistants approached PKK members during these meeting and asked them to participated in the research. Most PKK members who attended these meetings agreed to be subjects. Specific inclusion criteria were: 1) being age 20 - 60 years old, 2) living in Surabaya, and 3) being literate in the Indonesian language. The research assistants explained the study purpose, which was also explained in the information sheet attached to the questionnaire. Some women took questionnaires home to distribute among their community members or to their daughters. The completed questionnaires were then collected by a PKK representative in each village. Completion time for the questionnaire was between 10 and 15 minutes. Care was taken to assure the confidentiality of the data obtained, and all participants provided written informed consent to participate in the study. A total of 2,173 participants completed the questionnaire, but we had to exclude 206 participants due to incomplete responses. The final sample consisted of 1967 women. The data were collected between September 2016 and January 2017.

\section{Study instrument and data collection}

After providing their informed consent, participants completed the CHBMS. We used the Indonesian version of the CHBMS (the I-CHBMS) to investigate the HBM variables (see Dewi, 2018). The scale is specifically targeted at breast cancer and BSE and consists of 42 items with 5-point response scales ranging from 'strongly disagree' (1) to 'strongly agree' (5). The I-CHBMS contains six subscales, align with the six item in the HBM: perceived susceptibility, six items, e.g., 'I am very worried about getting breast cancer'; perceived severity, 12 items, e.g., 'Having breast cancer will endanger my relationship'; perceived benefits, five items, e.g., 'BSE can help me in finding a lump'; 
perceived barriers, eight items, e.g., 'I am afraid I'm not able to do BSE'; cues to action, eight items e.g., 'I often do things that can improve my health status'; and selfefficacy three items, e.g., 'I was able to do my own BSE last month'. Total scores were calculated for the subscales of the I-CHBMS. All subscales had an acceptable to very good internal consistency reliability, with Cronbach's alpha coefficients (respectively) of $.84, .87, .82, .83, .81, .67$. The item-total correlation ranged from $r=.37$ to $r=.78$.

After completing the I-CHBMS, participants answered some questions on sociodemographic characteristics, including age, level of education, and marital status. We also asked whether participants had experienced any breast affliction, whether they had a history of cancer in the family, and whether they had ever performed BSE. All these questions were answered either yes or no.

\section{Data analysis}

The data were tabulated in excel worksheets and analyzed using IBM SPSS (version 22.0). The significance level was set at $p<.05$. Frequency distributions described the socio-demographic characteristics of the participants, and chi-square tests were used to compare demographic properties between women performing BSE (either regularly or irregularly) and those who did not perform it at all. Independent-sample ttest were employed to compare HBM constructs between BSE performers and nonperformers. To examine the association between HBM variables and BSE practice among the participating women, logistic regression analysis was used. 


\section{Results}

After removal of incomplete response, the sample consisted of 1,967 women from Surabaya, with a mean age of $36.17(\mathrm{SD}=11.39)$. Most were married $(72.3 \%)$, and more than half

(53.4\%) had graduated from high school. Of all participants, $44.4 \%$ had at performed BSE at least once. As shown in Table 1, BSE practice was associated with age, education, history of breast afflictions, and family history of cancer ( $p$ 's $<.05)$.

Table 1. Socio-demographic characteristics of the participants

\begin{tabular}{|c|c|c|c|c|c|}
\hline & \multicolumn{2}{|c|}{$\begin{array}{l}\text { BSE performers } \\
\quad(\mathrm{n}=874)\end{array}$} & \multicolumn{2}{|c|}{$\begin{array}{l}\text { BSE non-performers } \\
(\mathrm{n}=1093)\end{array}$} & \multirow[t]{2}{*}{ Statistics } \\
\hline & $\mathrm{N}$ & $\%$ & $\mathrm{~N}$ & $\%$ & \\
\hline Age & & & & & $\chi^{2}(1)=5.892, p<.001$ \\
\hline$\leq 40$ & 536 & 61.30 & 728 & 66.66 & \\
\hline$>40$ & 338 & 38.70 & 365 & 33.40 & \\
\hline Marital status & & & & & $\chi^{2}(2)=.729, p=.69$ \\
\hline Single & 197 & 22.50 & 264 & 24.20 & \\
\hline Married & 639 & 73.10 & 784 & 71.70 & \\
\hline Widowed/divorced & 38 & 4.30 & 45 & 4.10 & \\
\hline Education & & & & & $\chi^{2}(3)=102.342, p<.001$ \\
\hline University & 258 & 29.50 & 175 & 16 & \\
\hline High school & 486 & 55.60 & 565 & 51.70 & \\
\hline Secondary & 80 & 9.20 & 201 & 18.40 & \\
\hline Primary & 50 & 5.70 & 152 & 13.90 & \\
\hline History of breast affliction & & & & & $\chi^{2}(1)=10.48, p<.001$ \\
\hline Yes & 34 & 3.90 & 17 & 1.60 & \\
\hline No & 840 & 96.10 & 1076 & 98.40 & \\
\hline Family history of cancer & & & & & $\chi^{2}(1)=28.437, p<.001$ \\
\hline Yes & 168 & 19.20 & 117 & 10.70 & \\
\hline No & 706 & 80.80 & 976 & 89.30 & \\
\hline
\end{tabular}

Independent samples t-tests (see Table 2 for an overview) revealed that perceived benefits, cues to action, and self-efficacy were significantly higher among BSE performers than among women who never performed BSE $(t$ 's $>6.48, p$ 's $<.001)$. Additionally, the 
perceived barriers were significantly lower among BSE performers $(p<.001)$. The groups did not differ with respect to perceived susceptibility and perceived severity of developing cancer $\left(t^{\prime} \mathrm{s}<-1.22, n s\right)$.

Table 2. Comparison of Health Belief Model factors among performers and non-performers of BSE

\begin{tabular}{|c|c|c|c|c|c|}
\hline \multirow{3}{*}{ Variable } & \multicolumn{2}{|c|}{ Performing BSE } & \multirow{3}{*}{$t$} & \multirow{3}{*}{$\mathrm{df}$} & \multirow{3}{*}{$p$} \\
\hline & Yes & No & & & \\
\hline & Mean (SD) & Mean (SD) & & & \\
\hline Susceptibility & $14.11(4.26)$ & $14.11(4.05)$ & -.01 & 1965 & .99 \\
\hline Severity & $38.63(8.53)$ & $39.10(8.42)$ & -1.22 & 1965 & .22 \\
\hline Benefits & $20.27(2.67)$ & $18.46(3.23)$ & 13.35 & $1963 *$ & $<.001$ \\
\hline Barriers & $16.34(4.75)$ & $19.52(5.05)$ & -14.25 & $1915^{*}$ & $<.001$ \\
\hline Cues to action & $29.38(4.72)$ & $27.88(5.40)$ & 6.48 & $1950 *$ & $<.001$ \\
\hline Self-efficacy & $11.26(2.06)$ & $9.03(2.56)$ & 20.92 & $1965^{*}$ & $<.001$ \\
\hline
\end{tabular}

Note: * Levene's test indicated unequal variances (F's $>14.12, p$ 's $<.001)$ so degrees of freedom were adjusted

Lastly, logistic regression was used to explain the probability of BSE practice. First, we looked at the predictive value of the HBM components (Model 1). The results showed that the HBM variables were significantly associated with BSE practice $\left(\chi^{2}(6)=485.92, p=.0001\right)$ and accounted for $29.3 \%$ of the variance of BSE practice. Next, we examined whether controlling for socio-demographic characteristics (age, marital status, education, history of breast affliction, and family history of cancer) would change the predictive value of the HBM components in explaining BSE practice, by including the socio-demographic variables in Model 2 in the first step, and the HBM variables in the second step. The results show that this 


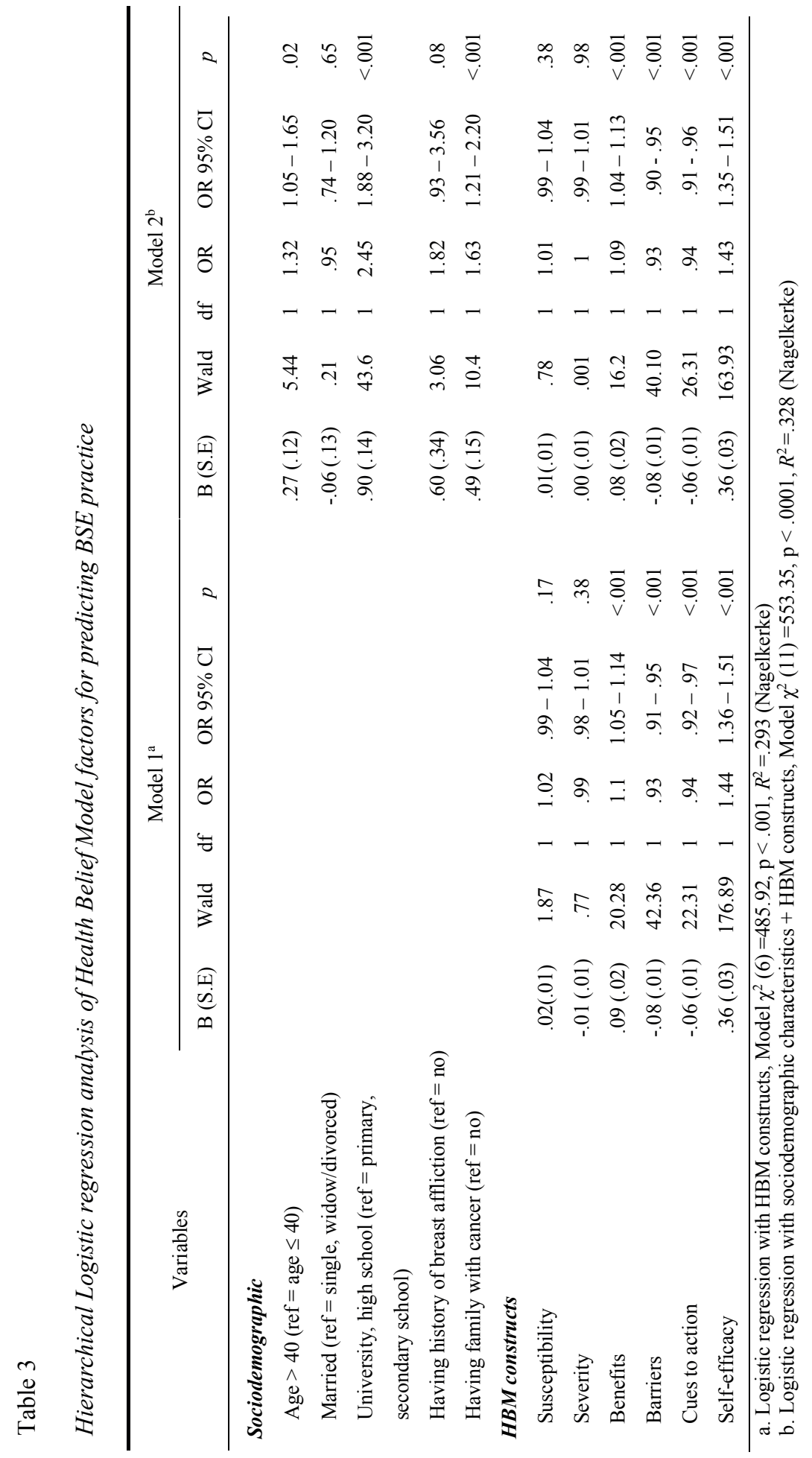


model significantly predicted BSE practice $\left(\chi^{2}(11)=553.35, p=.0001\right)$ and explained $32.8 \%$ of the variance in whether participants had ever utilized this screening method. There was $3.5 \%$ extra variance explained by sociodemographic variable in this model, compare to Model 1. Table 3 presents the full results.

Unique correlates of BSE practice in Model 1 were perceived benefits, perceived barriers, cues to action, and self-efficacy $(p$ 's $<.001)$. The women who perceived greater benefits of $\mathrm{BSE}(\mathrm{OR}=1.1, \mathrm{CI}=[1.05,1.14])$, and indicated higher self-efficacy $(\mathrm{OR}=1.44$, $\mathrm{CI}=[1.36,1.51)$, but perceived fewer barriers $(\mathrm{OR}=.93, \mathrm{CI}=[.91, .95])$ and, surprisingly, had fewer cues to action $(\mathrm{OR}=.94, \mathrm{CI}=[.92, .97])$ were more likely to perform BSE. When socio-demographic variables were controlled in Model 2, the HBM components which associated with BSE practice were identical to those in the first model: perceived benefits, perceived barriers, cues to action and self-efficacy were among HBM components which explained BSE behavior. In addition, age $(\mathrm{OR}=1.32, \mathrm{CI}=[1.05,1.65])$, education background $(\mathrm{OR}=2.45, \mathrm{CI}=[1.88,3.20])$ and having family members with cancer $(\mathrm{OR}$ $=, 1.63 \mathrm{CI}=[1.21,2.20])$ were each associated with BSE practice, suggesting that women who were older, highly educated and had family members with cancer were more likely to have engage in BSE practice.

\section{Discussion}

Breast cancer is the most predominant cancer among Indonesian women. Early detection and treatment of the disease have been shown to decrease mortality rates (Xiong et al., 2001). However, in Indonesia, almost $70 \%$ of breast cancer patients present in at a late stage of the disease, negatively affecting survival rates (Ng et al., 2011; Oemiati et al., 2011). 
Therefore, early detection strategies are important, and BSE is one of the best strategies applicable to achieve both breast (cancer) awareness and earlier detection of breast problems. Especially in LMICs where health-related resources are limited, and where socio-cultural influences tend to make women more hesitant to discuss issues related to breast health, empowering women to examine their own breasts is an important first step (Khokhar, 2013). The aim of the current research was therefore to investigate which psychosocial variables affect the likelihood of women's performing of BSE.

The findings of the present study seem promising, since $44.4 \%$ of the participants indicated they had previously performed BSE. Moreover, an older age, higher education, and having a history of family member with cancer were all positively correlated with performing BSE in this sample. These results support the findings of previous studies that older and welleducated women were more likely to perform breast cancer screening behavior (Guilford et al., 2017; Secginli \& Nahcivan, 2006), possibly because of increased knowledge and awareness.

In line with the HBM (Rosenstock, 1966), perceived benefits, perceived barriers, cues to action, and self-efficacy all impacted the likelihood that a woman would perform BSE. In contrast to expectation, however, the regression analysis revealed a negative association between cues to action and the likelihood of performing BSE. This result might be due to how this variable was measured: Cues to action were probed by asking about general positive health behaviors, such as maintaining a healthy diet, adherence to physician recommendations, regular exercise, and an ability to find health information, rather than asking about internal or external triggers that encourage BSE performance. We speculate that the participants who indicated that they had more of those type of cues to action might also have had higher optimism regarding their health status. Although in most cases optimism about one's health is associated with greater psychological and physical well-being, some 
studies have revealed less desirable outcomes, such as reduced health protective behavior (Tennen \& Affleck, 1987; Weinstein \& Lyon, 1999). In some cases, this health optimism may thus be unrealistic, including perceptions of being invulnerable to the disease, especially since these women already feel that they are taking good care of their health. Additionally, people with positive general health behaviors - measured here by the cues to action subscale of the HBM - tend to think that negative events are less likely to happen to them than to other people (Weinstein \& Lyon, 1999), which might cause them to forego performing BSE behavior. Since we cannot be certain that the current participants were indeed unrealistically optimistic about their health (behaviors), further research is necessary to investigate the association of cues to action with unrealistic optimism and with less engagement in BSE practice, particularly in light of how the variables were operationalized in the present study.

An additional possible explanation for the negative association between cues to action and BSE performance may be found in the Indonesian culture. Modesty tends to be an important value for Indonesian women, and this trait could encourage the belief that the breast is an intimate, personal organ, not to be openly discussed. These cultural characteristics may bring about defensive and protective thoughts and a hesitation to consider performing BSE, since it is considered an uncomfortable procedure (Avci, 2008).

In line with a finding among the Saudi population (Abolfotouh et al., 2015), our data demonstrated that perceived severity and susceptibility to breast cancer did not predict BSE performance, and the mean scores for these variables did not differ between the BSE performers and the non-performers. There are several possible explanations of this finding. First, women might have insufficient understanding about vulnerability to breast cancer, the severity of the disease, and how it influences the physical, psychological and social aspects of the patients and their family. Second, the participants in the present study might interpret their susceptibility to suffering from breast cancer as the will of God. Previous studies 
indicated that such fatalistic beliefs negatively affect early detection behaviors in Muslim societies (Azaiza \& Cohen, 2006; Halligan, 2006). The Indonesian population, is characterized by strong religious values, and our respondents were drawn from a largely Muslim population. Future research should focus on establishing the underlying reasons for the absence of a relationship between BSE performance - or other health-related behaviors and perceived severity and susceptibility.

The finding that perceived severity and perceived vulnerability were not correlated with BSE practice could also be explained by fear arousal theory. Rogers and Deckner (1975) defined a fear appeal as a persuasive form of communication that aims to arouse fear so as to promote precautionary motivation and self-protective action. Further, Ruiter et al. (2014), explained that fear arousal is an unpleasant emotional state, consisting of physiological, cognitive, affective, and behavioral responses triggered by the perceived threatening stimuli. The severity of and personal susceptibility to breast cancer are likely to be viewed as threats, and thus arouse fear. Moreover, if there is an additional assessment indicates that one is unable to effectively avert the risk, or that this aversion is not easily overcome, then this threat perception will result in ongoing fear arousal. Indeed, previous research indicated that perceived severity and susceptibility, both of which are components of perceived threat, were weak predictors of intention and risk-reducing behavior (Floyd et al., 2000; Milne et al., 2000; Ruiter et al., 2001). Thus, in order for these variables to cause enduring behavior change, risk communication must be combined with other behavioral change techniques such implementation intentions, self-efficacy training, or action instruction (Ruiter et al., 2014).

Among the socio-demographic variables examined, older age, well-educated and having family members with breast cancer were significantly associated with BSE practice. Our findings are consistent with those of Noroozi et al. (2011), who also reported that older women were more likely to perform BSE. It might be because they believe that the 
vulnerability of breast cancer is increasing with age. The results with regard to education indicated that BSE practice was also predicted by educational level, in which the odds to perform BSE were larger for women with higher education (i.e., high school and university graduates) compared to those with lower education (i.e. primary school). This finding is in line with those of studies in Turkey (Secginli \& Nahcivan, 2006) and Singapore (Straughan $\&$ Seow, 2000). Finally, the association between family cancer history and greater BSE practice is in line with a study in a Saudi population, which showed that family history of cancer was significantly correlated with BSE performance (Abolfotouh et al., 2015). One explanation of this relationship could be that women with relatives suffering from cancer understand the possible influence of genetic factors in the development of cancer, creating higher awareness of their own susceptibility. Marital status and history of breast affliction were not correlated with prior BSE performance in this sample.

Some limitations of the present study should be noted. First, we did not measure women's current level of knowledge about breast cancer in general or BSE practice in particular. Future research should include such measurements, since breast-related knowledge - or health literacy in general - could be directly related to perceptions of susceptibility and severity. Further, the unexpected finding that cues to action decreased the likelihood of performing BSE, and the non-significant relationships between BSE practice and perceived susceptibility and severity, suggest that some of the women in our study may have had unrealistically optimistic perceptions of their own health and thus feel less urgency about performing BSE. Therefore, future studies should investigate the impact of optimistic bias on perceptions of breast cancer susceptibility and of the need to engage in screening behaviors. Lastly, the data were collected by means of self-report questionnaires, and asked women to report only whether they had ever performed BSE, not whether they were aware of (and thought they followed) the BSE guidelines. The difference between women's self-reported 
knowledge and their actual knowledge, and the relationship between this difference and BSE practice, could be explored further in future studies as well.

\section{Conclusion}

Our study provides some starting points and recommendations for health education. Given the significant association between perceived benefits of BSE and actual BSE practice, health promotion activities could focus on the benefits of BSE practice as an early detection strategy with respect to local context and culture. Expression of reluctance should be respected but can be addressed, such as by the use of female health educators. The result of self-efficacy was positively associated with BSE practice suggests that employing methods to increase women's self-efficacy with regard to BSE, such as guided practice, or enactive mastery experiences, could improve women's confidence and comfort level with regard to practicing BSE regularly. Further, our investigation of psychosocial variables among a large, representative sample of women makes generalization to the larger population possible. 

Chapter 3.

Determinants of early breast cancer presentation: a qualitative exploration among female survivors in Indonesia

Published as:

Dewi, T. K., Massar, K., Ardi, R., \& Ruiter, R. A. C. (2020). Determinants of early breast cancer presentation: a qualitative exploration among female survivors in Indonesia. Psychology \& Health, 1-14. 


\section{Abstract}

Early presentation with breast cancer symptoms is crucial to the effectiveness of treatment and the affected women's long-term survival. However, in Indonesia, $60 \%-70 \%$ of breast cancer patients first present themselves to the hospital in an advanced stage (stage III or IV). Knowledge about the determinants of breast cancer early presentation could inform efforts to promote healthcare seeking at earlier symptomatic stages. In the current study, we explored the psychosocial determinants of early presentation among female breast cancer survivors. Methods: Face-to-face semi-structured interviews were conducted with 23 female breast cancer survivors in Surabaya, Indonesia (mean age $=49.8$ years). Directed content analysis approach was used to analyze the data. The results indicated that half of the respondents underwent breast cancer screening prior to onset of symptoms. Nine determinants of breast cancer early presentation were reflected in the women's responses: (lack of) knowledge, perceived behavioral control, previous health related experiences and risk perceptions, attitudes and beliefs, norms, competing priorities, financial issues, instrumental factors, and health provider factors. In conclusion, we suggest that health promotion efforts should focus on both internal and external psychosocial determinants related to the breast cancer early presentation, and on involving women's social environment as target for education. Additionally, providing accessible and affordable healthcare is important to support early presentation. 


\section{Introduction}

It is estimated that in Indonesia, breast cancer has become the major type of cancer among women, placing first in the rankings and accounting for $30.9 \%$ of all new cancer diagnoses in 2018, and constituting $11 \%$ of all cancer related deaths (IARC, 2018a).

Treatment in an early stage of breast cancer gives a better prognosis for long-term survival (Xiong et al., 2001), however, similar to other developing countries, poor treatment outcomes among breast cancer patients in Indonesia are reported, largely due to the late presentation of the disease. Previous research in Indonesia revealed that approximately $60 \%$ $70 \%$ of breast cancer patients come to the hospital at an advanced stage, and $35 \%$ of presented with metastasized tumors (Irawan et al., 2008).

Previous studies have shown that several demographic, psychosocial, and cultural factors are associated with late presentation, for example lower education, being unmarried, and having a lower income were found to be associated with breast cancer late presentation and treatment adherence (DiMatteo, 2004). Moreover, psychosocial and cultural factors were also found to be significant barriers to achieving an early diagnosis and effective treatment of breast cancer. For example, utilization of traditional therapy and a negative attitude towards clinical treatment were associated with patient delay in the Malaysian population (Norsa'adah et al., 2011). Additionally, studies among African women in developing countries identified several main barriers to achieving early presentation: poor knowledge about symptoms and risk factors, a fear of cancer treatments, embarrassment in disclosing symptoms to healthcare professionals, and taboos and stigmatization surrounding the breasts and breast afflictions (Gullatte et al., 2010; Jones et al., 2014). Furthermore, lack of social support from family members and spouse, as part of a supportive social network, were shown to contribute to delay in presentation with breast cancer among women in Uganda (Odongo et al., 2015). 
To the best of our knowledge, qualitative research about the factors that contribute to breast cancer early presentation among breast cancer survivors is lacking, especially for the Indonesian population. Indonesia is marked by a high degree of religious, cultural, and social diversity, as well as limited health care services. Exploring both the perceived subjective and objective barriers and facilitating factors that contributed to these survivors' breast cancer early presentation is essential. The knowledge gained from this research could be used to improve the proportion of breast cancer prevalence identified at an early stage, allowing for more effective treatment.

To understand the influences of the psychosocial determinants of breast cancer early presentation, behavioral theories such as the Theory of Planned Behavior (TPB) could be considered. According to TPB, the most proximal determinant of health-related behavior is one's behavioral intention to engage in the behavior (Ajzen, 1991). Behavioral intention, in turn, is determined by attitudes towards the behavior, subjective norms, and perceived behavioral control. Importantly, the variables predicting intention are modifiable through health promotion and education, which makes it relevant to identify them in the context of early breast cancer presentation. In the current research, we therefore included these variables, as well as breast cancer survivors' accounts of their lived experiences from the first time they noticed a symptom to their diagnosis. Identifying influences from both the individual and socioecological context (i.e. cultural, environmental, and provider related factors) would be beneficial to understand the multiple factors that determine survivors' early presentation, which in turn is essential to plan effective interventions to promote early presentation to healthcare providers and BSE practice. 


\section{Methods}

\section{Respondents and study setting}

The respondents were recruited through social media advertisements, the breast cancer communities in Surabaya ('Reach to Recovery Surabaya' and 'Wisnuwardhana Breast

Cancer Foundation'), and through referral by other respondents. Data were collected between July to November 2018. Inclusion criteria were (a) aged $18-65$, (b) breast cancer survivor, (c) residing in Surabaya at the time of diagnosis, and (d) having presented in an early stage of breast cancer. To determine the early presentation, we used a 3-month interval between first noticing a symptom and the first medical consultation as the golden standard, since the literature indicates that a delay of presentation with symptomatic breast cancer of 3 months or more is associated with lower survival (Burgess et al., 1998; Richards et al., 1999).

The breast cancer survivors who met the inclusion criteria and who were willing to participate provided their telephone number, and were subsequently contacted by the interviewer to schedule the interview. Prior to interview, the interviewer explained the study purpose and all respondents provided written informed consent to participate in the study. A total number of 44 breast cancer survivors who met the inclusion criteria were approached, and 23 women (mean age 49.8 years) agreed to participate.

This study was approved by the Ethical Committee of Health Research, Faculty of Public Health, Airlangga University and the Ethics Research Committee of Psychology and Neuroscience at Maastricht University. The interviewers conducted semi-structured interviews in comfortable places for both the interviewee and the interviewer: the interviewee's home, a meeting room in the interviewee's office, a café, a meeting room at Oncology Hospital Surabaya, or a consultation room in the Faculty of Psychology Airlangga University. If the interview was conducted in a public place like a café, a comfortable seating 
area was created in the corner of the room, outside hearing distance of other people, so the respondents' privacy could be respected.

\section{Materials and Analysis}

The demographic information and illness background of respondents was queried: age, marital status, level of education, employment, family monthly income, family history of breast cancer, and health insurance status. The interview protocol was constructed using the TPB as a conceptual framework and contained questions on attitudes, subjective norms, and perceived behavioral control towards breast cancer early presentation supplemented with questions about women's knowledge on breast cancer symptoms, risk factor, and its screening and treatment modalities; and their healthcare-seeking behaviors. All abovementioned questions allowed the respondents to reflect on their lived experiences prior to their breast cancer diagnosis, and upon first noticing symptoms.

The face-to-face semi-structured interviews approximately took 30 to 80 minutes to complete. All interviews were conducted in Bahasa and were audio-recorded with the permission of the respondents. They were transcribed verbatim, and ATLAS.ti version 8.3.1. was used to analyze the data.

For data analysis, we used a directed content analysis approach, where coding categories were derived from existing theory and salient prior research, and were defined both before and during the coding of the data (Hsieh \& Shannon, 2005). Besides this theoretical deduction of codes, additional codes were induced from the chunks of text. The texts were thoroughly read and tentative categories were deduced, revised, and eventually reduced to two themes: the internal and external factors related to breast cancer early presentation. The first and third author discussed the codes, categories, and themes until 
agreement on the themes was reached. Sample texts were also discussed with second and fourth authors, after translating them first into English, to discuss results and verify coding.

\section{Results}

\section{Sociodemographic and illness variables}

Demographic and illness variables are summarized in Table 1. The majority of the respondents were married and had a university education, worked as a private employee, and can be considered as having a higher economic position. Most respondents had been diagnosed with an early stage of breast cancer and had no family history of breast cancer. More than half of the respondents had health insurance. Others financed their own medical expenses.

Twenty-one respondents indicated various kinds of symptoms prior to being diagnosed with breast cancer. Most of them stated that there was a lump or solid part in their breast or in the area near it. Some of these women also stated this was a painful spot. One other symptom mentioned by a respondent was fluid coming out of their nipple. Other symptoms that were mentioned were being physically exhausted, feeling extremely cold, and a feeling of having a low immune system (e.g., being hospitalized several times in a short amount of time). The respondents first realized their symptoms when they were doing BSE, accidentally touched the lump while e.g. showering, or a lump being found by the partner. Two respondents did not show any symptom before being diagnosed: One of these women consumed Hormone Replacement Therapy (HRT) due to her previous health problem, thus her personal doctor recommended her to do routine mammography. Another respondent intentionally went for a mammography since there was a discount for mammography price reduction. For these two respondents, the breast cancer diagnosis was made based on these mammography results. For 
Table 1 Demographic Characteristics of Study Respondents

\begin{tabular}{|c|c|}
\hline Variable & n (\%) \\
\hline Mean age & 49.8 \\
\hline \multicolumn{2}{|l|}{ Breast cancer stage } \\
\hline 1 & $2(8.7 \%)$ \\
\hline 2 & $14(60.86 \%)$ \\
\hline $3 \mathrm{~A}$ & $5(21.74 \%)$ \\
\hline No answer & $2(8.7 \%)$ \\
\hline \multicolumn{2}{|l|}{ Marital Status } \\
\hline Single & $2(8.7 \%)$ \\
\hline Married & $19(82.6 \%)$ \\
\hline Divorced/Widowed & $2(8.7 \%)$ \\
\hline \multicolumn{2}{|l|}{ Education } \\
\hline Senior High School & $5(21.74 \%)$ \\
\hline Diploma-3 & $2(8.7 \%)$ \\
\hline Bachelor degree & $15(65.21 \%)$ \\
\hline Master degree & $1(4.35 \%)$ \\
\hline \multicolumn{2}{|l|}{ Employment } \\
\hline Unemployed & $6(26.09 \%)$ \\
\hline Public employee & $4(17.39 \%)$ \\
\hline Private employee & $13(56.52 \%)$ \\
\hline \multicolumn{2}{|l|}{ Family monthly income } \\
\hline$<\operatorname{Rp} 3.000 .000$ & $1(4.35 \%)$ \\
\hline Rp. $3.000 .000-10.000 .000$ & $9(39.13 \%)$ \\
\hline$>$ Rp. 10.000 .000 & $13(56.52 \%)$ \\
\hline \multicolumn{2}{|l|}{ Age when first diagnosed with breast cancer } \\
\hline $20-29$ & $2(8.7 \%)$ \\
\hline $30-39$ & $7(30.44 \%)$ \\
\hline $40-49$ & $9(39.13 \%)$ \\
\hline $50-60$ & $5(21.74 \%)$ \\
\hline \multicolumn{2}{|l|}{ Family history of breast cancer } \\
\hline No & $18(78.26 \%)$ \\
\hline Yes & $5(21.74 \%)$ \\
\hline \multicolumn{2}{|l|}{ Health insurance } \\
\hline No & $11(47.83 \%)$ \\
\hline Yes & $12(52.17 \%)$ \\
\hline
\end{tabular}


the other respondents, the diagnosis was made from a combination of mammography, USG, and/or Fine Needle Aspiration Biopsy (FNAB).

Upon noticing the first symptom, various types of health seeking behaviors were performed by the respondents: searching for information by browsing the internet or asking relatives who had had the same breast problem; or engaging in non-medical behaviors, e.g. taking traditional medication; and ignoring their symptoms. Most respondents undertook action to receive a first consultation with the doctor to get an examination, between one day and three months after noticing the first symptom, and it took between one day and one month after this first consultation to get the diagnosis. However, two respondents indicated a significant diagnosis delay: 6 months, and three years respectively, due to initial false negative test results. Some respondents tried to find a second opinion to confirm their diagnosis.

\section{Qualitative results}

We grouped the factors related to breast cancer early presentation that emerged from the interviews; these included behaviors associated with the breast cancer early detection as well as receiving a medical examination. Nine categories are reflected in our data, forming two themes: internal factors, and external factors.

\section{Theme 1: Internal factors}

Within this theme, several subthemes were examined, i.e. breast cancer related knowledge, perceived behavioral control, previous health-related experiences and risk perceptions, and attitudes and beliefs. 
Breast-cancer-related knowledge. Some respondents indicated a lack of knowledge about breast cancer, but when probed, some could explain what breast cancer was, the symptoms, or which treatments would be available. Further, they indicated that breast cancer could be detected at an earlier stage by performing BSE or by undergoing a mammography. They gained the breast cancer-related knowledge from various sources: mass media (newspaper, television, radio, magazine articles) and social media (Facebook, Instagram). Other sources of information mentioned included: receiving health education in women's community meetings $\left(\mathrm{PKK}^{1}\right)$ or church, a leaflet from a healthcare facility, information provided by their health practitioner or a public figure, or having relatives who suffer from breast cancer. The women indicated that the information they gained served as a valuable source for their breast awareness and according to them, was associated with their early presentation: "I know BSE from my reading ... I often did that. One day, when I performed BSE ... and I found the lump [in my breast]” (P. 17).

Perceived Behavioral Control. Upon being asked whether they felt they were able to act upon noticing a symptom, some respondents indicated that they were confident they could visit the doctor to have a breast cancer examination. "I was sure I could go alone. I can go to the doctor" (P 7). Some respondents also indicated that they had the confidence to do BSE: "It is a simple thing, it is a very simple thing that we can do, I mean we can do it while having a shower or lying in the bed before sleeping” (P. 17).

The respondents thus indicated that if they perceived that they had control over their behavior, the early presentation would be more likely to occur. However, some respondents reported that they did not have any information about where they could go or what they

\footnotetext{
${ }^{1}$ PKK: Pembinaan Kesejahteraan Keluarga (Women's Family Welfare Movement), a nation-wide women's NGO that seeks to reach every married woman in a certain geographic area.
} 
should do if they noticed a breast cancer symptom, something which could have delayed their early presentation.

Previous health related experience and risk perceptions. The women with previous health related experiences reported having greater awareness about any abnormality in their body, and indicated a higher risk perception. These health-related experiences and risk perceptions led to seek medical attention early. As one woman stated: "I have endometriosis ... My doctor asked me to take HRT and warned me to have a regular mammography. I didn't know what mammography was, but I did that as suggested” (P 12).

Only three respondents reported that they felt that they had an increased chance of getting breast cancer prior to be diagnosed (e.g. due to genetics), but most women indicated a low risk perception.

Attitudes and Beliefs. Most of the respondents indicated that they had a positive attitude towards early presentation and breast examination. This might have caused them to present with early-stage breast cancer, which in turn allowed fast diagnosis, fast treatment, and a speedier recovery: "I think these [doing BSE and having doctor examination] are positive things, ... the earlier we know our diagnosis, the better the treatment” (P. 14). In contrast, a few respondents expressed a negative attitude towards breast cancer screening, mainly because of fear for the diagnosis.

Some respondents indicated awareness of the benefits of a healthy lifestyle to prevent cancer. In contrast, some women reported thinking that breast cancer is something scary, and that therefore one should never think about an illness otherwise it will happen to them. Others mentioned that breast cancer was a taboo subject; that it was a curse or a punishment; and that in general individuals in society perceived that getting breast cancer was not a high risk. 
To sum up, the respondents mentioned that the combination of negative attitudes, (folk) beliefs, and lack of knowledge about risks and symptoms among women in their social surroundings contributed to the inhibition of early detection and presentation.

\section{Theme 2: External factors}

In this theme, we studied norms, instrumental support, competing priorities, health provider factors, and financial issues as external determinants of women's early presentation behavior.

Norms. The majority of the respondents indicated that significant others (e.g., spouse, friend) persuaded them to go to the doctor to have a medical examination. Moreover, the women indicated that they were influenced by the behaviors of others in their direct social network, both positively and negatively. The influence from the environment could relate to both their absenteeism of early detection: "The people I knew, none of them did routine BSE or mammography ... we didn't understand [if there were procedures to detect breast cancer earlier]" (P. 12); or their early presentation performance: "My colleagues asked me to have breast examination since one of our colleagues survived from breast cancer" (P. 3)

Competing priorities. Some respondents expressed that early presentation was significantly related to their daily schedule: the behaviors were more likely to occur when they felt that they had the time to perform them. Conversely, if they perceived that they had competing priorities, they would postpone these behaviors: "I asked my son to find information about the service hour in Kayoon, but I have to wait until my work is done ... I plan to visit the clinic after my work is done" (P. 18). 
Instrumental support. Respondents mentioned that having assistance from others to have breast cancer examinations (e.g., accompanying them on the visits) would improve the likelihood to engage in such behaviors. The women indicated that such instrumental support could also be facilitated by their workplace: "When my office had an anniversary celebration, we had the doctor from Kayoon here in the office, I had a pap-smear and CBE, the doctor was well experienced"'(P. 18).

Health provider factors. According to some respondents, when they perceived that healthcare providers were accessible, their likelihood of visiting it was improved. However, the difficulty of accessing it at a time convenient to them would contribute to a delay: "I went to a hospital, but that time the doctor was not there ... I planned to come back, but ... I didn't know, I didn't go" (P. 2).

Furthermore, the respondents reported that part of their decision to have a medical examination following their symptom presentation was related to the healthcare provider status, which according to them it made them feel reassured and safe, e.g., being familiar, female, or known for their competence: "I went to this doctor, our family know her. And fortunately, a female doctor" (P. 1).

Financial Issues. Most of our respondents went to a private hospital and/or medical lab to get their diagnosis and paid it for themselves, or used private or national health insurance (BPJS Kesehatan ${ }^{2}$ ). Most of the women in our sample who have a relatively high income, indicated that financial budget was not perceived to be a barrier for a breast cancer examination: " $I$ have the money, so I go for an examination. I think it would only cost a small amount of

\footnotetext{
2 BPJS Kesehatan: Badan Penyelenggara Jaminan Sosial Kesehatan (Social security agency for health), a government insurance companies which administers the Indonesian health insurance.
} 
money" (P. 23). Furthermore, a respondent with a lower economic background also indicated that financial issues were less significant compared to her motivation to identify what her symptom was, in the context of early detection behavior, even though she could not pay for the examination only by herself: "No [I did not count the cost of mammography as a barrier] ... I have to [perform mammography]. I have my families donated money to pay my mammography" (P. 16).

Interestingly, some respondents indicated that they thought if they used basic health insurance the possibility of a false negative diagnosis was increased: These respondents went for an initial examination by using public health insurance and ended up with a non-breast cancer diagnosis. Further, they tried to find a second opinion, without using basic health insurance, which ultimately resulted in a breast cancer diagnosis: "I used BPJS, I chose the best doctor, general surgeon, for the examination. He said it was only benign cyst. But later, I knew there was a breast cancer in my breast from another doctor examination. Without using BPJS. I hate BPJS" (P. 4). Thus, this indicates a lack of trust in the quality of care under the public healthcare system when they used basic health insurance.

Additionally, discount rates for having mammography would also improve the likelihood of engaging the screening behavior. Some of the respondents indicated that they had a health insurance that helped them in their decision to go for an examination. Thus, although financial barriers were not directly identified as a barrier to go for breast cancer screening among our respondents, they did acknowledge that for others, with less financial means or lower quality health insurance, not having the funds to pay for the screening could constitute a risk factor for delays and late presentation. 


\section{Discussion}

The aim of this current study was to explore factors related to breast cancer early presentation among breast cancer survivor in Surabaya Indonesia. Our study examined nine determinants related to breast cancer early presentation: breast cancer related knowledge, perceived behavioral control, previous health related experiences and risk perceptions, attitudes and beliefs, norms, competing priorities, financial issues, instrumental factors, and health providers factors.

Respondents in our research differed in their knowledge about breast cancer and its symptoms. Some respondents showed inadequate knowledge about symptoms, severity, stages, risk factors, medical treatments and cancer service pathways. This lack of knowledge also caused lowered awareness of their vulnerability, and the seriousness of the disease, which negatively influenced the likelihood of early presentation. This result is in line with studies in other developing countries that found lack of knowledge to be a significant predictor of breast cancer delay (Agarwal et al., 2009; Al-Dubai et al., 2012; Iskandarsyah et al., 2014). This finding may be a result of limited public health education programs for women in Surabaya, limiting knowledge of breast cancer, and in some cases causing women to have misleading beliefs about the causes and cure of breast cancer.

Most of our respondents had received their information about breast cancer from mass media, and only a few reported getting information from health education meetings or leaflets. This result is in line with a study among Chinese women, which indicated that media campaigns, e.g., through radio, television, and newspapers, was an effective way to improve knowledge and increase the practice of breast health-related behaviors (Sun et al., 2007). Thus, as an initial effort to increase knowledge among a larger population, media-based health education campaigns could be considered as an effective channel to improve breast cancer awareness. Importantly however, as noted by Wakefield et al. (2010) "concurrent 
availability of and access to key services and products are crucial to persuade individuals motivated by media messages to act on them" (p.11). Furthermore, social media (i.e., internet-based communications, tools, and aids) are potential channels for health promotion that can be used to improve breast cancer literacy. One systematic review on social media's effects on health promotion and behavior change, indicated that there is clear evidence that social media can be effective to improve health knowledge, behavior, and outcomes, which meet both individual and population health needs (Korda \& Itani, 2013).

Health insurance coverage and affordability were, probably also due to the composition of this sample (middle to high income), not considered to be a barrier to achieve breast cancer early presentation. Those who were not covered by health insurance perceived that the benefits of breast examination outweighed the financial expense, and they were willing to pay in order to identify their breast abnormality. In contrast, some women also stated that they thought that the basic healthcare insurance offered in Indonesia - used mainly by individuals from lower socio-economic positions - would not allow them to receive adequate, high quality care, and even possibility of false negative screening outcomes. This latter finding reflects results from a systematic review (Unger-Saldaña \& Infante-Castañeda, 2009) that found that socio-economic position is related to delay in screening behaviors if women are from ethnic minorities, lower educated, live in rural areas, have a lack of health insurance, and experience barriers to access healthcare.

Our findings further suggest that the accessibility of healthcare services, e.g., arranging transport, distance from home to healthcare service, as well as the ease of making appointments at the facilities seemed to stimulate early presentation. This is in line with research indicating that positive perceptions of accessibility to healthcare impact positively on help-seeking behavior (Facione \& Giancarlo, 1998), while poorer access to healthcare service appears to be a barrier to early presentation (Caplan, 2014). Furthermore, women in 
this study indicated that they were more likely to delay making an appointment if they had competing priorities, e.g., childcare, employment, or family commitments. Moreover, access to healthcare was influenced by women's perceived behavioral control: having the confidence, ability, and knowledge about what to do when they noticed a symptom. This confidence in turn is likely to be influenced by trust in their physician and concern over the care they received. Indeed, previous research showed that patient-doctor communication in South Asia is generally perceived as dissatisfying by patients, due to the doctors' paternalistic/one-way consultation style where there is not much room for questions the patient may have (Claramita, et al., 2013). This likely also caused our respondents to be hesitant to ask the health care provider for further information about their disease, and/or treatment plan.

Furthermore, our results indicated that negative attitudes and beliefs, and social influences caused some women to perceive breast cancer as something scary and related to punishment, which contributed to an aggravated delay in actioning screening behaviors. This was also found in other Asian populations, where cancer is perceived as a taboo subject, a shameful and contagious disease, and related to moral wrongdoing (Iskandarsyah et al., 2014; Karbani et al., 2011; Rajaram \& Rashidi, 1999). These beliefs may result in some women realizing that breast cancer is a serious illness, but being less likely to perceive that it can be cured, which increases the risk of them not visiting healthcare services after the onset of symptoms. Given the finding that women also lack knowledge, further health education should focus on increasing breast cancer literacy, including not only providing information on the severity of breast cancer, but also its better prognosis if detected earlier. In particular, such a focus on the positive outcomes of early detection could alleviate women's fear of a diagnosis, thereby preventing the delay in seeking treatment after the onset of symptoms (Stapleton et al., 2011). 
Interestingly, our data suggest that most of the women in this sample have positive attitudes toward breast cancer early presentation, which possibly increased the likelihood that they sought medical consultation once they noticed any bodily change(s). This positive attitude seems to shape their help seeking behavior: Our respondents indicated that they firmly believed that if there was something wrong with their body, they should go to the doctor immediately to identify what their symptom(s) implied, thereby increasing the chance of speedy recovery. This finding is in line with previous research using the TPB to predict behavioral intentions for screening behavior which showed attitudes to be the strongest predictor (Cooke \& French, 2008).

Importantly, early presentation in our sample was more likely for women who indicated they received (social) support from their environment, both in the form of perceived norms about screening behavior, as well as instrumental support. The women indicated that when they perceived that most women in their environment engage in a breast cancer early presentation practice, their likelihood to perform this behavior increased. Furthermore, support from their environmental surroundings, e.g., having others as companion to a doctor visit, or facilitation of breast cancer screening from their workplace, were associated with an increased likelihood to perform early presentation. The Indonesian population is typical of a communal society, which is characterized by a strong family support system (Claramita, et al., 2013). In these societies, the family and the close social circle of a woman play a major role in shaping and facilitating health-related behaviors, such as breast cancer early presentation

\section{Limitations}

Although our results offer insight into breast cancer early presentation, and as such inform future health promotion efforts, several limitations should be considered. First, the 
respondents resided in an area that provides a comprehensive breast cancer treatment to patients, which can only be afforded by a population with a high social economic position. Our findings are, therefore, not generalizable to other populations, i.e. those with lower socio-economic positions. This also suggests that in Indonesia, breast cancer early presentation and effective treatment may mainly be accessible - or, affordable - for women with higher socio-economic positions. There is therefore a need for easily accessible and high-quality healthcare services in areas where women with a lower socioeconomic background work and reside. The lack of knowledge present in our current, highly educated, sample, furthermore suggests that this lack may be even greater among the less well-educated population in Indonesia. Second, the time frame between the onset of the symptoms and the diagnosis was obtained from respondents' self-report, which may contain recall bias and may not accurately reflect the actual time between the onset of symptoms and their first medical examination.

\section{Conclusion}

This study has identified several modifiable psychosocial, environmental, structural, and cultural determinants which both hinder and facilitate breast cancer early presentation. We suggest that breast cancer education should not only include information about breast cancer and its symptoms, but should also focus on increasing women's risk perception, and on improving the skills to recognize normal and abnormal breast anatomy. Given the impact of women's social environment and social norm on breast cancer early presentation, breast education should be provided not only to the women, but also their social environment, i.e., their partner and extended family, should also be involved. Additionally, our findings also suggest the need of accessible and affordable healthcare, especially for those with lower social economic positions or living in rural areas, to facilitate early presentation. 



\section{Chapter 4.}

\section{The role of psychosocial variables in breast self-examination practice: Results from focused group discussions in Surabaya, \\ Indonesia}

\section{Based on:}

Dewi, T. K., Ruiter, R. A., Ardi, R., \& Massar, K. (2021). The role of psychosocial variables in breast self-examination practive: Results from focused group discussions in Surabaya, Indonesia. Manuscript submitted for publication. 


\section{Abstract}

Breast cancer is a global life-threatening disease. Breast self-examination (BSE) followed by timely diagnosis and treatment is a viable screening method for populations with limited health care access, such as Indonesia. Knowledge of the beliefs underlying BSE could benefit the development of future health education efforts to promote BSE and breast cancer awareness among Indonesian women, ultimately stimulating timely presentation in healthcare settings. The purpose of this study was to explore the underlying beliefs of BSE among women in Surabaya, Indonesia, in accordance with the Reasoned Action Approach (RAA) framework, and to investigate what these women considered an effective approach to improve breast cancer awareness and promote BSE in their social networks. Nine focus group discussions (FGDs) were conducted with 62 women in Surabaya, Indonesia (mean age $=32.9$ years). Directed content analysis was employed to analyze the data. Coding of the transcripts cantered around six psychosocial determinants of performing BSE: knowledge, attitude and beliefs, risk perception, norms, perceived behavior control and intention. Furthermore, the participants identified face-to-face meetings with visual media and healthcare professionals as effective channels to enhance breast cancer awareness. This study sheds light on the application of the RAA for BSE behavior. Additionally, it revealed the importance of face-to-face meetings involving healthcare professionals and women's social networks for breast education. 


\section{Introduction}

Breast cancer remains a public health concern, especially in low-and middle-income countries (LMICs) that have limited access to timely diagnoses and treatment (IARC, 2018b). In Indonesia, of the different types of cancers, breast cancer has the highest incidence and is the second highest cause of death (IARC, 2018a). However, despite its high mortality level, awareness of breast cancer and need for early detection, timely diagnosis and treatment are low among Indonesian women. Approximately $70 \%$ of breast cancer patients present with advanced stages of breast cancer, which have a negative effect on treatment options and prognosis (Irawan et al., 2008; Ng et al., 2011). Thus, early detection is imperative.

In Indonesia, breast self-examination (BSE) is a breast cancer screening modality that besides clinical breast examination (CBE) is widely promoted by the government (Ministry of Health RI, 2015a). Because mammography has not been designated as an organized program and is not covered by the national health insurance, it is costly and there has been limited access to the procedure (Choridah et al., 2019). The American Cancer Society (ACS) no longer recommends BSE to detect breast cancer in its early stages because it is not significantly associated with survival rates (American Cancer Society, 2017). However, BSE followed by timely diagnosis and treatment is a viable screening method for populations with limited health care access. This concurs with the ACS' recommendation that breast awareness is vital to afford women the opportunity to promptly report to healthcare if they notice any changes in how their breasts normally look and feel (American Cancer Society, 2017). Research has revealed BSE is associated with increased medical advice seeking behavior and undergoing biopsies (Hackshaw \& Paul, 2003), which are associated with earlier diagnosis and more enhanced treatment outcomes (Miller \& Baines, 2011).

Research has shown that despite its potential benefits, only a few women engage in breast cancer screening practices such as BSE (Dewi et al., 2019; Ministry of Health RI, 
2018). Various facilitating and inhibiting factors predict BSE behavior. Dewi et al. (2019) found that BSE was positively associated with higher perceived benefits, lower perceived barriers, and higher self-efficacy among Indonesian women. Agarwal et al. (2009) identified lack of breast cancer awareness, social taboos of cancer, misconceptions about cancer treatments, and beliefs in traditional medication as the primary obstacles involved in early detection of breast cancer in LMICs.

The Reasoned Action Approach (RAA; Fishbein \& Ajzen, 2010) was employed as a theoretical framework to shed light on the potential determinants of BSE in Agarwal et al's study. The RAA postulates that individuals' decision to engage in health-protective behavior is linked to their beliefs about such. Individuals' behavior is determined by their behavioral intentions, which are linked to their attitude towards the behavior, subjective norms, and perceived behavioral control to engage in such. In a meta-analysis, McEachan et al. (2016) revealed that RAA subcomponents are significant predictors of health behavior.

The Indonesian population is characterized by their strong religious values, cultural and social diversity, and limited health care services. This unique sociocultural environment may influence Indonesians' perceptions, attitudes and behaviors (Sitorus \& Budhwar, 2003). Accordingly, focus group discussions (FGDs) with Indonesian women were conducted to capture their lived experiences concerning their BSE behavior. The purpose of this study was first to explore the potential beliefs that underlie BSE motivation among Indonesian women, using the RAA as a theoretical framework. The second purpose was to explore an effective approach to enhance breast cancer awareness in Indonesians' social networks. The study findings could benefit the development of health education efforts to promote BSE and breast 
cancer awareness among Indonesian women (see Bartholomew Eldredge et al., 2016; Peters, 2018).

\section{Methods}

\section{Participants and study setting}

This study formed part of a broader project that explored factors that contribute to BSE and the development of breast cancer awareness among Indonesian women, particularly in Surabaya. The participants were recruited from seven sub-districts in Surabaya that had a low rate of breast and cervical cancer screening: Pabean Cantikan, Kenjeran, Tambaksari, Rungkut, Tenggilis, Karang Pilang, and Dukuh Pakis (Dinas Kesehatan Kota Surabaya, 2015). Through the $\mathrm{PKK}^{3}$ Surabaya city office, the researchers contacted the PKK chief in each of the seven sub-districts who approached women during the monthly PKK meeting to participate in the study and subsequently, screened them for eligibility.

The participants included 62 women between the ages of 18 and 65 years who had not or rarely $(\leq 3)$ performed BSE in the previous year, had no history of breast cancer or other chronic illnesses and spoke Indonesian. They were divided into nine groups, which each comprised between five and eight, in accordance with their sub-districts. The FGDs were conducted between August and November 2018. The participants received a basket of groceries and IDR 50,000 (approx. 10 Euro) as compensation.

\footnotetext{
${ }^{3}$ PKK: Pembinaan Kesejahteraan Keluarga (Women's Family Welfare Movement), a nation-wide women's NGO that seeks to reach every married woman in a certain geographical area. It organized a regular meeting for its members every month.
} 


\section{Procedure and materials}

The FGDs were held in the discussion room in the Faculty of Psychology Airlangga University and a meeting room in the PKK village office or sub-districts office. Every FGD was led by the first author or two psychology graduate research assistants. The research assistants received training that involved basic skills to conduct FGDs as well as practical aspects thereof, including those in the FGD guidelines. They were also provided with information about the medical and psychological aspects of breast cancer early detection, especially BSE.

After the participants were briefly informed about the study, they signed an informed consent sheet. Subsequently, they provided demographic information, including age, marital status, education, employment, family monthly income, family history of breast cancer, and insurance status. The duration of each FGD, which was audio recorded and transcribed verbatim was between 75 and 100 minutes. Five internship bachelor students observed the FDGs and took notes of the participants' non-verbal responses. To ensure the validity of the transcriptions, an observer who had been present during the FGD also transcribed the FGD they had observed.

The FGD protocol was constructed by employing the RAA as a conceptual framework and contained questions on attitudes, subjective norms and perceived behavioral control towards BSE and the underlying beliefs. These were supplemented with questions about women's knowledge on breast cancer symptoms, risk factors, and effective ways to improve breast cancer awareness in their environment.

\section{Data Analysis}

The transcriptions of the FDGs were processed using ATLAS.ti version 8.3.1. Directed content analysis (Hsieh \& Shannon, 2005) was employed to explore beliefs underlying 
various factors that influence BSE among Indonesian women in Indonesia as well as a possible effective approach to improve breast cancer awareness. Themes were clustered using the RAA framework (Fishbein \& Ajzen, 2010). Additionally, an inductive process was used to explore different categories, which were subsequently grouped into themes, that emerged from the text. The first and third authors, and an independent researcher first analyzed three FGDs to establish acceptable inter-rater reliability. Codes, categories and themes that were generated from these FGDs were compared, reviewed, discussed and refined until consensus was achieved, thus leading to an enhanced coding scheme and criteria. Subsequently, this coding scheme was employed to analyze the remaining FGDs. Parts of the text were translated into English to enable a discussion of the codes and themes with co-authors not familiar with the Indonesian language.

\section{Results}

The participants' demographic information is displayed in Table 1. The majority earned a low salary, did not have a family history of cancer, and were covered by health insurance.

\section{Psychosocial factors related to BSE practice}

In this section, the participants' perspectives related to their underlying beliefs of factors that may contribute to BSE are provided. Six themes emerged from the FGDs.

Theme 1. Breast cancer and BSE related knowledge. The participants related that although they had heard about breast cancer, they did not know exactly what it was. Those who had heard about the disease noted it was frightening, dangerous and fatal. Some knew that breast 
Table 1 Demographic Characteristics of Study Respondents

\begin{tabular}{|c|c|}
\hline Variable & n (\%) \\
\hline Mean age & 32.9 \\
\hline \multicolumn{2}{|l|}{ Marital Status } \\
\hline Single & $14(22.58 \%)$ \\
\hline Married & $45(72.58 \%)$ \\
\hline Divorced/Widowed & $3(4.84)$ \\
\hline \multicolumn{2}{|l|}{ Education } \\
\hline Elementary School & $6(9.68 \%)$ \\
\hline Junior High School & $9(14.52 \%)$ \\
\hline Senior High School & $39(62.90 \%)$ \\
\hline College & $8(12.90 \%)$ \\
\hline \multicolumn{2}{|l|}{ Employment } \\
\hline Unemployed & $41(66.13 \%)$ \\
\hline Student & $4(6.45 \%)$ \\
\hline Private employee & $10(16.13 \%)$ \\
\hline Public employee & $2(3.23 \%)$ \\
\hline Entrepreneur & $5(8.06 \%)$ \\
\hline \multicolumn{2}{|l|}{ Family monthly income } \\
\hline$<I D R 3.000 .000$ & $40(64.52 \%)$ \\
\hline IDR 3.000.000 - 10.000.000 & $19(30.65 \%)$ \\
\hline$>$ IDR 10.000 .000 & $2(3.23 \%)$ \\
\hline No answer & $1(1.61 \%)$ \\
\hline \multicolumn{2}{|l|}{ Family history of breast cancer } \\
\hline No & $52(83.87 \%)$ \\
\hline Yes & $10(16.13 \%)$ \\
\hline \multicolumn{2}{|l|}{ Health insurance } \\
\hline No & $23(37.1 \%)$ \\
\hline Yes & $39(62.9 \%)$ \\
\hline
\end{tabular}

cancer could be cured if detected early, metastasize to other organs, and chemotherapy, radiotherapy and mastectomy could be used to treat it. Some also indicated that although breast cancer could be present without any symptoms, a sufferer could suddenly be in an 
advanced stage. They also did not know the cause of it and how to prevent it: "From what I understand, breast cancer is a very scary disease and the cause is almost unknown" (P. 18)

The participants also related various misconceptions about breast cancer: it was contagious, caused by a bacterial infection and cured by alternative medication: "It (breast cancer) is caused by bacterial infection so can spread out everywhere" (P. 3). Although several participants acknowledged they did not know what the symptoms of breast cancer symptoms were, some related a lump in the breast or armpit, painful spot, retracted nipple, fluid from the nipple, different size of the breast and swollen breast were symptoms of the disease. They were also aware that the symptoms in each stage could differ; for example, while the early stage was not painful, the advanced stage was marked by metastasis. They acquired information about breast cancer from TV, public figures, friends/family, the Internet/social media, medical books and newspapers.

The majority of the participants related that although they had never heard about BSE, they regarded it as interesting and important. Because the FDGs allowed us to provide brief information about BSE procedures, the participants concluded what the advantages of BSE were: they could practice it on their own, it could be employed to detect breast cancer early and it could improve breast cancer awareness: "I think BSE is interesting, made me feel aware with my [own breast] condition" (P. 49). They felt BSE allowed them to detect any abnormality sooner and thus lessen anxiety and acquire treatment. Furthermore, they noted BSE was free and less shameful than consulting a doctor. However, misinformation, including believing that BSE could prevent breast cancer was noted. Most did not know the right time to conduct BSE and only a few acknowledged that they knew how to count fertile periods so as to start BSE.

Some women were familiar with BSE and were able to explain the procedures: touching breasts to feel lumps and using a mirror to determine breast shape. The participants related 
that they had learned about BSE from various sources, including family, friends, leaflets in medical centers and PKK meetings. As expressed by the respondents: "BSE ... I've seen the poster or leaflet in the hospital, shown the procedures with pictures, but I never did that" (P. 51), and "I heard [about BSE] from my husband, he asked me to examine my breast-stand in front of the mirror and examine whether there were lumps on my breast" (P. 19).

Theme 2. Attitudes and beliefs. Most of the participants expressed a positive attitude towards BSE. They asserted that BSE is an important health-protective behavior as it could improve breast cancer awareness and allowed them to identify any breast abnormality early, which enabled a speedy recovery: "I feel that BSE practice is important, so we could notice earlier if there was a symptom, so it would be easier to be cured" (P. 52). They noted that the positive aspects of BSE outweighed the negative thereof. Some even believed that BSE could prevent breast cancer.

However, some of the participants highlighted the disadvantages of BSE: they believed they would feel ashamed, uncomfortable and afraid if they discovered any symptoms, which inhibited BSE: "I feel afraid if I [examined my breast and] found any lump ... it will shock me. I am not ready [with breast cancer positive diagnosis]" (P. 46).

Some of the participants disclosed beliefs related to breasts and breast cancer, which may have also inhibited BSE. These included the notions that the breast was sensitive and an important female-symbolic organ, breast cancer was frightening and taboo, virgins should not examine their breasts often and poor people who suffered from breast cancer had to accept their fate: "My aunt who died from breast cancer was not taking a medical treatment ... well, 
people who do not have enough money to afford the medication could only surrender to their fate" (P. 25).

Theme 3. Risk perception. Almost all the participants declared they were vulnerable to breast cancer due to their poor health awareness, unhealthy lifestyles, breastfeeding issues, early menstruation, menopause, genetic factors, exposure to stress or previous health problems related to their breasts. It is noteworthy that some believed all women were susceptible to breast cancer. They also shared misleading information on what constituted a high risk for breast cancer, including bra uncleanliness, a dirty body and environment, storing money in bra, sleeping with a bra and never being pregnant. A few indicated that they did not feel at risk because they were physically active: “... it is impossible that I would suffer from breast cancer, because I have a healthy lifestyle, I eat healthy food, I do exercises, thus I feel that I have the right for not being ill", (P. 38).

Theme 4. Subjective Norms. Most of the participants indicated that no one or they were unaware of anyone in their social network who practiced BSE. They shared that they did not generally discuss BSE as they felt embarrassed speaking about it. While some acknowledged if they knew someone who practiced it, they would appreciate this and it would encourage them to perform BSE, others related that this would have no effect on them. "If we know a person who performs BSE, I think it is good, she cares with her own health. If she could manage to be kind to and take care for herself, why wouldn't we [do the same]" (P. 49).

Theme 5. Perceived behavior control. Both the participants who had previous knowledge about BSE and those who learned about it during their FGD believed they would be able to 
practice BSE because it appeared easy: “... if I know how to do it correctly, I think I could do $i t$ " (P. 11). They were also willing to learn the correct procedures of BSE.

Some of the participants acknowledged whether they would perform BSE depended on whether they had more important priorities. Furthermore, their low motivation, which was displayed in forgetting to practice BSE and/or feeling lazy or too tired to perform BSE, also played a role in whether they performed BSE.

Some, however, related that if they were reminded by a cue, they would perform BSE: "I used to forget BSE, but sometimes if I unintentionally exposed to objects related to it, I would remember to perform it. [For example] I saw the news about breast cancer on TV, and I remember to practice it" (P. 6). However, the practical notion that they could practice it themselves and was a free screening method motivated them to participate in the procedure.

Theme 6. Intention. The majority of participants related they were willing to practice BSE because of the advantages related to it: "Yes, I would not think twice to perform it, if we think that it is good to prevent breast cancer" (P. 49). However, they also stressed it was imperative to have proper BSE education so as to practice it correctly.

On the contrary, a few participants indicated that they had no intention of practicing BSE as it was uncomfortable, they felt embarrassed, were afraid of finding symptoms, and were not sufficiently familiar with the correct BSE procedures. They also perceived BSE was irrelevant as they had no breast cancer symptoms.

\section{Intervention approaches to improve breast cancer awareness}

Research has revealed the importance of identifying an effective approach to enhance breast cancer awareness to promote the early detection of breast cancer. Consequently, we asked the 
participants what forms of communication and which people and/or organizations would be effective to improve breast cancer awareness.

Breast consultation agents. While most of the married participants stated that their husband was the most likely person with whom they would like to consult, the unmarried participants preferred to discuss these issues with their parents and family, but particularly their mother. "For me, the first person whom I tell [about my breast problem] would be the one living in my home, my husband for sure. After that, I would discuss it with my other families like my mother or mother in law. But, my husband will always come first" (P. 54).

The participants shared they would be willing to undergo further examination if necessary after first discussing this with a significant other. They added they would be willing to consult with a medical doctor because of their understanding of breast health and they would be able to suggest more advanced health advice.

Although most of the participants preferred to consult with a female doctor, their main priority was a competent medical doctor. A few participants also stated that they would prefer a medical doctor they knew.

Communication patterns. Some participants believed that face-to-face both formal or informal meetings were most effective for breast education. Formal meetings could either be incorporated with regular PKK meetings, incidental meetings among women in a village, or part of a regular POSYANDU ${ }^{4}$. Some participants noted regular meetings were more likely

\footnotetext{
${ }^{4}$ POSYANDU is a basic form of health activity initiated by the government (Ministry of Home Affairs, Ministry of Health, National Board of Family Planning Coordination, and Family Welfare Movement (PKK)), organized by and for the community, and assisted by the health worker. It serves families with toddlers (under 5 years old), who are invited to a monthly meeting for being weighed, receiving 1 portion of a healthy meal, and get a basic vaccination for free.
} 
to be attended by more participants than incidental meetings because the former were already part of their schedule.

The participants believed that breast education should not merely involve verbal explanations, but an LCD projector should be employed to display picture(s) of breast cancer or use breast statues to demonstrate how to practice BSE. The participants also noted that posters and social media could be employed. Some participants cautioned against social media because not all women use it and the information provided might not be read or misinterpreted. The participants concurred that social media could complement face-to-face meetings. One participant asserted that health ministry officials, medical doctors and other health professionals were among the most reliable sources of breast education information. Although breast cancer survivors were mentioned as a source of information, communication from health professionals was more convincing: "I think it is more reliable that we get the information [on breast cancer education] by the medical doctor. Just like what you (the interviewer) do now, but you are also accompanied by a doctor. Because I think (s)he knows better, more convincing than a breast cancer survivor", (P. 29).

\section{Discussion}

\section{Psychosocial factors related to BSE practice}

The majority of participants had limited breast cancer literacy, marked by misconceptions about breast cancer and unfamiliarity with BSE. Although most related they had heard about breast cancer, they admitted their knowledge about symptoms, severity, risk factors and medical treatments was inadequate. They added because BSE was new to them, their information about its procedures, advantages and when to perform it was limited. Because of their limited knowledge, the population under study could develop beliefs, values 
and fear that lead to metaphors, which are commonly used across cultures to bring meaning to a phenomenon that is difficult to understand (see Sontag, 1978 and Johnson et al., 1999). These beliefs may influence them not to discuss breast cancer and its symptoms openly, which may inhibit their BSE behavior and exacerbate their reluctance to seek medical advice. Research has revealed a lack of awareness and knowledge about breast cancer in the Indonesian population, which could delay seeking healthcare (e.g., Anwar et al., 2018; Iskandarsyah et al., 2014; Solikhah et al., 2019). Although knowledge does not lead to behavior change directly (Bartholomew Eldredge et al., 2016), it is an imperative prerequisite for other behavior determinants, including risk perception, beliefs, perceived norms and skills. Thus, it is vital to provide health education in which correct and relevant information on breast cancer and BSE to promote BSE and early detection.

Those who had knowledge about breast cancer and BSE related various sources: their social network, health-related professions, the mass media and social media. This concurs with Dewi et al. (2020) who revealed that breast cancer related knowledge was acquired from the mass media and social media. In a systematic review of social media's effect on health promotion, Korda and Itani (2013) found that social media can enhance health knowledge, behavior and outcomes effectively to meet individual and population health needs. Thereof, social media can be utilized to disseminate knowledge and create awareness of breast cancer and BSE.

The findings further suggested BSE performance was associated with cognitive and affective attitudes towards BSE. The participants perceived BSE as a beneficial screening method to identify any breast abnormality early and enable a speedy recovery. Although they were afraid and embarrassed to perform BSE, they were positive that it was a free screening method, which they could conduct and less embarrassing than a medical examination. This finding is in accordance with RAA (Fishbein \& Ajzen, 2010), which revealed that attitude 
was a significant predictor of behavior intention and further, distinguishes between cognitive and affective components of attitude. Our finding is also in accordance with the Health Belief Model's (HBM) construct of perceived benefits (Rosenstock, 1966). The HBM posits that health behavior is determined by personal beliefs about a disease and strategies available to reduce the occurrence of that disease (see Iskandarsyah et al., 2014). Thus, if the participants perceived performing BSE to be effective in reducing the threat of suffering from a late stage of breast cancer, this could increase the likelihood of engaging in the procedure.

Most of the participants indicated a high risk-perception towards breast cancer, which could increase their likelihood of performing BSE. This concurs with Al-Sharbatti et al. (2013) who found that university students who perceived themselves to be at risk of breast cancer generally practiced BSE. In this study, this high risk-perception towards breast cancer was due to their misconceptions about the factors they believed made them vulnerable to the disease such as unclean bras, thus revealing their low breast cancer literacy.

Due to the nature of the FGDs, the participants acquired information about BSE procedures. This enabled them to disclose that they were able to perform BSE themselves, which may have increased their likelihood to perform BSE. Previous research have revealed that self-efficacy or perceived behavior control are significant predictors of health behavior, including breast cancer screening (Dewi et al., 2019; Didarloo et al., 2017; Norman \& Cooper, 2011). However, the need for BSE education to be able to practice it correctly was emphasized.

The findings revealed the participants did not speak about breast cancer and BSE in their social networks frequently. However, they acknowledged that if those in their social networks had a positive attitude towards BSE and practiced it, they would be encouraged to do so. This finding revealed the participants represented communal society, which was characterized by a strong family support system that played a major role in shaping health- 
related behaviors (Claramita et al., 2013). This concurs with Henriksen et al. (2015) who found that women in Denmark who were soon to receive their first invitation to participate in a breast screening programmed were influenced by their acquaintances' attitudes.

In essence, the findings revealed evidence of psychosocial factors that contributed to BSE among the participants as breast cancer and BSE related knowledge, attitudes and beliefs, risk perception, perceived behavioral control, subjective norms and intention, which could be the key factors to promote BSE practice (Figure 1).

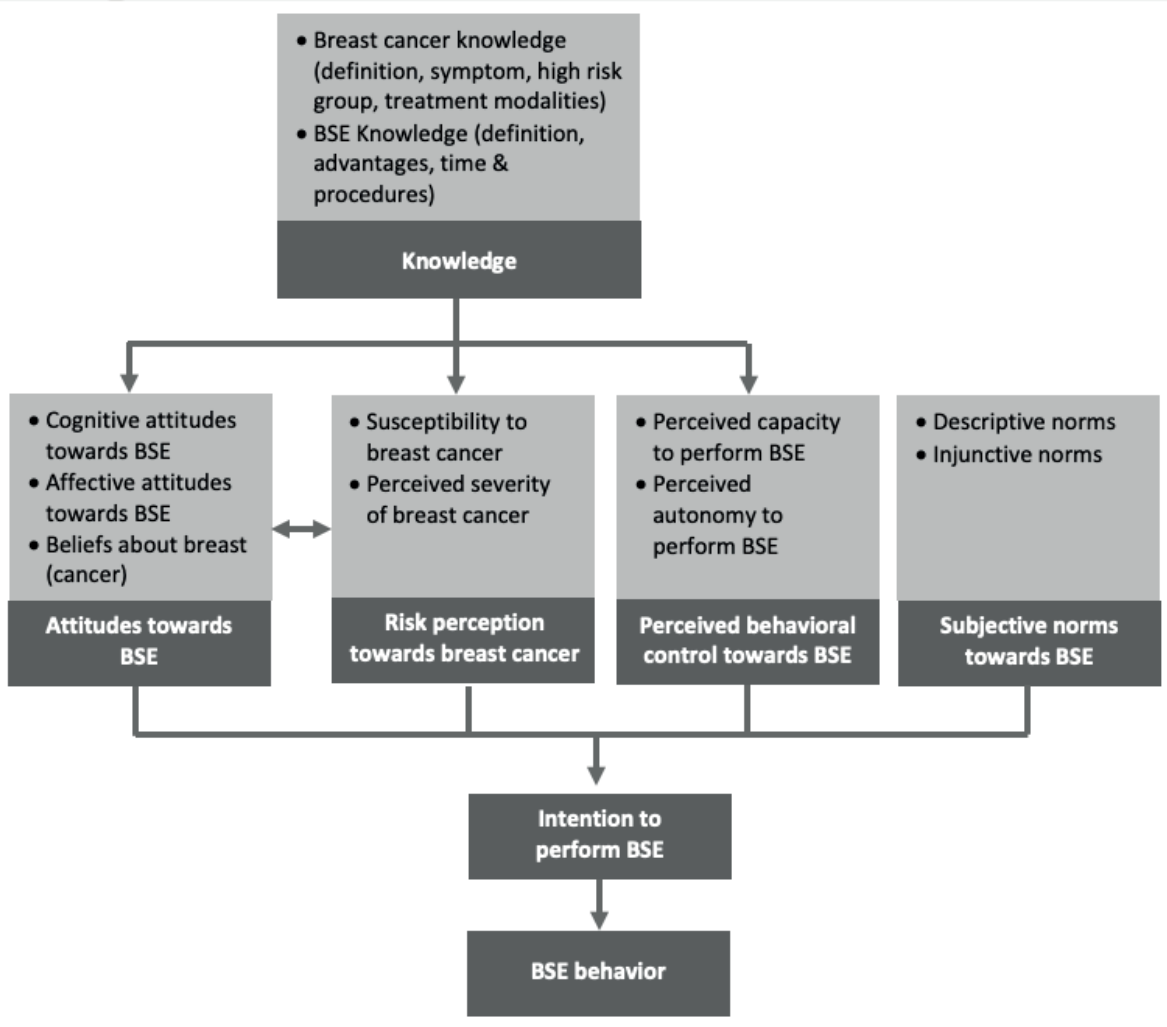

Figure 1. Women lived experiences with BSE

\section{Intervention approaches to improve breast cancer awareness}

The participants related that face-to-face meetings that encompassed oral and written information could promote breast cancer awareness effectively. Informal meetings in which 
word-of-mouth and written information was shared could improve breast cancer awareness. The participants noted that they trusted information from healthcare professionals more than from other agents. This concurs with Hesse et al. (2005) and Viswanath and Ackerson (2011) who found that physicians were a more trusted source of information than other sources. Thus, the involvement of healthcare professionals should be employed to communicate breast education.

Potential breast consultation agents that the participants approved of were explored. While most of the married participants stated that their husband was the most likely person with whom they would consult, those who were unmarried preferred to discuss issues with their family, particularly their mother. This concurs with Kim et al. (2015) who found that Korean Americans obtained health information from friends, church members and family. The participants acknowledged that after discussions with significant people, they were willing to consult with a medical practitioner if necessary, preferably a female doctor or a competent doctor they knew. This concurs with Jones et al. (2014) who revealed health care professionals' standard was considered as a determinant that increases the likelihood of undergoing a breast cancer examination among women in LMICs.

\section{Limitations}

This study has several limitations. First, most of the participants were married, housewives or unemployed and had a low family income. These demographic characteristics may have had a considerable influence on their perceptions and beliefs related to breast cancer and BSE. Thus, it is recommended that further quantitative research among the general population be conducted to confirm the findings. Second, because the participants were recruited through PKK meetings, those women who were socially active in the community and actively engaged in most PKK activities would be more likely to participate 
in the study, leading to potential bias. Finally, by employing FGDs, the participants may have responded to the questions in a socially desirable manner, which may have led to bias.

\section{Conclusion}

Several underlying beliefs of BSE motivation framed within the RAA were identified. These findings can guide the development of intervention strategies to promote BSE under population being studied by providing guidance on what beliefs need to be strengthened, removed, changed or installed in Indonesian women to promote regular BSE performance. It is imperative to improve breast cancer and BSE literacy among women to increase their breast cancer awareness. Information on breast cancer, including symptoms, risk factors and skills to perform BSE and recognize normal and abnormal breast anatomy are essential for breast education. Further quantitative research is needed to validate the six determinants of BSE practice revealed in this study. We believe that face-to-face meetings in which visual media and healthcare professionals are employed to enhance breast cancer awareness are vital. Breast education should also involve significant others in women's social networks. 

Chapter 5.

Breast self-examination as a route to early detection in a lower middle-income country: Assessing psychosocial determinants among women in Surabaya, Indonesia

Based on:

Dewi, T. K., Ruiter, R. A.C., Diering, M., Ardi, R., \& Massar, K.,. (2021). Breast selfexamination as a route to early detection in a lower middle-income country: Assessing psychosocial determinants among women in Surabaya, Indonesia. Manuscript submitted for publication. 


\section{Abstract}

Regular breast self-examination (BSE) is considered an important first step for its early detection, especially in countries with limited healthcare access. This study aimed to confirm and assess the psychosocial determinants of intention to perform BSE and BSE performance. The study was conducted on 204 women aged 18-65 years in Surabaya, Indonesia. A 64-item survey was conducted, included variables from Theory of Planned Behavior, Reasoned Action Approach, and Health Belief Model, presented questions about demographics, breast cancer knowledge and behavior related to BSE. Two hundred and four respondents completed the survey and were included in the study. Most women (72.5\%) expressed intention to perform BSE; however, only $7.8 \%$ and $2.9 \%$ performed BSE per week and per month, respectively, in the past year. Breast cancer knowledge and attitudes towards BSE were uniquely associated with BSE performance. Perceived behavioral control (PBC) and BSE attitudes were unique correlates of intention. Perceived benefits and barriers and subjective norms were significantly associated with intention and BSE behavior in bivariate analyses. To conclude, breast screening education should incorporate strategies for improving attitudes towards BSE, PBC and breast cancer knowledge with perceived benefits and barriers and subjective norms as relevant targets. 


\section{Introduction}

Breast cancer continues to be the major type of cancer among women in Indonesia, with an incidence of $30.8 \%$ of all new cancer diagnoses among women, and constituting $9.6 \%$ of all cancer related deaths (IARC, 2020b). Estimates indicate that approximately $70 \%$ of patients present with an advanced stage of breast cancer, which negatively impacts treatment options and prognosis (Irawan et al., 2008; Ng et al., 2011). Therefore, early detection remains as cornerstone for breast cancer control in Indonesia.

Mammography is the most universally accepted method of breast cancer screening, and is the golden standard (American Cancer Society, 2017). However, there is limited access to it in Indonesia: Mammography has not been designated as an organized national screening program, and is not covered by Badan Penyelenggara Jaminan Sosial Kesehatan (BPJS Kesehatan) the Indonesian national health insurance, making it costly and causing only a few to have access to this screening method (Choridah et al., 2019). Additionally, some limitations of mammography are also noted, i.e., poor accuracy in women with dense breast tissue, relatively high rate of false positives, or personal discomfort (Armstrong et al., 2007; Berg, 2009). Moreover, mammography showed less effective performance on women under 50 years old (Olsen \& Gøtzsche, 2001), while most women in Indonesia are diagnosed with breast cancer precisely at these younger ages (Ministry of Health RI, 2019). Thus, other screening methods are more appropriate in low- and middle-income countries (LMICs) where women do not have access to more advanced screening methods such as mammography (Yip et al., 2018).

Regular breast self-examination (BSE), combined with breast awareness, is one of the strategies for achieving the early detection of breast cancer. The American Cancer Society (ACS) highlights the importance of breast awareness; that is, women should be familiar with the normal condition of own breasts and promptly report to healthcare in the case of changes (American Cancer Society, 2017). Evidence from LMICs exists that regular BSE is positively 
associated with the identification of breast cancer in an early stage (Yip et al., 2018), which thereby improves treatment outcomes (Hackshaw \& Paul, 2003; Lam et al., 2008; Miller \& Baines, 2011). As such, BSE practice followed by a prompt medical professional examination in the case of detected abnormalities may serve as a viable screening method for detecting breast cancer in an early stage, allowing improved prognosis.

A thorough understanding of factors that serve as determinants of the intention to perform BSE behavior is required to identify relevant targets for intervention to promote the early presentation of breast cancer. The study used the Theory of Planned Behavior (TPB), Reasoned Action Approach (RAA) and the Health Belief Model (HBM) as conceptual frameworks. According to TPB (Ajzen, 1991) and RAA (Fishbein \& Ajzen, 2010), beliefs associated with a health behavior guides the decision of whether to perform such. Behavioral beliefs form attitudes; normative beliefs shape individual perceived norms; and control beliefs structure perceived behavioral control (PBC). Additionally, the HBM, which was introduced by Rosenstock (1966), explains health behavior as being determined by a person's beliefs about a disease and available strategies for reducing the occurrence of the disease. Specifically, the model proposes that if individuals perceive that they are at risk for a disease in terms of perceived severity and vulnerability, then they will be motivated to reduce the threat by performing the recommended action provided that they expect positive health outcomes and perceive no major barriers in performing the precautionary action.

Our previous quantitative and qualitative studies (Dewi et al., 2019; Dewi et al., 2020; Dewi et al., 2021) provide support for the hypothesis that the TPB, RAA and HBM components are instrumental for predicting BSE practice. Interestingly, although these models do not consider knowledge an (important) determinant of behavior but a background variable, the abovementioned studies suggested that Indonesian women lack basic knowledge about breast cancer and its symptoms, BSE, and the relationship between breast cancer and BSE 
performance. Therefore, the current study aims to assess women's understanding of breast cancer and BSE.

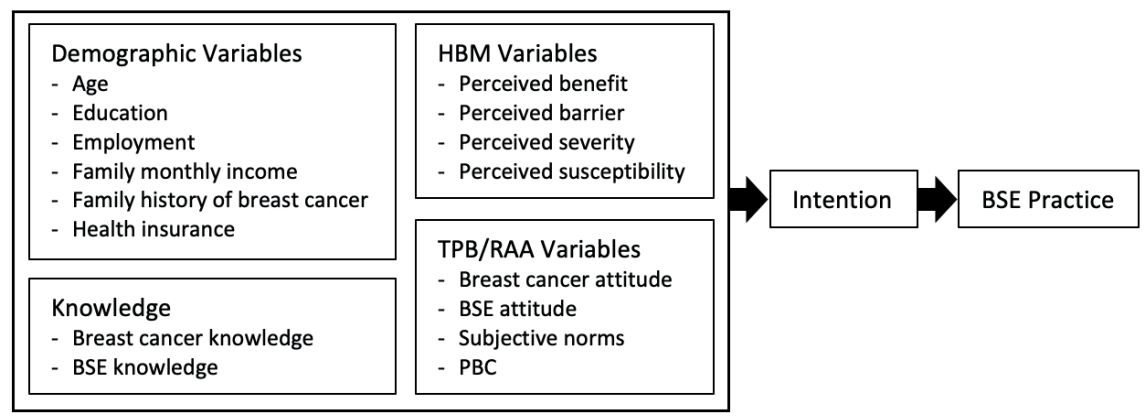

Figure1. Theoretical framework for BSE practice

Specifically, the current research aims to confirm and assess the psychosocial determinants of the intention to perform BSE among Indonesian women, and the extent to which these determinants are associated with BSE performance (Figure 1). Identifying the relevant and changeable psychological determinants of intention and BSE performance will provide insight into important targets for future educational campaigns on breast cancer awareness, and stimulate regular BSE among Indonesian women (see Crutzen et al., 2017).

\section{Methods}

The cross-sectional study was conducted in Surabaya, East Java. The specific inclusion criteria included age (18-65 years old); women who lived in Surabaya for at least 1 year at the time of the study and who never have been diagnosed with breast cancer. The respondents completed an online survey (constructed using Qualtrics ${ }^{\mathrm{TM}}$ ), which contained measures of TPB/RAA and HBM constructs related to BSE practice and questions pertaining to knowledge about breast cancer and BSE, BSE behavior and socio-demographics. At the end of the survey, the 
participants were offered to join a raffle, in which they could win one of 30 packages of mobile phones/OVO/GOPAY credit worth IDR 100,000 each.

The study recruited 268 participants. After data inspection, 62 responses were considered incomplete, which were thus excluded. The final sample consisted of $n=204$ respondents. Data were collected between April and May 2020.

The questionnaire originally consisted of 72 items designed for the target variables identified in the literature and in the abovementioned qualitative studies. The TPB/RAA constructs were attitudes towards breast cancer and BSE, subjective norm and PBC towards performing BSE; the HBM constructs were composed of perceived benefit, perceived barrier, perceived severity and perceived susceptibility. Other variables included knowledge about breast cancer and BSE, BSE behavior and socio-demographics. Table 1 lists the sample items for all constructs.

The items measuring the TPB/RAA and HBM constructs and understanding of BSE procedures were rated using a 7-point Likert-type scale ranging from $1=$ strongly disagree to 7 = strongly agree. To assess knowledge about breast cancer, the survey included 23 items pertaining to the definition, symptoms, risk factors and screening modalities of breast cancer, which could be answered with 'yes', 'no' and 'I don't know'. BSE behavior was assessed using one question: 'Did you practice BSE in the past year?' (never; performed but not regularly; performed regularly on a monthly basis; and performed regularly on a weekly basis). Demographics recorded were age, level of education, employment, family monthly income, family history of breast cancer and health insurance.

The questionnaire was constructed in English, translated into Bahasa and back-translated into English to ensure construct and face validity. The first and third authors were responsible for the translation process. 
Table 1. Overview of psychosocial measures

\begin{tabular}{|c|c|c|c|c|}
\hline Variables and sample item & $\begin{array}{l}\text { Number } \\
\text { of items }\end{array}$ & $\begin{array}{l}\text { Min } \\
\text { score }\end{array}$ & $\begin{array}{l}\text { Max } \\
\text { score }\end{array}$ & $\alpha$ \\
\hline Intention & 3 & 1 & 7 & .58 \\
\hline - I intend to perform BSE monthly as recommended. & & & & \\
\hline Attitude towards breast cancer & 3 & 1 & 7 & .61 \\
\hline - I believe that BSE is related to moral wrongdoing. & & & & \\
\hline Attitude towards BSE & 5 & 1 & 7 & .68 \\
\hline - I believe that BSE is easy to perform. & & & & \\
\hline Subjective norms & 4 & 1 & 7 & .85 \\
\hline $\begin{array}{l}\text { - I believe that most people who are important to me approve of me } \\
\text { performing BSE monthly. }\end{array}$ & & & & \\
\hline $\mathrm{PBC}$ & 3 & 1 & 7 & .71 \\
\hline - I am confident I can make time to perform BSE monthly. & & & & \\
\hline $\begin{array}{l}\text { Perceived barriers } \\
\text { - I would skip BSE monthly practice if I have competing priorities e.g., } \\
\text { childcare, employment, family commitments. }\end{array}$ & 4 & 1 & 7 & .70 \\
\hline $\begin{array}{l}\text { Perceived susceptibility } \\
\text { - I believe it is impossible that I would suffer from breast cancer. }\end{array}$ & 3 & 1 & 7 & .69 \\
\hline $\begin{array}{l}\text { Perceived severity } \\
\text { - If I was diagnosed with breast cancer I think I would have to die } \\
\text { soon. }\end{array}$ & 5 & 1 & 7 & .67 \\
\hline $\begin{array}{l}\text { Breast cancer knowledge } \\
\text { - From what I understand, breast cancer is contagious. * }\end{array}$ & 23 & 1 & 23 & .76 \\
\hline $\begin{array}{l}\text { BSE Knowledge } \\
\text { - From what I understand, BSE is painful.* }\end{array}$ & 7 & 7 & 49 & $\mathrm{n} / \mathrm{a}$ \\
\hline
\end{tabular}

Note: *Reversed item

Data were tabulated in Excel worksheets and analyzed using IBM SPSS (version 23.0). After factor and reliability analyses, eight items were omitted resulting a final set of 64 items for the main analyses. An item with communality less than 0.3 in the factor analysis and a corrected item-total correlation less than 0.3 in the reliability test was omitted.

The items reflecting the TPB/RAA and HBM constructs and breast cancer knowledge for each participant were averaged, whereas items measuring BSE knowledge were summed into 
a single measure to represent each psychosocial variable. Frequency distributions described the socio-demographic characteristics of the respondents. BSE performance was dichotomized into women who indicated they were BSE performers (i.e. performed BSE but not regularly; performed BSE regularly on a monthly basis; and performed BSE regularly on a weekly basis, $\mathrm{n}=131$ ) and those who indicated they did not perform BSE (non-performers; $n=73$ ). Chi square tests and independent sample t-tests were employed to compare the demographic properties and psychosocial variables, respectively. Furthermore, bivariate correlation analysis was utilized to measure the univariate association between variables. The correlations were considered to show weak, moderate, and strong associations if $r=.10-.23, r=.24-.36$ and $r$ $>.37$, respectively (Cohen, 1988). The study used hierarchical multivariate regression analysis to assess the contribution of the variables pertaining to intention to perform BSE. Finally, hierarchical logistic regression was used to measure the unique correlates of BSE practice.

\section{Results}

\section{Sample descriptives}

The final sample consisted of 204 women residing in Surabaya aged 18 to 61 years $(M=$ $29.72, S D=8.79)$. The majority were employed $(56.3 \%)$, achieved a higher vocational or university education (66.2\%) and obtained a family monthly income equal to Surabaya's regional standard monthly income or above $(69.6 \%)$. Moreover, they had no family history of breast cancer (74\%), had health insurance $(72.5 \%)$ and had performed BSE in the past year $(64.2 \%)$. Table 2 indicates that BSE practice is associated with age $(p<.05)$. In other words, women in the younger age group were less likely to perform BSE compared with those in the older age group $\left(\chi^{2}(1)=10.12, p<.001, V=.223\right)$. However, no differences were observed between BSE performers and non-performers for other demographic variables $(p>.05)$. 
Table 2. Socio-demographic and psychosocial characteristics of the participants

\begin{tabular}{|c|c|c|c|c|c|}
\hline & \multicolumn{2}{|c|}{ BSE Performers } & \multicolumn{2}{|c|}{ BSE Non-performers } & \multirow{2}{*}{ Statistics } \\
\hline & $\mathrm{n}$ & $\mathrm{n} / \mathrm{N} \%$ & $\mathrm{n}$ & $\mathrm{n} / \mathrm{N} \%$ & \\
\hline Age (years) & & & & & $\chi^{2}(1)=10.12, p=.001, V=.223^{*}$ \\
\hline $18-30$ & 67 & 32.8 & 54 & 26.5 & \\
\hline $31-65$ & 64 & 31.4 & 19 & 9.3 & \\
\hline Education $^{\mathrm{a}}$ & & & & & $\chi^{2}(1)=2.72, p=.099, V=.116$ \\
\hline Lower education & 34 & 16.7 & 27 & 13.2 & \\
\hline Higher Education & 97 & 47.5 & 46 & 22.5 & \\
\hline Employment & & & & & $\chi^{2}(1)=2.30, p=.129, V=.106$ \\
\hline Unemployed (and student) & 52 & 25.5 & 37 & 18.1 & \\
\hline Working & 79 & 38.7 & 36 & 17.6 & \\
\hline Family monthly income $^{b}$ & & & & & $\chi^{2}(1)=.33, p=.565, V=.04$ \\
\hline Below regional standard & 38 & 18.6 & 24 & 11.8 & \\
\hline Regional standard and above & 93 & 45.6 & 49 & 24 & \\
\hline Family history of breast cancer & & & & & $\chi^{2}(2)=.75, p=.684, V=.061$ \\
\hline Yes & 27 & 13.2 & 12 & 5.9 & \\
\hline No & 96 & 47.1 & 55 & 27 & \\
\hline I don’t know & 8 & 3.9 & 6 & 2.9 & \\
\hline Health insurance & & & & & $\chi^{2}(1)=.10, p=.753, V=.022$ \\
\hline Yes & 96 & 47.1 & 52 & 25.5 & \\
\hline No & 35 & 17.2 & 21 & 10.3 & \\
\hline
\end{tabular}

Note: $* p<.01, N=204$

a'Lower education: up to senior high school; higher education: higher vocational education or university

'Surabaya's regional standard monthly income: IDR. 4,200,000

The independent sample t-tests were then conducted, which revealed that intention to perform BSE, attitudes towards breast cancer, attitudes towards BSE, perceived benefits of BSE, subjective norms towards BSE, PBC towards BSE and breast cancer knowledge were significantly higher among BSE performers $(t \mathrm{~s}>2.67, p \mathrm{~s}<.01)$. Interestingly, the perceived barriers of performing BSE were also higher among BSE performers compared with nonperformers $(t(202)=-2.67, p=.008, d=.338)$. Table 3 provides a full overview of the results. 
Table 3. Comparison of psychosocial and knowledge variables among performers and nonperformers of BSE

\begin{tabular}{|c|c|c|c|}
\hline & \multicolumn{2}{|c|}{ BSE performers BSE non-performers } & \multirow[t]{2}{*}{ Statistics } \\
\hline & Mean (SD) & Mean (SD) & \\
\hline Intention & $5.63(0.85)$ & $5.05(0.98)$ & $t(202)=4.45, p<001, d=-.689^{*}$ \\
\hline Breast cancer attitude & $6.20(0.76)$ & $5.81(1.18)$ & $t(202)=2.90, p=.004, d=-.396^{*}$ \\
\hline BSE attitude & $6.07(0.56)$ & $5.53(.82)$ & $t(202)=5.63, p<001, d=-1.095^{*}$ \\
\hline Subjective norm & $4.79(1.11)$ & $4.24(1.17)$ & $t(202)=3.31, p=.001, d=-.423^{*}$ \\
\hline $\mathrm{PBC}$ & $5.77(.73)$ & $5.40(.84)$ & $t(202)=3.35, p=.001, d=-.597^{*}$ \\
\hline Perceived barriers & $3.75(1.12)$ & $4.19(1.16)$ & $t(202)=-2.67, p=.008, d=.338^{*}$ \\
\hline Perceived benefit & $6.22(0.57)$ & $5.98(.70)$ & $t(202)=2.75, p=.006, d=-.589^{*}$ \\
\hline Perceived susceptibility & $3.93(1.15)$ & $3.89(1.18)$ & $t(202)=.21, p=.831, d=-.029$ \\
\hline Perceived severity & $3.93(0.90)$ & $4.15(0.90)$ & $t(202)=-1.66, p=.099, d=.271$ \\
\hline Breast cancer knowledge & $15.02(3.36)$ & $12.34(3.33)$ & $t(202)=5.46, p<001, d=-.239^{*}$ \\
\hline BSE knowledge & $32.47(4.93)$ & $31.31(4.97)$ & $t(202)=1.60, p=.110, d=-.047$ \\
\hline
\end{tabular}

Note: ${ }^{*} p<.01, N=204$

\section{Determinants of intentions}

Bivariate correlation analysis found strong positive correlations of BSE intention to attitudes towards BSE, PBC and perceived benefits of BSE. BSE behavior and subjective norms demonstrated a moderate positive correlation with intention, whereas perceived barriers showed a moderate negative correlation with intention. Additionally, knowledge about breast cancer and BSE indicated weak correlations with intention. Table 4 lists the full results.

Multivariate regression analysis was performed to predict intention. Age was entered into the first block, whereas psychosocial variables (breast cancer knowledge, BSE knowledge, attitudes towards BSE, perceived benefits of BSE, subjective norms towards BSE, PBC towards BSE and perceived barriers of BSE) were entered into the second block. The full model explained $32.2 \%$ of variance in intention to perform $\operatorname{BSE}(F(8,195)=13.035$, $p<.001, f^{2}=.48$ ). The study found attitudes towards BSE and PBC as unique correlates of intention; that is, respondents who displayed high levels of attitudes towards $\operatorname{BSE}(B=.34$, 


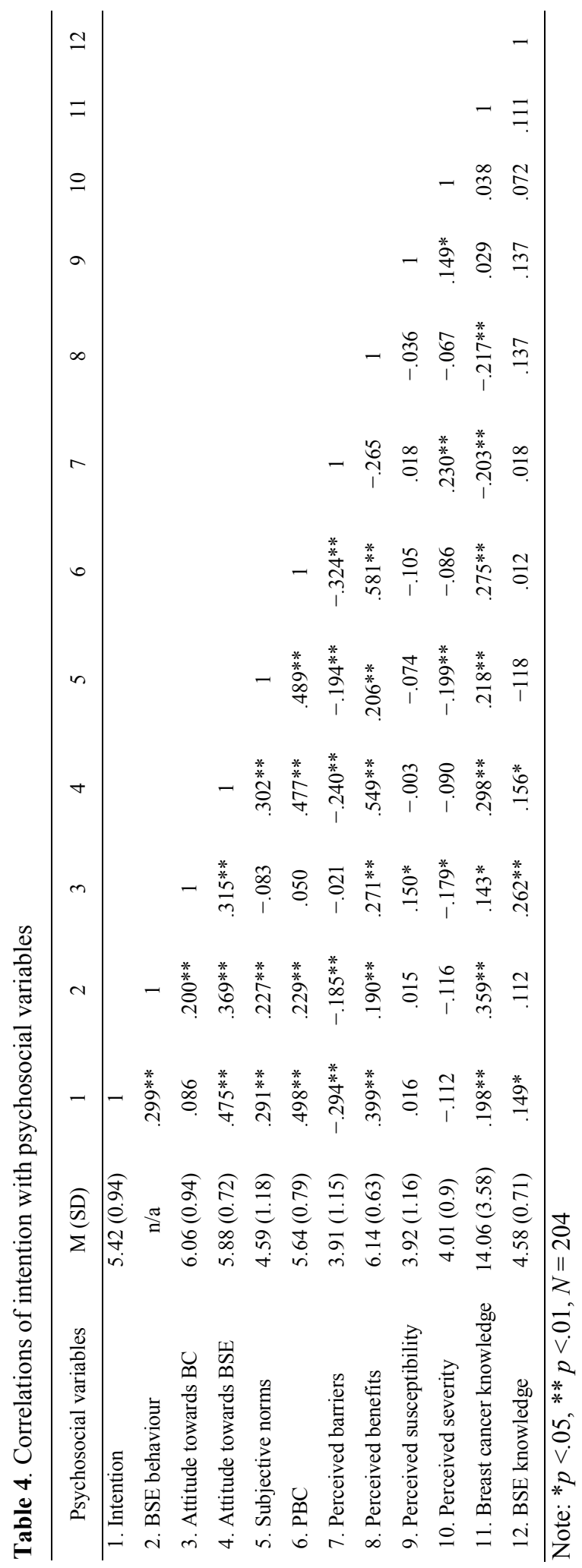


$95 \% C I=[.14-.53])$ and $\mathrm{PBC}(B=.35,95 \% C I=[.16-.55])$ were more likely to indicate an intention to perform BSE (Table 5).

Table 5. Multiple regression analysis of demographic and psychosocial variables for predicting intention towards BSE

\begin{tabular}{lccccc}
\hline Variable & $B$ & $B$ 95\% CI & $S E B$ & $\beta$ & $p$ \\
\hline Having older age & .09 & -.15 to.33 & .12 & .05 & .472 \\
Breast cancer knowledge & -.01 & -.04 to.03 & .02 & -.03 & .661 \\
BSE knowledge & .02 & -.01 to.04 & .01 & .11 & .069 \\
Attitude towards BSE & .34 & .14 to. 53 & .10 & .26 & $.001^{* *}$ \\
Perceived benefit of BSE & .05 & -.18 to. 28 & .12 & .03 & .682 \\
Subjective norms towards BSE & .04 & -.08 to. 15 & .06 & .05 & .524 \\
PBC & .35 & .16 to. .55 & .10 & .30 & $<.001^{* *}$ \\
Perceived barriers towards BSE & -.10 & -.20 to.01 & .05 & -.12 & .056 \\
\hline
\end{tabular}

Note: ${ }^{*} p<.05, * * p<.01, N=204, R^{2}=.322$

\section{Determinants of BSE performance}

More than one-third of the respondents (35.8\%) never performed BSE in the past year.

Others indicated that they performed BSE in the past year (performed but not regularly [53.4\%], performed on a monthly basis $[7.8 \%]$ and performed on a weekly basis $[2.9 \%])$.

Bivariate correlation analysis indicated weak positive associations of BSE performance to attitudes towards breast cancer, subjective norms, PBC and perceived benefits. Moreover, the study found a weak negative correlation between BSE performance and perceived barriers. Furthermore, the result exhibited moderate positive associations of BSE performance to breast cancer knowledge, attitudes towards BSE and intention to perform BSE. Attitudes towards BSE and breast cancer knowledge showed strong positive correlations with BSE performance (Table 4).

Logistic regression analysis was used to elucidate the probability of BSE practice in the sample. After controlling for age (first block), the researchers added psychosocial variables with significant correlation to BSE practice into the second block. The results displayed the 
model significantly predicted BSE practice $\left(\chi^{2}(9)=56.69, p<.001\right)$ and explained $24.3 \%-$ $33.3 \%$ of variance in whether participants ever utilized the screening method. The unique correlates of BSE performance were breast cancer knowledge and attitudes towards BSE ( $p$ S $<.05)$. Respondents who indicated high levels of breast cancer knowledge $(O R=1.19,95 \%$ $C I=[1.70-1.33])$ and positive attitudes towards $\operatorname{BSE}(O R=2.08,95 \% C I=[1.12-3.87])$ were more likely to perform BSE. Table 6 displays the results.

Table 6. Logistic regression analysis of BSE practice

\begin{tabular}{lcccccc}
\hline & $B(S E)$ & Wald & $d f$ & OR & OR 95\% CI & $p$ \\
\hline Having older age & $-.33(.39)$ & .75 & 1 & .72 & $.34-1.52$ & .387 \\
Breast cancer knowledge & $.18(.06)$ & 10.04 & 1 & 1.19 & $1.70-1.33$ & $.002^{* *}$ \\
BSE Intention & $.43(.23)$ & 3.65 & 1 & 1.54 & $.99-2.40$ & .056 \\
Attitude towards BC & $.36(.20)$ & 3.16 & 1 & 1.43 & $.96-2.13$ & .076 \\
Attitude towards BSE & $.73(.32)$ & 5.40 & 1 & 2.08 & $1.12-3.87$ & $.020^{*}$ \\
Perceived benefit of BSE & $-.34(.37)$ & .83 & 1 & .71 & $.35-1.48$ & .363 \\
Subjective norms & $.23(.17)$ & 1.70 & 1 & 1.26 & $.89-1.76$ & .192 \\
Perceived behavioural control & $-.10(.32)$ & .10 & 1 & .91 & $.49-1.68$ & .757 \\
Perceived barriers towards & $-.11(16)$ & .49 & 1 & .89 & $.65-1.23$ & .483 \\
BSE & & & & & & \\
\hline
\end{tabular}

Note: $* p<.05, * * p<.01, N=204$

Model $\chi^{2}(9)=56.69, p<.001, R^{2}=.243\left(\right.$ Cox \& Snell), $R^{2}=.333$ (Nagelkerke)

\section{Discussion}

The present study aimed to investigate the relevant and changeable psychosocial determinants contribute to the intention and past year BSE behavior. The study included variables from the TPB (Ajzen, 1991)/RAA (Fishbein \& Ajzen, 2010) and HBM (Rosenstock, 1966) as well as variables informed by findings of previous qualitative study (Dewi et al., 2020; Dewi et al., 2021). Knowledge gained from the current study can inform interventions that aim to promote regular BSE practice by targeting the main explanatory factors of the (non-) performance of this preventative behavior. The results indicate that regular BSE on a monthly basis in the past 
year was not prevalent among the respondents, which is consistent with the previous study (Dewi et al., 2019). Additionally, the likelihood of performing BSE behavior in the past year was associated with adequate knowledge about breast cancer and positive attitudes towards BSE. Together, the two variables explained approximately $33.3 \%$ of variance in BSE behavior.

In line with previous findings (Dewi et al., 2020; Dewi et al., 2021), the current data demonstrated that breast cancer knowledge is a correlate of BSE behavior, thus, the higher the respondents' understanding of the nature of breast cancer in terms of definition, symptoms, risk factors and screening modalities, the higher the likelihood they performed BSE in the past year. In the same manner, previous studies on women populations in Turkey, Uganda and Nigeria confirmed that adequate knowledge of breast cancer significantly improves the likelihood of women to perform BSE (Canbulat \& Uzun, 2008; Elsie et al., 2010; Okolie, 2012). Together, the findings that (a) knowledge about breast cancer serves as a unique predictor of BSE performance and (b) the low rates of regular BSE practice in the current sample imply that low BSE performance may be due to the lack of breast cancer knowledge. This conclusion is in line with that of Didarloo et al. (2017), who conducted a study among students in Iran and found that respondents with high levels of knowledge about breast cancer performed BSE 5.51 times more than those with low levels of knowledge. This finding highlights the necessity of improving breast cancer literacy among Indonesian women and the need to support the education on breast cancer screening.

As noted by Bartholomew Eldredge et al. (2016), knowledge does not directly lead to a behavior change; women's understanding of breast cancer alone is insufficient for the management of a BSE behavior. Ajzen et al. (2018) suggested that a more positive attitudes towards a health behavior plays a major role in facilitating such a behavior. In line with these suggestions, the current study finds that women with positive attitudes towards BSE were 2.08 times more likely to perform the behavior than women with negative attitudes. This finding 
supports previous research among Indian-Australian women which reported that respondents with positive attitudes towards general check-ups regularly practiced breast screening as recommended (Kwok et al., 2015). Conversely, women with a negative perception of BSE, felt embarrassed to perform it or experienced difficulty in performing were less likely to perform BSE. This result is in line with that of Al-Dubai et al., (2012), who proposed that a negative attitudes towards BSE will impede BSE behavior.

The intention to perform BSE regularly among respondents was relatively high. However, only $7.8 \%$ and $2.9 \%$ of the respondents indicated that they performed BSE regularly (monthly and weekly, respectively). Additionally, although the intention was positively correlated with BSE behavior, the measure of intention failed to explain any unique variance in BSE behavior. This finding supported intention-behavior gap hypothesis, i.e., participants with positive intentions failed to perform the behavior (Sheeran, 2002). Moreover, the current data indicated that $32.2 \%$ of variance in intention to perform BSE was predicted by the positive attitudes towards BSE and a high PBC. Thus, the study concluded that women who perceived BSE as an important process and were able to perform it were more likely to report increased intention to perform such. This finding is aligned with those of Wang et al. (2019), who conducted a study in China, and concluded that behavioral attitudes was one of the unique correlates of intention to perform breast cancer screening. Additionally, the current finding that women who felt confident with their autonomy and capacity to perform BSE indicated high levels of intention to perform such is in line with that of Roncancio et al. (2015) on Latinas. The authors documented that PBC was a strong predictor of the intention to be screened for cervical cancer.

Several changeable psychosocial variables, i.e. perceived benefits, perceived barriers and subjective norms failed to explain the unique variances of intention and BSE behavior. However, in the bivariate correlation analysis, these variables were significantly associated with intention to perform BSE and BSE behavior. Similarly, previous studies reported evidence 
that if women perceived BSE as highly beneficial, then they would be more likely to form positive intentions and/or perform BSE (Dewi et al., 2019; Didarloo et al., 2017; Wang et al., 2019). Vice versa, intention and/or BSE behavior would be less likely to occur when women perceived certain obstacles in BSE performance (Ahmadian et al., 2016; Dewi et al., 2019; Gonzales et al., 2018). Additionally, a strong family support system characterized the Indonesian population (Claramita et al., 2013). Thus, the notion that women's breast cancer screening behavior would be influenced by the support they (perceive to) receive from their close social circles is not surprising. Indeed, previous study highlighted the significance of subjective norms, such as encouragement from daughters or relatives, to participate in breast screening (Karbani et al., 2011). Moreover, Park (2000) found that, in general, individuals from collectivistic cultures (i.e. Indonesia) score higher on subjective norms and social attitudes. However, such results did not necessarily translate to high levels of behavioral intention. Therefore, the study suggests that developers of programs or interventions should focus on the role of subjective norms in the transmission of information about the advantages of performing BSE. Moreover, developers should formulate strategies for overcoming barriers to BSE performance during education on breast cancer awareness, e.g., involving women's close friends or family to health education activities.

The study was interested in exploring the distribution of demographic and psychosocial determinants among women who performed BSE in the past year (compared with nonperformers). The results indicated that women who performed BSE in the past year reported higher levels of intention to perform BSE, positive attitudes towards BSE and breast cancer (i.e. they feel that breast cancer is not related to moral wrongdoing or a taboo topic), subjective norms and $\mathrm{PBC}$ compared with those of non-performers. Furthermore, BSE performers were found to possess a better understanding of breast cancer and were more likely to perceive that performing BSE is beneficial for them. Interestingly, the study also found that women who 
performed BSE viewed more obstacles to BSE performance compared with those who did not perform BSE. The study inferred that BSE performers gained a more realistic view of BSE performance but found it important, nonetheless, which contributed to their decision to perform. Moreover, in line with previous research, younger women were less likely to perform BSE compared with older women perhaps because they perceived a lower risk of or susceptibility to breast cancer (see Al-Dubai et al., 2012).

The present study has several limitations. Firstly, data were collected through a crosssectional study, and the sample size was relatively limited. Thus, the causal relationship of the psychosocial variables to intention to perform BSE and BSE behavior could not be established. Therefore, longitudinal research that focuses on actual performed behavior should be conducted to establish such relationships. Secondly, data were collected through a self-report questionnaire. Thus, issues related to the subjectivity of a self-report measurement (e.g. social desirability bias) should also be considered in interpreting the results. Thirdly, the study sample generally achieved high levels of education, obtained considerable family incomes, was without a family history of breast cancer and secured health insurance. Therefore, populations from different socio-economic backgrounds, such as women from lower socio-economic groups, may display different patterns of associations. Additionally, the current sample, which is highly educated, exhibited low levels of breast cancer awareness, which suggested that this deficiency may be even greater among groups from lower socio-economic brackets.

\section{Conclusions}

The study assessed the relevant psychosocial determinants associated with the intention to perform BSE and past performance of BSE among women in Surabaya, Indonesia.

Furthermore, it confirmed the findings from the previous qualitative studies as well as the relevance of variables included in the influential models used to explain health behavior. The 
study provided strong evidence that improving literacy in breast cancer, including information about breast cancer symptoms and risk factors and the advantages and necessity of various forms of breast cancer screening, may serve as a basic foundation to support education interventions for breast cancer screening in Indonesia. Specifically, the study suggested that interventions should include methods and applications that aim to strengthen women's positive attitudes towards BSE to improve the intention to perform BSE and the likelihood of performing such a behavior. Moreover, such interventions should incorporate messages that enable the participants to generate information about effective strategies for coping with barriers that may impede BSE behavior. Finally, the study suggested that interventions should focus on increasing the knowledge and enhancing the attitudes of the social networks of women (i.e. close friends and family) because subjective norms play a significant role in the development of BSE behavior. 

Chapter 6.

General Discussion 
This final chapter elaborates on the results from the empirical studies and forms a comprehensive need assessment by identifying the relevant and changeable determinants of breast self-examination (BSE) practice in the Indonesian context. Thus, informing the critical targets for future tailored breast awareness and BSE campaigns among Indonesian women. Further, the chapter proposes implications and recommendations that emerged from the findings, and directions for further research are discussed.

\section{Main findings}

Chapter 2 is a cross-sectional study exploring the determinants of BSE based on the Health Belief Model (HBM) among the general population in Surabaya, Indonesia. The results supported the conceptualization of HBM (Rosenstock, 1966; Sheeran \& Abraham, 2003); such that if a woman perceived greater positive results from performing BSE, indicated higher confidence in her ability to perform BSE, and perceived fewer negative attributes of performing BSE, she was significantly more likely to perform BSE. These results confirmed previous studies in Low and Middle-Income Countries (LMICs), which found that breast cancer screening was determined by women's high perceived benefits of the behavior, having high self-efficacy, and low perceived barriers (Wang et al., 2019; Darvishpour et al., 2018; Didarloo et al., 2017; Ahmadian et al., 2016; Noroozi et al., 2011). In contrast to our expectations, we found that cues to action were negatively associated with the likelihood to perform BSE. Cues to action in the current study were operationalized as general positive health behaviors (e.g., maintaining a healthy diet, regular exercise); thus, we speculate that this type of cues to action might have activated women's health optimism. Previous studies indicated that general health optimism might lead to reduced health-protective behavior (see Carver \& Scheier, 2014; Chipperfield et al., 2019). Additionally, in line with findings among the Saudi population (Abolfotouh et al., 2015), the results showed that perceived severity and 
susceptibility did not predict BSE performance in our sample. To conclude, the study indicated that several HBM components are significantly associated with BSE behavior, suggesting BSE education should promoting women's perceived benefits and self-efficacy to perform BSE, introduce strategies to overcome barriers in performing BSE, and help them identifying personally relevant cues to action.

In Chapter 3, we explored psychosocial determinants of BSE and the lived experiences of breast cancer survivors, using semi-structured interviews. The interview guideline was developed using the Theory of Planned Behavior (TPB) framework to understand breast cancer early presentation, including behavior associated with early detection (e.g., BSE) and medical examination when noticing any symptom. We found that some respondents indicated a lack of breast cancer-related knowledge: symptoms, severity, stages, risk factors, medical treatments, and cancer service pathways - i.e., information about what to do and where to go when they noticed a symptom. Previous studies in LMICs also found that lack of knowledge was a significant predictor of breast cancer delay (Agarwal et al., 2009; Al-Dubai et al., 2012; Iskandarsyah et al., 2014). Further, the respondents disclosed when they were having the confidence, ability, and knowledge about BSE practice and what to do prior to noticing any symptom, the likelihood of early presentation would be improved. This finding replicated a previous study in the Latinas population, indicating that PBC was a strong predictor for screening behavior (Roncancio et al., 2015). Aligned with studies in the UEA and Iranian women, which indicated that risk perceptions were positively associated with breast cancer screening uptake (Allahverdipour et al., 2011; Al-Sharbatti et al., 2013), most of the respondents reported having a low perceived risk due to both health optimism and not having previous health-related experience, thus inhibit their early presentation. 
Further, most respondents indicated their positive attitudes, e.g., perceived early presentation as beneficial for a speedy recovery. However, few respondents also disclosed negative attitudes (e.g., feel ashamed) and stated some beliefs (e.g., breast cancer is related to moral wrongdoing) towards breast cancer, which aggravated the delay in seeking help. These findings were also found in other Asian populations, which related to cancer as taboo, shameful, and related to moral wrongdoing (Iskandarsyah et al., 2014; Karbani et al., 2011; Rajaram \& Rashidi, 1999).

External factors associated with breast cancer early presentation were also disclosed. The persuasion from their spouse or the occurrence of early presentation from friends was associated with early presentation. This finding concurs with a study among women in Denmark, which identified that subjective norms played a role in screening behavior (Henriksen et al., 2015). Additionally, their competing priorities, e.g., childcare, employment, and family commitments, contributed to the respondents' decision to perform such behavior. This finding confirmed previous qualitative studies in developed and developing countries that indicated competing priorities were identified as barriers for cancer screening uptake (Bukirwa et al., 2015; Hall et al., 2016; Hulme et al., 2016). Further, we found that having a friend or family member accompany them to medical appointments or screening facilitation from the workplace would improve the likelihood of engaging in such behavior. This indicated the population being studied was typically a communal society characterized by a strong family support system that played a major role in shaping health-related behaviors (see Cholil, 2017; Claramita et al., 2013; Sa'ir et al., 2020). The study also found that women's perception about healthcare providers' accessibility and comfortability impacted their decision to have a medical examination, replicated the previous study in developing countries, indicating positive perception of accessibility and comfortability to healthcare promotes screening behavior (Akinyemiju, 2012; Donnelly et al., 2013; Lim \& Ojo, 2017.) 
Finally, although financial issues were mostly not identified as barriers from participants themselves, our respondents did recognize that early presentation would require financial expenses; thus, they thought that others with less financial means and a lower quality of health insurance might constitute a risk for delayed presentation. Additionally, there was also an indication of a lack of trust in the quality of care under the public healthcare system (i.e., the increase of false-negative diagnosis) when they used basic health insurance, used mainly by individuals from a lower socioeconomic position, in which they perceived it would not allow them to receive adequate and high-quality care. This finding reflects the results from a systematic review conducted by Unger-Saldaña \& Infante-Castañeda (2009), that socioeconomic position may be associated with delay in screening behavior. In conclusion, the study suggests that breast education should focus on both internal and external psychosocial determinants related to breast cancer early presentation and involve women's social environment as the target for education. Additionally, providing accessible and affordable healthcare is vital to support the early presentation.

Chapter 4 presents the findings of a qualitative study aimed at exploring psychosocial determinants of BSE by investigating the potential beliefs that underlie BSE motivation among women who never or rarely $(\leq 3)$ perform BSE in Surabaya, Indonesia. The FGD guideline was developed using the Reasoned Action Approach (RAA) framework. Additionally, the most effective approaches in improving breast awareness in their social networks were also explored. Confirming the previous study in Chapter 3, lack of breast cancer and BSE knowledge among respondents was evidenced. Further, the findings related that some respondents showed positive attitudes towards BSE, which are commonly associated with BSE benefits. In contrast, negative attitudes (e.g., feel embarrassed and fear of noticing any abnormality) and beliefs about breast and breast cancer (e.g., the breast was a 
vital female-symbolic organ and concerned over the high treatment cost, thus, may not be affordable for them) disclosed by some respondents. They may add to the decision for screening absenteeism. These findings aligned with Ajzen et al. (2018) who postulates that human behavior is guided by their attitudes towards it and general attitudes towards its physical objects. In contrast to what we found in Chapter 3, most respondents declared their susceptibility to breast cancer; even some were led by misleading information (e.g., sleeping with a bra). Previous literature indicated that risk perception, i.e., individual perceived probability and severity of adverse outcomes (Pligt, 1996), are critical determinants of health behavior (Ferrer \& Klein, 2015). Additionally, women in this study acknowledged that their competing priorities (e.g., childcare, employment, and family commitment) or low motivation (i.e., displayed in forgetting and feeling lazy or too tired) might omit their BSE performance. However, some women expressed their confidence to perform BSE since it appeared easy. These findings aligned with previous studies in Iran and the UK, which found that self-efficacy or PBC are significant predictors of BSE performance (Didarloo et al., 2017; Norman \& Cooper, 2011). Finally, the women stated that they did not generally discuss BSE due to embarrassment. However, in line with Chapter 3, some women acknowledged that if those in their social networks had a positive attitude towards BSE and performed it, they would be encouraged to do so.

Upon noticing any symptom, the finding indicated that the women were most likely to consult with their husband or parents - particularly their mother and family if they were unmarried. This result concurs with a qualitative study in Jordan that the women experienced and appreciated the encouragement from their families for seeking breast health care (Taha et al., 2012). Further, the participants preferred to consult with a female doctor; however, their main priority was a competent medical doctor. The result is aligned with those of Jones et al. (2014), who revealed that health care professionals' standard was considered a determinant 
that increases the likelihood of breast cancer screening uptake in LMICs. The respondents mentioned formal or informal face-to-face or group meetings that encompassed oral and written information could promote breast cancer awareness effectively. The intervention could incorporate formal meetings with regular PKK (Indonesia: Pembinaan Kesejahteraan Keluarga, English: Women's Family Welfare Movement) or POSYANDU (Indonesia: Pos Pelayanan Terpadu, English: Integrated Service Post) monthly meetings. Additionally, the findings suggested that health ministry officials, medical doctors, and other health professionals were among the most reliable sources of breast education information. This result concurs with surveys in the US which found that physicians were a more trusted source of information (Hesse et al., 2005; Viswanath \& Ackerson, 2011). In conclusion, the study sheds light on the application of the RAA for BSE performance. Furthermore, it suggested the importance of face-to-face meetings involving healthcare professionals and women's social networks for breast education.

Lastly, to confirm and assess potential psychosocial factors of BSE practice generated from our previous quantitative and qualitative findings, we conducted a cross-sectional survey based on all three theoretical frameworks: the HBM, TPB and RAA, presented in Chapter 5. Most women (72.5\%) expressed intention to perform BSE; however, only $7.8 \%$ and $2.9 \%$ performed BSE per week and per month, respectively, in the past year, indicated that regular BSE on a monthly basis was not prevalent among our respondents despite their high measure on intention. Additionally, the study found that intentions to perform BSE did not explain any unique variance of BSE behavior. Therefore, these findings supported the well-known intention-behavior gap hypothesis (Sheeran, 2002), that is, the respondents showed a high score on intentions but failed to translate this into actual behavior. Further, our finding indicated that the women who perceived that BSE is an important and beneficial process 
reported a higher measure of BSE intention. This finding concurs with a study in China which found that behavioral attitudes were unique correlates of breast cancer screening intention (Wang et al., 2019). Additionally, the result related that the women who felt confident with their ability to perform BSE indicated a high measure of intention, which is aligned with previous research that $\mathrm{PBC}$ was a strong predictor of intention to attend cervical cancer screening among the Latinas population (Roncancio et al., 2015). Furthermore, the result suggested that women with a good understanding of breast cancer were more likely to perform BSE. This finding confirming previous studies indicated adequate breast or cervical cancer knowledge was a significant predictor for its screening uptake (Annan et al., 2019; Didarloo et al., 2017). However, we also noted that women who perceived BSE as highly beneficial, perceived fewer obstacles to perform it, and were influenced by the support they perceive to receive from their close social circles were more likely to perform BSE. Even though these three determinants were failed to explain any unique variances of both intention and BSE behavior in regression analysis, they were significantly associated with intention and BSE behavior in the bivariate correlation analysis. Therefore, future breast education should also focus on intervening in these variables (see Crutzen \& Peters, 2021).

To summarized, our findings in Chapter 2-5 proposed six determinants of BSE behavior, i.e., breast cancer knowledge, BSE attitude, PBC, perceived benefits, perceived barriers, and subjective norms, which were relevant and changeable, and could be incorporated in a tailored breast cancer education in the Indonesia context. 


\section{Implication and recommendations}

\section{The role of breast cancer and BSE understanding in performing BSE}

There were conflicting perspectives about the knowledge-behavior relationship. Knowledge, although necessary, is not sufficient for producing the desired behavior, e.g., understanding breast cancer severity does not always mean that a woman would practice regular screening (see Ajzen et al., 2018; Bartholomew Eldredge et al., 2016; Fisher \& Fisher, 1992). However, consensus wisdom believes that uninformed or misinformed individuals may not effectively produce a desirable outcome. This proposition was well documented in this dissertation: Chapter 4 and 5 evidenced that breast cancer knowledge was a significant correlate of BSE behavior, implied that the higher respondents' understanding of the nature of breast cancer, the higher the likelihood of BSE performance. Notably, the TPB perspective (Ajzen, 1991; Ajzen et al., 2018) suggested that information accuracy is irrelevant to decision-making in performing a behavior. Instead, subjective information (i.e., beliefs) linked to behavior positive or negative outcomes, the normative expectations of significant others, and control factors that can facilitate or inhibit the performance of a behavior indeed determined the intentions and actions. However, Chapter 5 indicated that breast cancer measures, which contain general knowledge about breast cancer (i.e., definition, symptoms, risk factors, and screening modalities), instead of specific knowledge about BSE, served as unique correlates of BSE practice. This finding confirmed previous studies conducted in LMICs, which found that adequate breast or cervical cancer knowledge was a significant predictor for its screening performance (Annan et al., 2019; Didarloo et al., 2017).

Besides its direct effect on BSE practice, our studies suggested that breast cancer knowledge may also have an indirect effect, i.e., knowledge may be associated with attitudes and self-efficacy (PBC), which promote the BSE practice. As we found in Chapter 4, 
attitudes might mediate the knowledge-behavior association. For example, knowledge about BSE benefits (e.g., a beneficial screening method to identify breast abnormality earlier) developed positive attitudes to perform the behavior, promoting such behavior. Additionally, the findings in Chapter 5 evidenced BSE knowledge was positively correlated with attitudes towards it, which in turn, positively associated with BSE intention and practice. These findings reflect the Knowledge, Attitude and Practice (KAP) Model, i.e., a cognitive process where individual knowledge about a behavior positively influences their attitude towards it, and further, this positive attitude intervenes their decision to engage in such (Valente et al., 1998). In addition, the mediating role of attitudes in knowledge-behavior relationships also reflects the TPB and RAA conceptual frameworks (Ajzen, 1991; Fishbein \& Ajzen, 2010). Further, this concurred with previous studies, which found that attitude mediating knowledge-behavior in colorectal cancer screening and food safety context (Kwol et al., 2020; McCaffery et al., 2003).

The findings in Chapter 4 indicated that knowledge about BSE advantages and correct procedures, and time to perform it was limited. However, due to the nature of FGDs, where the participants acquired information about what, how, and when to perform BSE, the woman disclosed that they could perform BSE, which may have increased their likelihood of performing BSE. This finding implied that self-efficacy or perceived behavioral control appear to mediate the knowledge-behavior relationship. Previous studies indicated that mediating role of self-efficacy on knowledge and behavior association was also evidenced for self-care behavior in chronic kidney disease among outpatients in northern Taiwan (Wu et al., 2016) and dietary behavior in the US context (Rimal, 2009).

In sum, our results indicated that an understanding of the nature of breast cancer directly promotes BSE practice. Thus, we suggest that the correct understanding of breast cancer would be relevant to initiating BSE behavior in the Indonesian context, because 
currently such information is lacking. Additionally, BSE knowledge as a distal determinant of BSE practice is also propositioned, suggesting that a sufficient understanding about BSE benefits and procedures might promote positive attitudes and perceived behavioral control, which in turn influence women's decision to engage in BSE. To sum up, we suggest that knowledge is necessary, but on its own likely is not sufficient for behavior change.

\section{Implications for BSE and breast awareness education in the Indonesian context}

This dissertation consists of the first step of the Intervention Mapping approach: the need assessment of community capacities and needs to create a logic model of the problem. Intervention Mapping is a protocol for systematic theory-and evidence-based behavior change planning to form an ecological approach to assess and intervene in health problems and promote community participation (Bartholomew Eldredge et al., 2016). The dissertation overviews women's problems and needs related to breast cancer awareness and screening behavior. Additionally, determinants related to behavior at risk were explored, and strategies to change each determinant are also discussed in this section.

The determinants related to BSE practice in this dissertation were explored using the HBM, TPB, and RAA frameworks. The HBM proposed that health behavior is influenced by personal beliefs or perceptions about a disease and the strategies available to an individual to reduce the occurrence of the disease (Rosenstock, 1966; Sheeran \& Abraham, 2003). Specifically, health behavior is influences by perceived susceptibility (i.e., perceived personal vulnerability to the risk of incurring a disease), perceived severity (i.e., beliefs about the seriousness of the disease and its consequences), perceived benefits (i.e., beliefs about the benefits of performing a health behavior), perceived barriers (i.e., perceived personal costs of performing a health behavior), cues to action (i.e., the internal or external triggers that encourage the performance of health behavior), and self-efficacy (i.e., beliefs regarding their 
ability to perform a health behavior; see Carpenter, 2010; Champion, 1999; Champion \& Scott, 1997). In addition, according to TPB and RAA, the most proximal determinant of health-related behavior is the intention to engage in the behavior, in which behavior intention is determined by attitudes - positive or negative evaluation towards the behavior, subjective norms - perceived social pressure to engage or not to engage in a behavior, and perceived behavioral control - the beliefs that behavior is under an individual's control (see Ajzen, 1991; Fishbein \& Ajzen, 2010). Further, the RAA extends the TPB by differentiating the subcomponents of the attitude (instrumental - cognitive evaluations vs. experiential affective components), subjective norms (injunctive - perception of others' approval of behavior vs. descriptive - perception of others' behavior), and perceived behavioral control (autonomy - the degree of control over a behavior vs. capacity - perceived capability of performing behavior). Exploring and assessing the psychosocial factors related to BSE practice using multiple theories: HBM, TPB, and RAA frameworks would help shape a more comprehensive understanding of BSE determinants. Thus, informing the program planner with relevant and changeable determinants targeted for intervention.

As described earlier, understanding the nature of breast cancer significantly promote BSE behavior among our sample. Additionally, Chapter 5 confirmed that women who perceived that performing BSE is highly beneficial (attitude) were more likely to performed BSE in the past year. This finding concurs with previous studies indicated that perceived benefits are positively associated with intention and actual BSE performance (Didarloo et al., 2017; Wang et al., 2019). Moreover, Chapter 5 confirmed that attitudes were unique correlates of intention and BSE behavior, concurs with previous research among IndianAustralian women that respondents with high scores on the attitudes towards general checkups regularly practiced breast screening as recommended (Kwok et al., 2015). Taken together, these results imply that promoting breast cancer and BSE literacy, focusing on its 
benefits, is of utmost essential for the first step of breast cancer education. Thus, the intervention should provide the women with information about the nature of breast cancer, including the cause, symptoms, risk factors, treatment modalities, and disease prognosis that breast cancer can cure when women present early and follow prompt medical treatment needed. This information may help the women understand basic information about breast cancer and avoid misleading beliefs, negative values, and fears, which are commonly developed to bring meaning to a difficult-to-understand phenomenon (Sontag, 1978). Additionally, the intervention should also promote women's understanding of breast cancer screening methods (including BSE), specifically, providing the women with information about the advantages and necessities of performing such and when and how to perform it correctly. Informing the benefits of performing the screening method by incorporating strategies to promote women's perceived benefits would stimulate the women's positive attitude towards it, promoting the screening uptake. It should also be noted that the intervention focused on strengthening understanding of screening benefits would alleviate the negative attitudes that may arise towards the screening, e.g., feeling embarrassed or fear of finding any abnormality. Thus, promoting the feeling that 'breast cancer screening benefits outweighed its downsides' would be necessary at this point. Moreover, informing the correct time and procedures to perform screening would promote the women's feeling of being capable of performing such behavior, improving the likelihood of such. For example, information about the importance of calculating fertile periods, and about steps and techniques of BSE should be regarded as essential messages for such education.

We recognized that the women also had limited knowledge about what to do and where to go prior to noticing any symptom; thus, we suggest that policymakers (i.e., health ministry) and healthcare providers may provide official references about breast cancer diagnosis pathways, and inform women about the further actions required once they identify 
any abnormality. Disseminating this knowledge would help women take the correct actions needed prior to noticing any symptom as soon as possible, thus enabling early diagnosis and treatment, which in turn improves their disease prognosis.

The finding in Chapter 5 supported the well-known intention-behavior gap hypothesis (i.e., the respondents showed a high score on intentions but failed to translate these into actual behavior, see Sheeran, 2002). Additionally, our results related a higher PBC and low perceived barriers were served as personal determinants of BSE practice, implied that women who had high confidence to perform BSE and related less obstacle to performing it were more likely to perform BSE. Thus, it is critical for breast cancer intervention to provide strategies to help women gain self-efficacy over their capacity to perform BSE, improve the sense of control over their BSE behavior, and introduce strategies to overcome BSE barriers. Therefore, breast cancer education should incorporate behavior change strategies related to improving skills, self-efficacy, and capability, as well as overcoming barriers (see Bartholomew Eldredge et al., 2016; Kok et al., 2016). Developing this skill can be achieved, for example, by a demonstration video showing how to perform BSE, giving an example of how to perform BSE by using a statue, and the women are asked to practice it and discussed whether they had performed it correctly (Lerman et al., 2012; McAlister et al., 2008). The education and practice about how to count the fertile periods as means to start BSE may also be taught in such intervention. Additionally, since BSE performance was less likely to happen when one perceives more obstacles, effective strategies to cope with barriers that impede BSE behavior should be commenced. For example, the women are asked to list potential barriers to performing BSE and related and trained effective strategies to overcome them (Marlatt \& Donovan, 2005). In addition, the women can be asked to arrange a BSE practice schedule once a month based on their fertile period. Any tools (e.g., reminder apps 
on their mobile phone) or women's social networks (e.g., husband, family, close friends) could be employed to provide such reminders.

Finally, Chapter 3 and 4 informed that women's direct social networks (e.g., spouse, children, family, neighbor, friends, colleagues), healthcare providers (e.g., CHCs, hospitals, physician), or their communities (e.g., PKK, NGO, religious communities) might interfere their BSE behavior and early presentation. Thus, involving these social networks to develop and implement such interventions is imperative. A literature review in the Arabic population supported multi-level interventions targeting both women, men, health care professionals, and/or larger health care systems were more likely to be efficacious than single educational interventions or public awareness campaigns (Donnelly \& Hwang, 2015). The intervention could incorporate the strategies to increasing the knowledge and enhancing the attitudes of women's direct social networks. Additionally, strategies to expand local capacities and infrastructures by incorporating breast education into PKK or POSYANDU monthly meetings may facilitate face-to-face meetings that encompassed oral, visual, and written information to transfer the knowledge (see Schiavo, 2007) may be proposed. The finding also indicated that intervention could use social media and posters to disseminate breast cancer and BSE-related knowledge (Chapter 4). However, the program planner should note that the education should use these means of media to supplement two-way communication meetings to avoid misleading information. Finally, breast education should be delivered by reliable resources (i.e., health ministry officials, medical doctors, and other health professionals) to make the information more convincing, following the suggestion of those Hesse et al. (2005) and Viswanath and Ackerson (2011), who found that physicians were a more trusted source of information than other sources. 


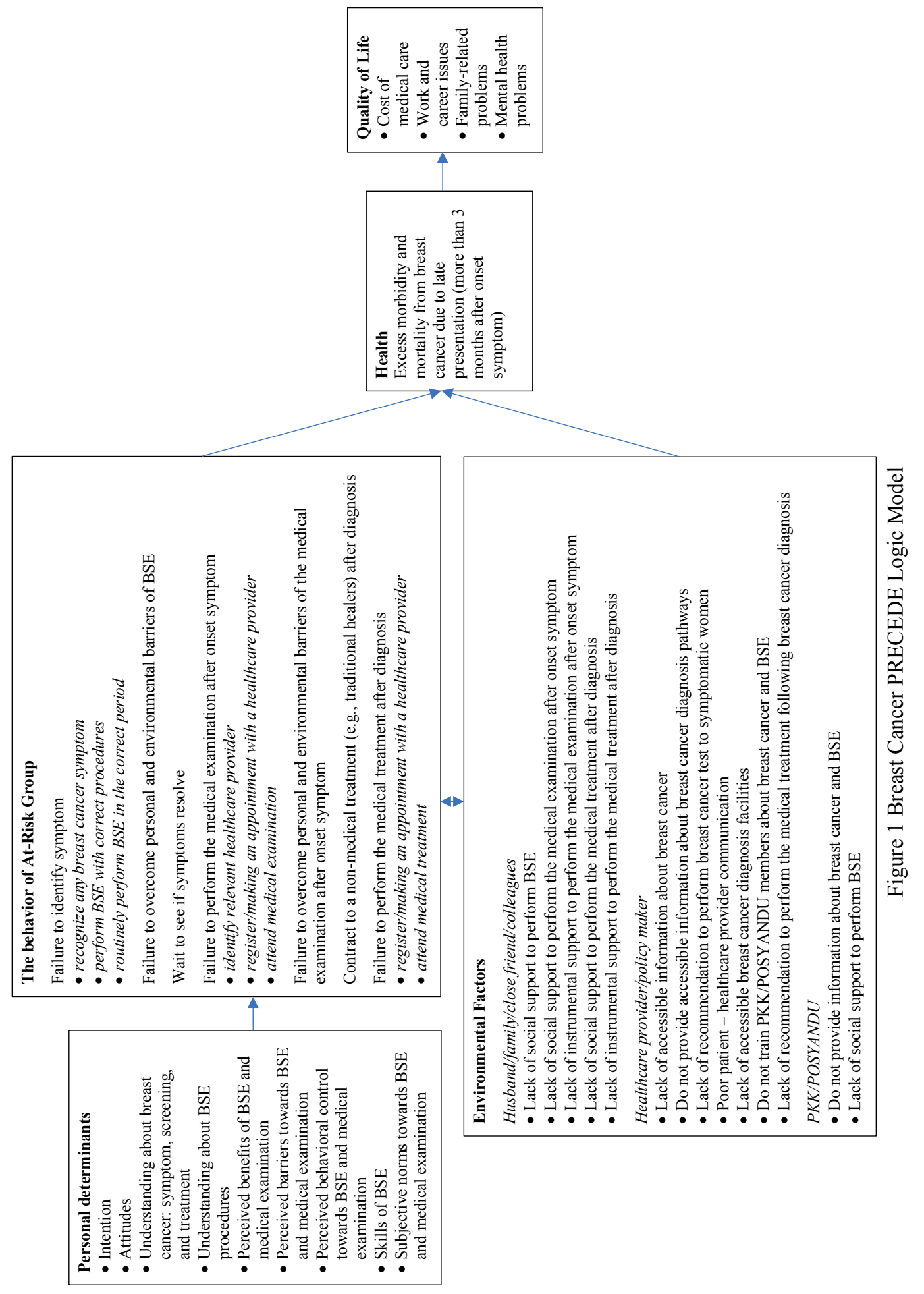


To sum up, the outcome of this dissertation suggests that breast education in the Indonesian context should focus on developing breast cancer literacy and BSE knowledge and incorporating strategies to promote understanding of BSE benefits and positive attitudes towards BSE. The education should also encompass methods to improve women's selfefficacy/PBC and skill to perform BSE and relevant strategies to overcome the barriers. Finally, the intervention should involve women's close social network as an essential support system to promote their screening behavior. Involving various stakeholders as part of the breast education team and working on essential determinants recommended above to conduct a tailored breast cancer intervention could be based on the proposed logic model shown in Figure 1. This logic model is created to analyzed health and quality of life problems and their causes and to decide on priorities, which is generated using PRECEDE (Predisposing, Reinforcing and Enabling Constructs in Ecosystem Diagnosis and Evaluation) model as a conceptual framework (see Bartholomew Eldredge et al., 2016; Green \& Kreuter, 1999; 2005)

\section{Implication for the patient - healthcare provider relationship}

Healthcare providers are among the significant key stakeholders related to women's breast cancer early presentation (Chapter 3 and 4). However, there was an indication of a lack of trust in the quality of care under the public health care system (Chapter 3). These issues of trust in women's physicians and concern over the care they received may be raised since there were poor patients - healthcare providers communication, where patients did not clearly understand the nature of the disease and its treatment options as well as its prognosis (see Claramita et al., 2013). This form of communication is based on the biomedical model, which assumed that poor health is a physical phenomenon that should be explained, identified, and treated with physical means, therefore, less consideration of a person's psychological 
conditions, individual and social beliefs, attitudes, and norms, or other factors that may intervene health and illness (Schiavo, 2007). Therefore, promoting a two-way consultation style where there is more room for the patients' questions and the opportunity to ask further information about their disease and treatment plan is crucial (see Claramita et al., 2013; Donnelly, 2008). This form of a patient-centered approach, known as the biopsychosocial model (Schiavo, 2007), highlights the importance of patients' feelings, literacy levels, needs, and other essential factors that may promote patients' compliance and outcomes.

Indonesian medical schools' curricula have adopted a more competency-based education by incorporating socio-behavioral competencies (i.e., communication and professionalism; Indonesian Medical Council, 2006). However, a discourse analysis on an Indonesian medical school's curriculum indicated that the implemented curriculum differed from the desired curriculum, emphasizing biomedical approaches (Claramita et al., 2011). Further development of a suitable communication skill model tailored to the needs of the Indonesian context is needed. For example, by incorporating communication skills that value local collectivistic culture (Werner \& Bower, 1982) and promote the use of a biopsychosocial model that is empathetic, sensible to the patient's needs and feelings, and aims to generate understanding of scientific and medical issues, motivational, and truly interdependent (Schiavo, 2007). A better patient - healthcare provider communication would allow exploration and facilitation of patients' worries and concerns, enabling a better patient understanding of disease course and treatment plan, promoting health-seeking behavior. 


\section{Future directions}

This dissertation provides an important first step to understand BSE practice in the Indonesian context. Notwithstanding, we identified some opportunities for future research. Firstly, we performed cross-sectional studies in Chapter 2 and 5; therefore, the causal association among study variables cannot be established. For example, we found in Chapter 5, attitude towards BSE was a unique correlate of BSE behavior. Even though this association is well supported by literature (Ajzen et al., 2018; Fishbein \& Ajzen, 2010) and previous studies (Al-Dubai et al., 2012; Kwok et al., 2015; Wang et al., 2019), the possibility

of a bi-directional relationship, i.e., whether attitude served as a cause or an effect concerning breast cancer screening, might exist. For example, there was a possibility that performing BSE promote positive attitudes towards it. This possibility is reflected by the grudging acceptance model, i.e., behavior is first initiated, and this experienced learning would promote attitude shift (Valente et al., 1998). Therefore, further longitudinal studies are needed to provide insight into the mechanism of the associations between BSE practice and its correlates.

Second, all studies in this dissertation were conducted using self-reports (i.e., questionnaire, interview, and FGD). Although the self-report method is suited for a need assessment to capture respondents' perspectives and lived experiences (Crutzen \& Göritz, 2010), these may lead to a potential bias: the respondents may have responded to the questions in socially desirable manner, thus exaggerating their responses; or their responses might be simplified and reduced; thus, the association between study variables might be underreported. Therefore, future research may consider varied assessments to understand the variables and their associations better, for example, by exploring the women's direct social 
networks' (e.g., husband, family, friends), healthcare providers', and policy makers' perspectives.

Third, the studies in this dissertation were conducted in Surabaya only. Even though Surabaya is the second-largest city in Indonesia with high diversity, the views represented by our respondents may not be representative of all Indonesian women, which may hold different characteristics. Additionally, the respondents in these studies were generally recruited through PKK meetings, breast cancer foundations, and online questionnaires. Even though our respondents represented a varied sociodemographic status and covered the perspectives of both BSE performers and non-performers. However, those women socially active in PKK meetings and breast cancer foundations or who had an internet connection to access the online questionnaires would be more likely to participate in the study. Therefore, women in a more remote area and limited internet access, which may have different psychosocial issues related to any means of screening behavior - including BSE and more vulnerable to the health risk behavior, may be underrepresented in these studies. Further study may involve respondents from other provinces and those residing in more remote areas to gather a more comprehensive understanding of BSE behavior determinants and enable generalization for the overall Indonesian women population.

Last but not least, our studies evidenced both proximal and distal relation of knowledge on behavior: Chapter 5 found that breast cancer knowledge was a unique correlate of BSE practice, and Chapter 3-5 indicated that knowledge was a prerequisite for other determinants (see Ajzen et al., 2018; Bartholomew Eldredge et al., 2016). We suspect that this direct knowledge-behavior relationship might arise when there was no basic general knowledge in a given domain, thus prevent an individual from initiating an action in that domain. For example, there was no or misleading information about basic knowledge of breast cancer in our sample, thus significantly prevent them from initiating a BSE behavior (see Annan et al., 
2019). Therefore, future meta-analysis studies to inform the mechanism linking to the knowledge-behavior direct relationship (i.e., the relationship may be promoted under which population, what study design, and how the variables are being measured) are needed.

\section{Conclusion}

This dissertation highlights relevant and changeable determinants of BSE behavior in Surabaya, Indonesia context. The findings further inform the key targets for future tailored breast awareness education to stimulate regular BSE and other screening behaviors among Indonesian women. This goal can be attained through work further on psychosocial determinants relevant to BSE behavior: improving breast cancer and BSE literacy, incorporating strategies to promote women's perceived benefits and positive attitudes towards BSE; and incorporating methods to improve women's self-efficacy and skill to perform BSE, and practicing relevant strategies to overcome the barriers to perform such. Finally, to celebrate their communal culture, involving women's social networks as their sources of subjective norms is essential. These may include the empowerment of women's spouse, family, friends, PKK, or POSYANDU and involvement of healthcare providers, health policymakers, and scholars to plan, develop, implement and evaluate breast education. A joint collaboration of these relevant key stakeholders to translate empirical findings to practical interventions may foster a sustainable behavior change with the ultimate goal to reduce breast cancer mortality in Indonesia. 



\section{References}

Abolfotouh, M. A., Bani Mustafa, A. A., Mahfouz, A. A., Al-Assiri, M. H., Al-Juhani, A. F., \& Alaskar, A. S. (2015). Using the health belief model to predict breast selfexamination among Saudi women. BMC Public Health, 15(1), 1163. https://doi.org/10.1186/s12889-015-2510-y

Agarwal, G., Ramakant, P., Sánchez Forgach, E. R., Rendón, J. C., Chaparro, J. M., Basurto, C. S., \& Margaritoni, M. (2009). Breast Cancer Care in Developing Countries. World Journal of Surgery, 33(10), 2069-2076. https://doi.org/10.1007/s00268-009-0150-z

Ahmadian, M., Carmack, S., Samah, A. A., Kreps, G. L., \& Saidu, M. B. (2016). Psychosocial predictors of breast self-examination among female students in Malaysia: A study to assess the roles of body image, self-efficacy and perceived barriers. Asian Pacific Journal of Cancer Prevention, 17, 1277-1284.

Ajzen, I. (1991). The theory of planned behaviour. Organizational Behavior and Human Decision Process, 50, 179-211.

Ajzen, I., Fishbein, M., Lohmann, S., \& Albarracin, D. (2018). The influence of attitudes on behavior. In The handbook of attitudes (2nd Edition, pp. 197-255). Routledge.

Akinyemiju, T. F. (2012). Socio-economic and health access determinants of breast and cervical cancer screening in low-income countries: analysis of the world health survey. PLOS ONE, 7(11), e48834. https://doi.org/10.1371/journal.pone.0048834

Albeshan, S. M., Hossain, S. Z., Mackey, M. G., \& Brennan, P. C. (2020). Can breast selfexamination and clinical breast examination along with increasing breast awareness facilitate earlier detection of breast cancer in populations with advanced stages at diagnosis? Clinical Breast Cancer, 20(3), 194-200. https://doi.org/10.1016/j.clbc.2020.02.001

Al-Dubai, S. A. R., Ganasegeran, K., Alabsi, A. M., Manaf, M. R. A., Ijaz, S., \& Kassim, S. (2012). Exploration of Barriers to Breast-Self Examination among Urban Women in Shah Alam, Malaysia: A Cross Sectional Study. Asian Pacific Journal of Cancer Prevention, 13(4), 1627-1632. https://doi.org/10.7314/APJCP.2012.13.4.1627

Allahverdipour, H., Asghari-Jafarabadi, M., \& Emami, A. (2011). Breast Cancer Risk Perception, Benefits of and Barriers to Mammography Adherence Among a Group of Iranian Women. Women \& Health, 51(3), 204-219. https://doi.org/10.1080/03630242.2011.564273

Allen, J. D., Sorensen, G., Stoddard, A. M., Peterson, K. E., \& Colditz, G. (1999). The relationship between social network characteristics and breast cancer screening practices among employed women. Annals of Behavioral Medicine, 21(3), 193-200. https://doi.org/10.1007/BF02884833

Al-Naggar, R. A., \& Bobryshev, Y. V. (2012). Practice and barriers of mammography among Malaysian women in the general population. Asian Pacific J Cancer Prev, 13, 35953600. https://doi.org/10.7314/APJCP.2012.13.8.3595

Al-Sharbatti, S. S., Shaikh, R. B., Mathew, E., \& Al-Biate, M. A. S. (2013). Breast selfexamination practice and breast cancer risk perception among female university students in Ajman. Asian Pacific Journal of Cancer Prevention, 14(8), 4919-4923. https://doi.org/10.7314/APJCP.2013.14.8.4919 
American Cancer Society. (2011). Global cancer facts \& figures. Atlanta, Ga: American Cancer Society.

American Cancer Society. (2017). ACS Breast Cancer Early Detection Recommendations. https://www.cancer.org/cancer/breast-cancer/screening-tests-and-earlydetection/american-cancer-society-recommendations-for-the-early-detection-ofbreast-cancer.html

American Cancer Society. (2021). Survival Rates for Breast Cancer. https://www.cancer.org/cancer/breast-cancer/understanding-a-breast-cancerdiagnosis/breast-cancer-survival-rates.html

Amoran, O. E., \& Toyobo, O. O. (2015). Predictors of breast self-examination as cancer prevention practice among women of reproductive age-group in a rural town in Nigeria. Nigerian Medical Journal : Journal of the Nigeria Medical Association, 56(3), 185-189. https://doi.org/10.4103/0300-1652.160362

Anderson, B. O., Yip, C.-H., Smith, R. A., Shyyan, R., Sener, S. F., Eniu, A., Carlson, R. W., Azavedo, E., \& Harford, J. (2008). Guideline implementation for breast healthcare in low-income and middle-income countries. Cancer, 113(S8), 2221-2243. https://doi.org/10.1002/cncr.23844

Annan, F. M., Oppong Asante, K., \& Kugbey, N. (2019). Perceived seriousness mediates the influence of cervical cancer knowledge on screening practices among female university students in Ghana. BMC Women's Health, 19(1), 140. https://doi.org/10.1186/s12905-019-0842-y

Anwar, S. L., Tampubolon, G., Van Hemelrijck, M., Hutajulu, S. H., Watkins, J., \& Wulaningsih, W. (2018). Determinants of cancer screening awareness and participation among Indonesian women. BMC Cancer, 18(1), 208. https://doi.org/10.1186/s12885-018-4125-z

Armitage, C. J., \& Conner, M. (2001). Efficacy of the Theory of Planned Behaviour: A metaanalytic review. British Journal of Social Psychology, 40(4), 471-499. https://doi.org/10.1348/014466601164939

Armstrong, K., Moye, E., Williams, S., Berlin, J. A., \& Reynolds, E. E. (2007). Screening mammography in women 40 to 49 years of age: A systematic review for the American College of Physicians. Annals of Internal Medicine, 146(7), 516-526. https://doi.org/10.7326/0003-4819-146-7-200704030-00008

Autier, P., Boniol, M., Gavin, A., \& Vatten, L. J. (2011). Breast cancer mortality in neighbouring European countries with different levels of screening but similar access to treatment: Trend analysis of WHO mortality database. BMJ, 343, d4411. https://doi.org/10.1136/bmj.d4411

Avci, I. A. (2008). Factors associated with breast self-examination practices and beliefs in female workers at a Muslim community. European Journal of Oncology Nursing: The Official Journal of European Oncology Nursing Society, 12(2), 127-133. https://doi.org/10.1016/j.ejon.2007.11.006

Azaiza, F., \& Cohen, M. (2006). Health beliefs and rates of breast cancer screening among Arab women. Journal of Women's Health, 15(5), 520-530. https://doi.org/10.1089/jwh.2006.15.520

Bandura, A. (1977). Self-efficacy: Toward a unifying theory of behavioral change. Psychological Review, 84(2), 191-215. https://doi.org/10.1037/0033-295X.84.2.191 
Bartholomew Eldredge, L. K., Markham, C. M., Ruiter, R. A. C., Fernández, M. E., Kok, G., \& Parcel, G. S. (2016). Planning health promotion programs: An intervention mapping approach. John Wiley \& Sons.

Berg, W. A. (2009). Tailored supplemental screening for breast cancer: What now and what next? AJR. American Journal of Roentgenology, 192(2), 390-399. https://doi.org/10.2214/AJR.08.1706

Bhoo Pathy, N., Yip, C. H., Taib, N. A., Hartman, M., Saxena, N., Iau, P., Bulgiba, A. M., Lee, S. C., Lim, S. E., Wong, J. E. L., \& Verkooijen, H. M. (2011). Breast cancer in a multi-ethnic Asian setting: Results from the Singapore-Malaysia hospital-based breast cancer registry. The Breast, 20, S75-S80.

https://doi.org/10.1016/j.breast.2011.01.015

Birhane, N., Mamo, A., Girma, E., \& Asfaw, S. (2015). Predictors of breast selfExamination among female teachers in Ethiopia using health belief model. Archives of Public Health, 73(1), 39. https://doi.org/10.1186/s13690-015-0087-7

Breastcancer.org. (2021a). Breast Cancer Stages. Breastcancer.Org. https://www.breastcancer.org/symptoms/diagnosis/staging

Breastcancer.org. (2021b). Metastatic Breast Cancer: Symptoms, Treatment, and More. Breastcancer.Org. https://www.breastcancer.org/symptoms/types/recur_metast

Broeders, M., Moss, S., Nyström, L., Njor, S., Jonsson, H., Paap, E., Massat, N., Duffy, S., Lynge, E., \& Paci, E. (2012). The impact of mammographic screening on breast cancer mortality in Europe: A review of observational studies. Journal of Medical Screening, 19(1_suppl), 14-25. https://doi.org/10.1258/jms.2012.012078

Bukirwa, A., Mutyoba, J. N., N.Mukasa, B., Karamagi, Y., Odiit, M., Kawuma, E., \& Wanyenze, R. K. (2015). Motivations and barriers to cervical cancer screening among HIV infected women in HIV care: A qualitative study. BMC Women's Health, 15(1), 82. https://doi.org/10.1186/s12905-015-0243-9

Burgess, C. C., Ramirez, A. J., Richards, M. A., \& Love, S. B. (1998). Who and what influences delayed presentation in breast cancer? British Journal of Cancer, 77(8), 1343-1348. https://doi.org/10.1038/bjc.1998.224

Canbulat, N., \& Uzun, Ö. (2008). Health beliefs and breast cancer screening behaviors among female health workers in Turkey. European Journal of Oncology Nursing, 12(2), 148-156.

Caplan, L. (2014). Delay in breast cancer: implications for stage at diagnosis and survival. Frontiers in Public Health, 2. https://doi.org/10.3389/fpubh.2014.00087

Carpenter, C. J. (2010). A meta-analysis of the effectiveness of health belief model variables in predicting behavior. Health Communication, 25(8), 661-669. https://doi.org/10.1080/10410236.2010.521906

Carver, C. S., \& Scheier, M. F. (2014). Dispositional optimism. Trends in Cognitive Sciences, 18(6), 293-299. https://doi.org/10.1016/j.tics.2014.02.003

Champion, V. L. (1984). Instrument development for health belief model constructs. Advances in Nursing Science, 6(3), 73-85. https://doi.org/10.1097/00012272198404000-00011 
Champion, V. L. (1999). Revised susceptibility, benefits, and barriers scale for mammography screening. Research in Nursing \& Health, 22(4), 341-348. https://doi.org/10.1002/(sici)1098-240x(199908)22:4<341::aid-nur8>3.0.co;2-p

Champion, V. L., \& Scott, C. R. (1997). Reliability and validity of breast cancer screening belief scales in African American women. Nursing Research, 46(6), 331-337. https://doi.org/10.1097/00006199-199711000-00006

Chipperfield, J. G., Hamm, J. M., Perry, R. P., Parker, P. C., Ruthig, J. C., \& Lang, F. R. (2019). A healthy dose of realism: The role of optimistic and pessimistic expectations when facing a downward spiral in health. Social Science \& Medicine, 232, 444-452. https://doi.org/10.1016/j.socscimed.2018.08.030

Cholil, M. (2017). Complexities in dealing with gender inequality: Muslim women and mosque-based social services in East Java Indonesia. Journal of Indonesian Islam, 11(2). http://repository.uin-malang.ac.id/2418/

Choridah, L., Icanervilia, A. V., de Wit, M. J. M., van Asselt, A. D. I., Kurniawan, W. T., Fahmi, Y. I., \& Rengganis, A. A. (2019). Knowledge and acceptance towards mammography as breast cancer screening tool among Yogyakarta women and health care providers (Mammography Screening in Indonesia). Journal of Cancer Education. https://doi.org/10.1007/s13187-019-01659-3

Claramita, M., Nugraheni, M. D. F., van Dalen, J., \& van der Vleuten, C. (2013). Doctorpatient communication in Southeast Asia: A different culture? Advances in Health Sciences Education, 18(1), 15-31. https://doi.org/10.1007/s10459-012-9352-5

Claramita, M., Sutomo, A. H., Graber, M. A., \& Scherpbier, A. J. (2011). Are patientcentered care values as reflected in teaching scenarios really being taught when implemented by teaching faculty? A discourse analysis on an Indonesian medical school's curriculum. Asia Pacific Family Medicine, 10(1), 4. https://doi.org/10.1186/1447-056X-10-4

Cohen, J., 1988. Statistical Power Analysis for the Behavioral Sciences, 2nd ed. Hillsdale, New Jersey: Erlbaum.

Consedine, N., Strongman, K., \& Magai, C. (2003). Emotions and behaviour: Data from a cross-cultural recognition study. Cognition and Emotion, 17(6), 881-902. https://doi.org/10.1080/02699930244000246

Cooke, R., \& French, D. P. (2008). How well do the theory of reasoned action and theory of planned behaviour predict intentions and attendance at screening programmes? A meta-analysis. Psychology \& Health, 23(7), 745-765. https://doi.org/10.1080/08870440701544437

Corbex, M., Burton, R., \& Sancho-Garnier, H. (2012). Breast cancer early detection methods for low and middle income countries, a review of the evidence. The Breast, 21(4), 428-434. https://doi.org/10.1016/j.breast.2012.01.002

Crutzen, R., \& Göritz, A. S. (2010). Social desirability and self-reported health risk behaviours in web-based research: three longitudinal studies. BMC Public Health, 10(1), 720 .

Crutzen, R., \& Peters, G-J. Y. (2021, May 21). The regression trap: why regression analyses are not suitable for selecting determinants to target in behavior change interventions. https://doi.org/10.31234/osf.io/jsfz9 
Crutzen, R.,Peters, G-J. Y., \& Noijen, J. (2017). Using confidence interval-based estimation of relevance to select social-cognitive determinants for behavior change interventions. Frontiers in Public Health, 5, 165. https://doi.org/10.3389/fpubh.2017.00165

Darvishpour, A., Vajari, S. M., \& Noroozi, S. (2018). Can Health Belief Model predict breast cancer screening behaviors? Open Access Macedonian Journal of Medical Sciences, 6(5), 949-953. https://doi.org/10.3889/oamjms.2018.183

Dewi, T. K. (2018). Validation of the Indonesian version of Champion's Health Belief Model Scale for breast self-examination. Psychology Research and Behavior Management, 11, 433-438. https://doi.org/10.2147/PRBM.S177124

Dewi, T. K., Massar, K., Ardi, R., \& Ruiter, R. A. (2020). Determinants of early breast cancer presentation: A qualitative exploration among female survivors in Indonesia. Psychology \& Health, 1-14.

Dewi, T. K., Massar, K., Ruiter, R. A. C., \& Leonardi, T. (2019). Determinants of breast selfexamination practice among women in Surabaya, Indonesia: An application of the health belief model. BMC Public Health, 19(1), 1581. https://doi.org/10.1186/s12889019-7951-2

Dewi, T. K., Ruiter, R. A., Ardi, R., \& Massar, K. (2021). The role of psychosocial variables in breast self-examination practive: Results from focused group discussions in Surabaya, Indonesia. Manuscript submitted for publication.

Didarloo, A., Nabilou, B., \& Khalkhali, H. R. (2017). Psychosocial predictors of breast selfexamination behavior among female students: An application of the health belief model using logistic regression. BMC Public Health, 17(1), 861. https://doi.org/10.1186/s12889-017-4880-9

DiMatteo, M. R. (2004). Variations in patients' adherence to medical recommendations: A quantitative review of 50 years of research. Medical Care, 42(3), 200-209. https://doi.org/10.1097/01.mlr.0000114908.90348.f9

Documet, P., Bear, T. M., Flatt, J. D., Macia, L., Trauth, J., \& Ricci, E. M. (2015). The association of social support and education with breast and cervical cancer screening. Health Education \& Behavior, 42(1), 55-64. https://doi.org/10.1177/1090198114557124

Donnelly, T. T. (2008). Challenges in providing breast and cervical cancer screening services to Vietnamese Canadian women: The healthcare providers' perspective. Nursing Inquiry, 15(2), 158-168. https://doi.org/10.1111/j.1440-1800.2008.00409.x

Donnelly, T. T., Al Khater, A.-H., Al-Bader, S. B., Al Kuwari, M. G., Al-Meer, N., Malik, M., Singh, R., \& Jong, F. C.-D. (2013). Arab women's breast cancer screening practices: A literature review. Asian Pacific Journal of Cancer Prevention, 14(8), 4519-4528. https://doi.org/10.7314/APJCP.2013.14.8.4519

Donnelly, T. T., \& Hwang, J. (2015). Breast cancer screening interventions for Arabic women: A literature review. Journal of Immigrant and Minority Health, 17(3), 925 939. https://doi.org/10.1007/s10903-013-9902-9

Drossaert, C. H. C., Boer, H., \& Seydel, E. R. (2003). Prospective study on the determinants of repeat attendance and attendance patterns in breast cancer screening using the 
theory of planned behaviour. Psychology \& Health, 18(5), 551-565.

https://doi.org/10.1080/0887044031000141207

Dundar, P. E., Ozyurt, B. C., \& Erdurak, K. (2012). Sociodemographic determinants of nonattendance in a population-based mammography screening program in the City of Manisa, Turkey. The Scientific World Journal, 2012.

https://doi.org/10.1100/2012/816903

Elsie, K., Gonzaga, M., Francis, B., Michael, K., Rebecca, N., Rosemary, B., \& Zeridah, M. (2010). Current knowledge, attitudes and practices of women on breast cancer and mammography at Mulago hospital. Pan African Medical Journal, 5(1).

Facione, N., \& Giancarlo, C. (1998). Narratives of breast symptom discovery and cancer diagnosis: Psychologic risk for advanced cancer at diagnosis. Cancer Nursing. 21(6), 430-440.

Fattahi Ardakani, M., Salehi Abargouei, A., Sotoudeh, A., Esmaeildokht, S., \& Bahrevar, V. (2020). Do subjective norms predict the screening of cancer patients' first-degree relatives? A systematic review and meta-analysis. Asian Pacific Journal of Cancer Prevention : APJCP, 21(6), 1521-1530. https://doi.org/10.31557/APJCP.2020.21.6.1521

Ferrat, E., Le Breton, J., Djassibel, M., Veerabudun, K., Brixi, Z., Attali, C., \& Renard, V. (2013). Understanding barriers to organized breast cancer screening in France: Women's perceptions, attitudes, and knowledge. Family Practice, 30(4), 445-451. https://doi.org/10.1093/fampra/cmt004

Ferrer, R. A., \& Klein, W. M. (2015). Risk perceptions and health behavior. Current Opinion in Psychology, 5, 85-89. https://doi.org/10.1016/j.copsyc.2015.03.012

Firouzbakht, M., Hajian-Tilaki, K., \& Bakhtiari, A. (2020). Comparison of competitive cognitive models in explanation of women breast cancer screening behaviours using structural equation modelling: Health belief model and theory of reasoned action. European Journal of Cancer Care, 30(1), e13328. https://doi.org/10.1111/ecc.13328

Fishbein, M., \& Ajzen, I. (2010). Predicting and changing behavior: The reasoned action approach. Psychology Press.

Fisher, J. D., \& Fisher, W. A. (1992). Changing AIDS-risk behavior. Psychological Bulletin, 111(3), 455-474. https://doi.org/10.1037/0033-2909.111.3.455

Floyd, D. L., Prentice-Dunn, S., \& Rogers, R. W. (2000). A Meta-Analysis of Research on Protection Motivation Theory. Journal of Applied Social Psychology, 30(2), 407-429. https://doi.org/10.1111/j.1559-1816.2000.tb02323.x

Frie, K. G., Ramadas, K., Anju, G., Sara, B., Muwonge, R., Sauvaget, C., Thara, S., \& Sankaranarayanan, R. (2013). Determinants of participation in a breast cancer screening trial in Trivandrum District, India. Asian Pac J Cancer Prev, 14, 73017307.

Gang, M., Kim, J. I., Oh, K. O., Li, C. Y., \& Song, Y. (2013). Factors Associated with Mammography Adherence among Married Chinese Women in Yanbian, China. 14(12), 7207-7213.

Ganz, P. A. (2008). Psychological and social aspects of breast cancer. Oncology (Williston Park, N.Y.), 22(6), 642-653. 
Ghoncheh, M., Mahdavifar, N., Darvishi, E., \& Salehiniya, H. (2016). Epidemiology, incidence and mortality of breast cancer in Asia. Asian Pacific Journal of Cancer Prevention, 17(sup3), 47-52. https://doi.org/10.7314/APJCP.2016.17.S3.47

Ghoncheh, M., Mohammadian-Hafshejani, A., \& Salehiniya, H. (2015). Incidence and mortality of breast cancer and their relationship to development in Asia. Asian Pacific Journal of Cancer Prevention, 16(14), 6081-6087. https://doi.org/10.7314/APJCP.2015.16.14.6081

Gonzales, A., Alzaatreh, M., Mari, M., Saleh, A. A., \& Alloubani, A. (2018). Beliefs and behavior of Saudi Women in the University of Tabuk toward breast self examination practice. Asian Pacific Journal of Cancer Prevention, 19(1), 121-126.

Green, L. W., \& Kreuter, M. (1999). Health promotion planning: An educational approach (3rd ed). Mayfield Publishing Company.

Green, L. W., \& Kreuter, M. (2005). Health Program Planning: An Educational and Ecological Approach (4th ed). McGraw-Hill Education.

Guilford, K., McKinley, E., \& Turner, L. (2017). Breast cancer knowledge, beliefs, and screening behaviors of college women: Application of the Health Belief Model. American Journal of Health Education, 48(4), 256-263. https://doi.org/10.1080/19325037.2017.1316694

Gullatte, M. M., Brawley, O., Kinney, A., Powe, B., \& Mooney, K. (2010). Religiosity, spirituality, and cancer fatalism beliefs on delay in breast cancer diagnosis in African American women. Journal of Religion and Health, 49(1), 62-72. https://doi.org/10.1007/s10943-008-9232-8

Gürsoy, A. A., Mumcu, H. K., Çalık, K. Y., Bulut, H. K., Nural, N., Kahriman, I. lknur, Hintistan, S., Erdöl, H., Yiğitbaş, Ç., \& Yılmaz, F. (2011). Attitudes and health beliefs associated with breast cancer screening behaviors among Turkish women. Journal of Transcultural Nursing, 22(4), 368-375. https://doi.org/10.1177/1043659611414137

Gyawali, B., Shimokata, T., Honda, K., Tsukuura, H., \& Ando, Y. (2016). Should lowincome countries invest in breast cancer screening? Cancer Causes \& Control, 27(11), 1341-1345. https://doi.org/10.1007/s10552-016-0812-8

Hackshaw, A. K., \& Paul, E. A. (2003). Breast self-examination and death from breast cancer: A meta-analysis. British Journal of Cancer, 88(7), 1047-1053. https://doi.org/10.1038/sj.bjc.6600847

Hajian Tilaki, K., \& Auladi, S. (2015). Awareness, attitude, and practice of breast cancer screening women, and the associated socio-demographic characteristics, in Northern Iran. Iranian Journal of Cancer Prevention, 8(4). https://doi.org/10.17795/ijcp.3429

Hall, N., Birt, L., Rees, C. J., Walter, F. M., Elliot, S., Ritchie, M., Weller, D., \& Rubin, G. (2016). Concerns, perceived need and competing priorities: A qualitative exploration of decision-making and non-participation in a population-based flexible sigmoidoscopy screening programme to prevent colorectal cancer. BMJ Open, 6(11), e012304. https://doi.org/10.1136/bmjopen-2016-012304

Halligan, P. (2006). Caring for patients of Islamic denomination: Critical care nurses' experiences in Saudi Arabia. Journal of Clinical Nursing, 15(12), 1565-1573. https://doi.org/10.1111/j.1365-2702.2005.01525.x 
Hassan, N. (2015). A cross sectional study on the motivators for Asian women to attend opportunistic mammography screening in a private hospital in Malaysia: The MyMammo study. BMC Public Health, 15(1).

Henriksen, M. J. V., Guassora, A. D., \& Brodersen, J. (2015). Preconceptions influence women's perceptions of information on breast cancer screening: A qualitative study. BMC Research Notes, 8, 404.

Hesse, B. W., Nelson, D. E., Kreps, G. L., Croyle, R. T., Arora, N., Rimer, B. K., \& Viswanath, K. (2005). Trust and sources of health information: The impact of the internet and its implications for health care providers: findings from the first health information national trends survey. American Medical Association, 165(22), 26182624.

Hofvind, S., Ursin, G., Tretli, S., Sebuødegård, S., \& Møller, B. (2013). Breast cancer mortality in participants of the Norwegian Breast Cancer Screening Program. Cancer, 119(17), 3106-3112. https://doi.org/10.1002/cncr.28174

Hsieh, H. F., \& Shannon, S. E. (2005). Three Approaches to Qualitative Content Analysis. Qualitative Health Research, 15(9), 1277-1288. https://doi.org/10.1177/1049732305276687

Hulme, J., Moravac, C., Ahmad, F., Cleverly, S., Lofters, A., Ginsburg, O., \& Dunn, S. (2016). "I want to save my life": Conceptions of cervical and breast cancer screening among urban immigrant women of South Asian and Chinese origin. BMC Public Health, 16(1), 1077. https://doi.org/10.1186/s12889-016-3709-2

IARC. (2018a). Indonesia fact sheet 2018. Accessed from http:/gco.iarc.fr/today/data/factsheets/populations/360-indonesia-fact-sheets.pdf on 12 September 2019.

IARC. (2018b). Latest global cancer data: Cancer burden rises to 18.1 million new cases and 9.6 million cancer deaths in 2018 (No. 263). https://www.iarc.fr/wpcontent/uploads/2018/09/pr263_E.pdf

IARC. (2020a). Breast fact sheet 2020. https://gco.iarc.fr/today/data/factsheets/cancers/20 Breast-fact-sheet.pdf

IARC. (2020b). Indonesia fact sheet 2020. https:/gco.iarc.fr/today/data/factsheets/populations/360-indonesia-fact-sheets.pdf

Indonesian Medical Council. (2006). The National Standards Competencies of Indonesian Medical Doctors. Indonesian Medical Council.

Irawan, C., Hukom, R., \& Prayogo, N. (2008). Factors associated with bone metastasis in breast cancer: A preliminary study in an Indonesian population. Acta Medica Indonesiana, 40, 178-180.

Iskandarsyah, A., de Klerk, C., Suardi, D. R., Soemitro, M. P., Sadarjoen, S. S., \& Passchier, J. (2014). Psychosocial and cultural reasons for delay in seeking help and nonadherence to treatment in Indonesian women with breast cancer: A qualitative study. Health Psychology, 33(3), 214-221. https://doi.org/10.1037/a0031060

Islam, R. M., Billah, B., Hossain, M. N., \& Oldroyd, J. (2017). Barriers to cervical cancer and breast cancer screening uptake in low-income and middle-income countries: A systematic review. Asian Pacific Journal of Cancer Prevention : APJCP, 18(7), 1751-1763. https://doi.org/10.22034/APJCP.2017.18.7.1751 
İzci, F., İlgün, A. S., Fındıkl1, E., \& Özmen, V. (2016). Psychiatric symptoms and psychosocial problems in patients with breast cancer. The Journal of Breast Health, 12(3), 94-101. https://doi.org/10.5152/tjbh.2016.3041

Janz, N. K., \& Becker, M. H. (1984). The Health Belief Model: A decade later. Health Education Quarterly, 11(1), 1-47. https://doi.org/10.1177/109019818401100101

Jedy-Agba, E., McCormack, V., Adebamowo, C., \& dos-Santos_Silva, I. (2016). Stage at diagnosis of breast cancer in sub-Saharan Africa: A systematic review and metaanalysis | Elsevier Enhanced Reader. The Lancet Global Health, 4(12), 923-935. https://doi.org/10.1016/S2214-109X(16)30259-5

Johnson, J. L., Bottorff, J. L., Balneaves, L. G., Grewal, S., Bhagat, R., Hilton, B. A., \& Clarke, H. (1999). South Asian womens' views on the causes of breast cancer: Images and explanations. Patient Education and Counseling, 37(3), 243-254. https://doi.org/10.1016/S0738-3991(98)00118-9

Jones, C. E., Maben, J., Jack, R. H., Davies, E. A., Forbes, L. J., Lucas, G., \& Ream, E. (2014). A systematic review of barriers to early presentation and diagnosis with breast cancer among black women. BMJ Open, 4(2), e004076. https://doi.org/10.1136/bmjopen-2013-004076

Karayurt, O., \& Dramal, A. (2007). Adaptation of Champion's Health Belief Model scale for Turkish women and evaluation of the selected variables associated with breast selfexamination. Cancer Nursing, 30(1), 69-77.

Karbani, G. A., Lim, J. N. W., Hewison, J., Atkin, K., Horgan, K., Lansdown, M., \& Chu, C. E. (2011). Culture, attitude and knowledge about breast cancer and preventive measures: A qualitative study of South Asian breast cancer patients in the UK. Asian Pacific Journal of Cancer Prevention : APJCP, 12(6), 1619-1626.

Khazaee-Pool, M., Montazeri, A., Majlessi, F., Foroushani, A. R., Nedjat, S., \& Shojaeizadeh, D. (2014). Breast cancer-preventive behaviors: Exploring Iranian women's experiences. BMC Women's Health, 14(41).

Khokhar, A. (2013). View point: How to make women familiar with their breasts? Asian Pacific Journal of Cancer Prevention: APJCP, 14(9), 5539-5542. https://doi.org/10.7314/apjcp.2013.14.9.5539

Kim, W., Kreps, G. L., \& Shin, C. N. (2015). The role of social support and social networks in health information-seeking behavior among Korean Americans: A qualitative study. International Journal for Equity in Health, 14(1), 40. https://doi.org/10.1186/s12939-015-0169-8

Kissal, A., \& Beşer, A. (2011). Knowledge, facilitators and perceived barriers for early detection of breast cancer among elderly Turkish women. Asian Pacific Journal of Cancer Prevention, 12, 975-984.

Kok, G., Gottlieb, N. H., Peters, G.-J. Y., Mullen, P. D., Parcel, G. S., Ruiter, R. A. C., Fernández, M. E., Markham, C., \& Bartholomew, L. K. (2016). A taxonomy of behaviour change methods: An Intervention Mapping approach. Health Psychology Review, 10(3), 297-312. https://doi.org/10.1080/17437199.2015.1077155

Korda, H., \& Itani, Z. (2013). Harnessing Social Media for Health Promotion and Behavior Change. Health Promotion Practice, 14(1), 15-23. https://doi.org/10.1177/1524839911405850 
Kwok, C., Tranberg, R., \& Lee, F. C. (2015). Breast cancer knowledge, attitudes and screening behaviors among Indian-Australian women. European Journal of Oncology Nursing, 19, 701-706. http://dx.doi.org/10.1016/j.ejon.2015.05.004

Kwol, V. S., Eluwole, K. K., Avci, T., \& Lasisi, T. T. (2020). Another look into the Knowledge Attitude Practice (KAP) model for food control: An investigation of the mediating role of food handlers' attitudes. Food Control, 110, 107025. https://doi.org/10.1016/j.foodcont.2019.107025

Lam, W. W. M., Chan, C. P., Chan, C. F., Mak, C. C. C., Chan, C. F., Chong, K. W. H., Leung, M. H. J., \& Tang, M. H. (2008). Factors affecting the palpability of breast lesion by self-examination.pdf. Singapore Medical Journal, 49. http://www.smj.org.sg/sites/default/files/4903/4903a8.pdf

Latkin, C. A., \& Knowlton, A. R. (2015). Social network assessments and interventions for health behavior change: A critical review. Behavioral Medicine (Washington, D.C.), 41(3), 90-97. https://doi.org/10.1080/08964289.2015.1034645

Lauby-Secretan, B., Scoccianti, C., Loomis, D., Benbrahim-Tallaa, L., Bouvard, V., Bianchini, F., \& Straif, K. (2015, June 10). Breast-cancer screening-Viewpoint of the IARC working group (world) [Research-article].

Http://Dx.Doi.Org/10.1056/NEJMsr1504363; Massachusetts Medical Society. https://doi.org/10.1056/NEJMsr1504363

Lauver, D. (1987). Theoretical perspectives relevant to breast self-examination. Advances in Nursing Science, 9(4), 16-24. https://doi.org/10.1097/00012272-198707000-00005

Lerman, R., Jarski, R., Rea, H., Gellish, R., \& Vicini, F. (2012). Improving symptoms and quality of life of female cancer survivors: A randomized controlled study. Annals of Surgical Oncology, 19(2), 373-378. https://doi.org/10.1245/s10434-011-2051-2

Leventhal, H. O., \& Brissette, I. (2012). The common-sense model of self-regulation of health and illness. In The Self-Regulation of Health and Illness Behaviour (pp. 5679). Routledge.

Leyva, B., Nguyen, A. B., Allen, J. D., Taplin, S. H., \& Moser, R. P. (2015). Is religiosity associated with cancer screening? Results from a national survey. Journal of Religion and Health, 54(3), 998-1013. https://doi.org/10.1007/s10943-014-9843-1

Lim, J. N. W., \& Ojo, A. A. (2017). Barriers to utilization of cervical cancer screening in Sub Sahara Africa: A systematic review. European Journal of Cancer Care, 26(1), e12444.

Lopes, L. V., Miguel, F., Freitas, H., Tavares, A., Pangui, S., Castro, C., Lacerda, G. F., Longatto-Filho, A., Weiderpass, E., \& Santos, L. L. (2015). Stage at presentation of breast cancer in Luanda, Angola-A retrospective study. BMC Health Services Research, 15(1), 471. https://doi.org/10.1186/s12913-015-1092-9

Ma, G. X., Gao, W., Lee, S., Wang, M., Tan, Y., \& Shive, S. E. (2012). Health seeking behavioral analysis associated with breast cancer screening among Asian American women. International Journal of Women's Health, 4, 235-243.

https://doi.org/10.2147/IJWH.S30738

Magai, C., Consedine, N., Neugut, A. I., \& Hershman, D. (2007). Common psychosocial factors underlying breast cancer screening and breast cancer treatment adherence: A conceptual review and synthesis. Journal of Women's Health, 16(1), 11-23. https://doi.org/10.1089/jwh.2006.0024 
Marlatt, G. A., \& Donovan, D. M. (2005). Relapse Prevention, Second Edition: Maintenance Strategies in the Treatment of Addictive Behaviors. Guilford Press.

Mason, T. E., \& White, K. M. (2008). Applying an Extended Model of the Theory of Planned Behaviour to breast self-examination. Journal of Health Psychology, 13(7), 946-955. https://doi.org/10.1177/1359105308095069

Mayne, T. J. (1999). Negative affect and health: The importance of being earnest. Cognition and Emotion, 13(5), 601-635. https://doi.org/10.1080/026999399379203

McAlister, A. L., Perry, C. L., \& Parcel, G. S. (2008). How individuals, environments, and health behaviors interact. In Health Behavior and Health Education (4th Edition, pp. 169-188). Jossey-Bass.

McCaffery, K., Wardle, J., \& Waller, J. o. (2003). Knowledge, attitudes, and behavioral intentions in relation to the early detection of colorectal cancer in the United Kingdom. Preventive Medicine, 36(5), 525-535. https://doi.org/10.1016/S00917435(03)00016-1

McEachan, R. R. C., Conner, M, Taylor, N. J. \& Lawton, R. J. (2010). Prospective prediction of health-related behaviours with the Theory of Planned Behaviour: a meta-analysis. Health Psychology Review, 1-48, https://doi.org/10.1080/17437199.2010.521684

McEachan, R. R. C., Taylor, N., Harrison, R., Lawton, R., Gardner, P., \& Conner, M. (2016). Meta-Analysis of the Reasoned Action Approach (RAA) to Understanding health behaviors. Ann Behav Med, 50, 592-612.

McLeroy, K., Bibeau, D. L., Steckler, A., \& Glanz, K. (1988). An ecological perspectove on health promotion programs. Health Education Quarterly. https://scottbarrykaufman.com/wp-content/uploads/2019/07/EcologicalPerspectiveMcLeroy.pdf

McPherson, K., Steel, C. M., \& Dixon, J. M. (2000). ABC of breast diseases. Breast cancerepidemiology, risk factors, and genetics. BMJ (Clinical Research Ed.), 321(7261), 624-628. https://doi.org/10.1136/bmj.321.7261.624

Miller, A. B., \& Baines, C. J. (2011). The role of clinical breast examination and breast selfexamination. Preventive Medicine, 53(3), 118-120. https://doi.org/10.1016/j.ypmed.2011.05.001

Milne, S., Sheeran, P., \& Orbell, S. (2000). Prediction and intervention in health-related behavior: A meta-analytic review of Protection Motivation Theory. Journal of Applied Social Psychology, 30(1), 106-143. https://doi.org/10.1111/j.15591816.2000.tb02308.x

Ministry of Health RI. (2013). Riset Kesehatan Dasar 2013 [Basic Health Research]. Jakarta: Kementerian Kesehatan RI.

Ministry of Health RI. (2015a). Manual book for national movement of cervical and breast cancer prevention and early detection program. Jakarta: Ministry of Health RI.

Ministry of Health RI. (2015b). Cancer Situations. Buletin Jendela Data Dan Informasi Kesehatan. Jakarta: Ministry of Health RI

Ministry of Health RI. (2018). Indonesia Health Profile 2017. Jakarta: Ministry of Health RI.

Ministry of Health RI. (2019). Basic Health Research National Report 2018 [Laporan Nasional RISKESDAS 2018]. Jakarta: Ministry of Health RI. 
Nahcivan, N. O., \& Secginli, S. (2007). Health beliefs related to breast self-examination in a sample of Turkish women. Oncology Nursing Forum, 34(2), 425.

Najjar, H., \& Easson, A. (2010). Age at diagnosis of breast cancer in Arab nations. International Journal of Surgery, 8(6), 448-452. https://doi.org/10.1016/j.ijsu.2010.05.012

Narimah, A., Rugayah, H. B., Tahir, A., \& Maimunah, A. H. (1999). Breast Examination, National Health and Morbidity Survey 1996 Volume 20. Public Health Institute, Ministry of Health, Malaysia.

Narod, S. A., Iqbal, J., \& Millr, A. B. (2015). Why have breast cancer mortality rates declined? Journal of Cancer Policy, 5, 8-17. https://doi.org/10.1016/j.jcpo.2015.03.002

Ng, C. H., Pathy, N. B., Taib, N. A., Teh, Y. C., Mun, K. S., Amiruddin, A., Evlina, S., Rhodes, A., \& Yip, C. H. (2011). Comparison of breast cancer in Indonesia and Malaysia-A clinico-pathological study between Dharmais Cancer Centre Jakarta and University Malaya Medical Centre, Kuala Lumpur. Asian Pacific Journal of Cancer Prevention: APJCP, 12(11), 2943-2946.

Njor, S., Nyström, L., Moss, S., Paci, E., Broeders, M., Segnan, N., \& Lynge, E. (2012). Breast cancer mortality in mammographic screening in Europe: A review of incidence-based mortality studies. Journal of Medical Screening, 19(1_suppl), 33-41. https://doi.org/10.1258/jms.2012.012080

Norman, P., \& Cooper, Y. (2011). The theory of planned behaviour and breast selfexamination: Assessing the impact of past behaviour, context stability and habit strength. Psychology \& Health, 26(9), 1156-1172. https://doi.org/10.1080/08870446.2010.481718

Noroozi, A., Jomand, T., \& Tahmasebi, R. (2011). Determinants of breast self-examination performance among Iranian women: An application of the health belief model. $J$ Cancer Educ, 26(2), 365-374. https://doi.org/10.1007/s13187-010-0158-y

Norsa'adah, B., Rampal, K. G., Rahmah, M. A., Naing, N. N., \& Biswal, B. M. (2011). Diagnosis delay of breast cancer and its associated factors in Malaysian women. BMC Cancer, 11(1), 141. https://doi.org/10.1186/1471-2407-11-141

Odongo, J., Makumbi, T., Kalungi, S., \& Galukande, M. (2015). Patient delay factors in women presenting with breast cancer in a low-income country. BMC Research Notes, 8(1), 467. https://doi.org/10.1186/s13104-015-1438-8

Oemiati, R., Rahajeng, E., \& Kristanto, A. Y. (2011). Tumor prevalence and influence factors in Indonesia. Buletin Penelitian Kesehatan, 39(4), 190-204.

Oh, K. M., Taylor, K. L., \& Jacobsen, K. H. (2017). Breast cancer screening among Korean Americans: A systematic review. Journal of Community Health, 42(2), 324-332. https://doi.org/10.1007/s10900-016-0258-7

Okolie, U. V. (2012). Breast self-examination among female undergraduates in Enugu, Southeast, Nigeria. International Journal of Nursing and Midwifery, 4(1), 1-7.

Olsen, O., \& Gøtzsche, P. C. (2001). Cochrane review on screening for breast cancer with mammography. The Lancet, 358(9290), 1340-1342. https://doi.org/10.1016/S01406736(01)06449-2 
Park, H. S. (2000). Relationships among attitudes and subjective norms: Testing the theory of reasoned action across cultures. Communication Studies, 51(2), 162-175.

PDQ ${ }^{\circledR}$ Adult Treatment Editorial Board. (2021). PDQ Breast Cancer Treatment (Adult). National Cancer Institute. https://www.cancer.gov/types/breast/patient/breasttreatment-pdq\#_185

PDQ ${ }^{\circledR}$ Screening and Prevention Editorial Board. (2020). PDQ Cancer Screening Overview (nciglobal,ncienterprise). National Cancer Institute. https://www.cancer.gov/aboutcancer/screening/patient-screening-overview-pdq

Pengpid, S., \& Peltzer, K. (2018). Prevalence and risk factors for cervical and breast cancer screening among women in the general population in Indonesia. Gender and Behavior, 16(3), 11994-12003. https://doi.org/10.10520/EJC-1357e7d788

Peters, G-J. Y. (2018). A practical guide to effective behavior change: How to identify what to change in the first place. In European Health Psychologist: Vol. 16(4) (pp. 142155). https://doi.org/10.31234/osf.io/hy7mj

Pilevarzadeh, M., Amirshahi, M., Afsargharehbagh, R., Rafiemanesh, H., Hashemi, S.-M., \& Balouchi, A. (2019). Global prevalence of depression among breast cancer patients: A systematic review and meta-analysis. Breast Cancer Research and Treatment, 176(3), 519-533. https://doi.org/10.1007/s10549-019-05271-3

Pligt, J. (1996). Risk perception and self-protective behavior. European Psychologist - EUR PSYCHOL, 1, 34-43. https://doi.org/10.1027/1016-9040.1.1.34

Rajaram, S. S., \& Rashidi, A. (1999). Asian-Islamic women and breast cancer screening: A socio-cultural analysis. Women \& Health, 28(3), 45-58.

https://doi.org/10.1300/J013v28n03_04

Richards, M. A., Westcombe, A. M., Love, S. B., Littlejohns, P., \& Ramirez, A. J. (1999). Influence of delay on survival in patients with breast cancer: A systematic review. The Lancet, 353(9159), 1119-1126. https://doi.org/10.1016/S0140-6736(99)02143-1

Rimal, R. N. (2009). Closing the knowledge-behavior gap in health promotion: The mediating role of self-efficacy. Health Communication, 12(3), 219-237. https://doi.org/10.1207/S15327027HC1203_01

Ritchie, D., Broucke, S. V. den, \& Hal, G. V. (2021). The health belief model and theory of planned behavior applied to mammography screening: A systematic review and metaanalysis. Public Health Nursing, 38(3), 482-492. https://doi.org/10.1111/phn.12842

Rogers, R. W., \& Deckner, C. W. (1975). Effects of fear appeals and physiological arousal upon emotion, attitudes, and cigarette smoking. Journal of Personality and Social Psychology, 32(2), 222-230. https://doi.org/10.1037/0022-3514.32.2.222

Roncancio, A. M., Ward, K. K., Sanchez, I. A., Cano, M. A., Byrd, T. L., Vernon, S. W., Fernandez-Esquer, M. E., \& Fernandez, M. E. (2015). Using the Theory of Planned Behavior to understand cervical cancer screening among Latinas. Health Education \& Behavior, 42(5), 621-626. https://doi.org/10.1177/1090198115571364

Rosenstock, I. M. (1966). Why people use health services. The Milbank Memorial Fund Quarterly, 44(3), Suppl:94-127.

Ruiter, R. A. C., Abraham, C., \& Kok, G. (2001). Scary warnings and rational precautions: A review of the psychology of fear appeals. Psychology \& Health, 16(6), 613-630. https://doi.org/10.1080/08870440108405863 
Ruiter, R. A. C., Kessels, L. T. E., Peters, G.-J. Y., \& Kok, G. (2014). Sixty years of fear appeal research: Current state of the evidence. International Journal of Psychology, 49(2), 63-70. https://doi.org/10.1002/ijop.12042

Sa'ir, A., Sholahudin, U., \& Trihartono, A. (2020). Social and cultural behavior in handling urban issues: The case of Surabaya, Indonesia. IOP Conference Series: Earth and Environmental Science, 485, 012012. https://doi.org/10.1088/1755$1315 / 485 / 1 / 012012$

Schiavo, R. (2007). Health Communication. From Theory to Practice. Jossey-Bass.

Schmid-Büchi, S., Halfens, R. J., Dassen, T., \& Borne, B. V. D. (2008). A review of psychosocial needs of breast-cancer patients and their relatives. Journal of Clinical Nursing, 17(21), 2895-2909. https://doi.org/10.1111/j.1365-2702.2008.02490.x

Schmidt, M. E., Wiskemann, J., \& Steindorf, K. (2018). Quality of life, problems, and needs of disease-free breast cancer survivors 5 years after diagnosis. Quality of Life Research, 27(8), 2077-2086. https://doi.org/10.1007/s11136-018-1866-8

Secginli, S., \& Nahcivan, N. O. (2006). Factors associated with breast cancer screening behaviours in a sample of Turkish women: A questionnaire survey. International Journal of Nursing Studies, 43(2), 161-171. https://doi.org/10.1016/j.ijnurstu.2005.02.004

Sheeran, P. (2002). Intention-behavior relations: A conceptual and empirical review. European Review of Social Psychology, 12, 1-30.

Sheeran, P., \& Abraham, C. (2003). The health belief model. In: Conner M, Norman P, editors. In Predicting Health Behaviour. Research and Practice with Social Cognition Models (pp. 23-61). Open University.

Shin, K. R., Park, H. J., \& Kim, M. (2012). Practice of breast self-examination and knowledge of breast cancer among female university students in Korea. Nursing \& Health Sciences, 14(3), 292-297. https://doi.org/10.1111/j.1442-2018.2012.00696.x

Sitorus, S., \& Budhwar, P. S. (2003). Doing business in Indonesia. Thunderbird International Business Review, 45(5), 587-609. https://doi.org/10.1002/tie.10091

Skinner, C. S., Tiro, J., \& Champion, V. L. (2015). Background on the health belief model. In Health Behavior: Theory, Research, and Practice (5th ed, pp. 75-94). Jossey-Bass.

Smalls, B. L., Aroh, A., McQuerry, K., Adegboyega, A., Schoenberg, N., \& Hatcher, J. (2018). Social support and breast cancer screening in rural Appalachia. PsychoOncology, 27(9), 2281-2288. https://doi.org/10.1002/pon.4828

Solikhah, S., Promthet, S., \& Hurst, C. (2019). Awareness level about breast cancer risk factors, barriers, attitude and breast cancer screening among Indonesian women. Asian Pacific Journal of Cancer Prevention, 20(3), 877-884. https://doi.org/10.31557/APJCP.2019.20.3.877

Sontag, S. (1978). Illness As Metaphor. Farrar, Straus and Giroux.

Sreedevi, A., Quereshi, M. A., Kurian, B., \& Kamalamma, L. (2014). Screening for breast cancer in a low middle-income country: Predictors in a rural area of Kerala, India. Asian Pacific Journal of Cancer Prevention, 15(5), 1919-1924. https://doi.org/10.7314/APJCP.2014.15.5.1919

Stapleton, J. M., Mullan, P. B., Dey, S., Hablas, A., Gaafar, R., Seifeldin, I. A., Banerjee, M., \& Soliman, A. S. (2011). Patient-mediated factors predicting early- and late-stage 
presentation of breast cancer in Egypt. Psycho-Oncology, 20(5), 532-537. https://doi.org/10.1002/pon.1767

Statistics of Surabaya. (2016). Kota Surabaya dalam angka 2016 [Surabaya municipality in figure]. Surabaya: Statistics of Surabaya.

Statistics of Surabaya. (2019). Kota Surabaya dalam angka 2019 [Surabaya municipality in figure]. Surabaya: Statistics of Surabaya.

Straughan, P. T., \& Seow, A. (2000). Attitudes as barriers in breast screening: A prospective study among Singapore women. Social Science \& Medicine (1982), 51(11), 16951703. https://doi.org/10.1016/s0277-9536(00)00086-1

Sun, A., Zhang, J., Tsoh, J., Wong-Kim, E., \& Chow, E. (2007). The effectiveness in utilizing Chinese media to promote breast health among Chinese women. Journal of Health Communication, 12(2), 157-171. https://doi.org/10.1080/10810730601150106

Taha, H., Al-Qutob, R., Nyström, L., Wahlström, R., \& Berggren, V. (2012). "Voices of Fear and Safety" Women's ambivalence towards breast cancer and breast health: A qualitative study from Jordan. BMC Women's Health, 12(1), 1-10. https://doi.org/10.1186/1472-6874-12-21

Tavafian, S. S., Hasani, L., Aghamolaei, T., Zare, S., \& Gregory, D. (2009). Prediction of breast self-examination in a sample of Iranian women: An application of the Health Belief Model. BMC Women's Health, 9, 37. https://doi.org/10.1186/1472-6874-9-37

Taylor, S. E. (2020). Health Psychology. McGraw Hill Ryerson.

Tennen, H., \& Affleck, G. (1987). The costs and benefits of optimistic explanations and dispositional optimism. Journal of Personality, 55(2), 377-392. https://doi.org/10.1111/j.1467-6494.1987.tb00443.x

Unger-Saldaña, K., \& Infante-Castañeda, C. (2009). Delay of medical care for symptomatic breast cancer: A literature review. Salud Pública de México, 51, s270-s285. https://doi.org/10.1590/S0036-36342009000800018

Valente, T. W., Paredes, P., \& Poppe, P. R. (1998). Matching the message to the process the relative ordering of knowledge, attitudes, and practices in behavior change research. Human Communication Research, 24(3), 366-385. https://doi.org/10.1111/j.14682958.1998.tb00421.x

van Schoor, G., Moss, S. M., Otten, J. D. M., Donders, R., Paap, E., den Heeten, G. J., Holland, R., Broeders, M. J. M., \& Verbeek, A. L. M. (2011). Increasingly strong reduction in breast cancer mortality due to screening. British Journal of Cancer, 104(6), 910-914. https://doi.org/10.1038/bjc.2011.44

Vernon, S. W. (1999). Risk perception and risk communication for cancer screening behaviors: A review. JNCI Monographs, 1999(25), 101-119. https://doi.org/10.1093/oxfordjournals.jncimonographs.a024184

Viswanath, K., \& Ackerson, L. K. (2011). Race, ethnicity, language, social class, and health communication inequalities: A nationally-representative cross-sectional study. PLoS ONE, 6(1). https://doi.org/10.1371/journal.pone.0014550

Wakefield, M. A., Loken, B., \& Hornik, R. C. (2010). Use of mass media campaigns to change health behavior. Lancet, 376(9748), 1261-1271.

https://doi.org/10.1016/S0140-6736(10)60809-4 
Wang, W. L., Hsu, S. D., Wang, J. H., Huang, L. C., \& Hsu, W. L. (2014). Survey of breast cancer mammography screening behaviors in Eastern Taiwan based on a health belief model. The Kaohsiung Journal of Medical Sciences, 30(8), 422-427. https://doi.org/10.1016/j.kjms.2014.04.007

Wang, X., Chen, D., Xie, T., \& Zhang, W. (2019). Predicting women's intentions to screen for breast cancer based on the health belief model and the theory of planned behavior. The Journal of Obstetrics and Gynecology Research, 45 (12), 2440-2451. https://doi.org/doi:10.1111/jog.14109

Weinstein, N. D. (1988). The precaution adoption process. Health Psychology, 7(4), 355386. https://doi.org/10.1037/0278-6133.7.4.355

Weinstein, N. D., \& Lyon, J. E. (1999). Mindset, optimistic bias about personal risk and health-protective behaviour. British Journal of Health Psychology, 4(4), 289-300. https://doi.org/10.1348/135910799168641

Werner, D., \& Bower, B. (1982). Helping Health Workers Learn: A Book of Methods, Aids and Ideas for Workers at The Village Level. Hesperian.

Wu, S. F. V., Hsieh, N.C., Lin, L.J., \& Tsai, J.M. (2016). Prediction of self-care behaviour on the basis of knowledge about chronic kidney disease using self-efficacy as a mediator. Journal of Clinical Nursing, 25(17-18), 2609-2618. https://doi.org/10.1111/jocn.13305

Xiong, Q., Valero, V., Kau, V., Kau, S.-W., Taylor, S., Smith, T. L., Buzdar, A. U., Hortobagyi, G. N., \& Theriault, R. L. (2001). Female patients with breast carcinoma age 30 years and younger have a poor prognosis. Cancer, 92(10), 2523-2528. https://doi.org/10.1002/1097-0142(20011115)92:10<2523::AIDCNCR1603>3.0.CO;2-6

Yip, C. H., Taib, N. A., Song, C. V., Pritam Singh, R. K., \& Agarwal, G. (2018). Early Diagnosis of Breast Cancer in the Absence of Population-Based Mammographic Screening in Asia. Current Breast Cancer Reports, 10(3), 148-156. https://doi.org/10.1007/s12609-018-0279-6 


\section{Summary}

Breast cancer remains a public health concern in Indonesia, due to its high incidence, late presentation, and high mortality rate. Therefore, early diagnosis followed by timely treatment is regarded as a cornerstone for breast cancer control. Utilizing mammography as populationbased breast cancer screening in Indonesia is quite challenging, due to the limited healthcare resources and effectiveness for younger age women as the most diagnosed age group. Consequently, breast self-examination (BSE) practice followed by a prompt medical professional examination in the case of detected abnormalities may serve as a viable screening method for detecting breast cancer in an early stage. However, the practice of BSE among the Indonesian population is still low. Therefore, the current dissertation set out to investigate the psychosocial determinants of BSE among women in Surabaya, Indonesia, with the ultimate aim to inform the development of (tailored) interventions.

Specifically, the objectives of this dissertation were twofold: 1) to explore the potential psychosocial determinants of BSE, and 2) to confirm and assess psychosocial determinants of BSE among women in Surabaya, Indonesia. To achieve these aims, we conducted four empirical studies - using both quantitative and qualitative methodology - which are made up of this dissertation and the major recommendations are summarized below.

Chapter 2 was a cross-sectional study to assess the association of Health Belief Model (HBM) components with BSE among women in Surabaya, Indonesia. We found that $44.4 \%$ of the total 1.967 respondents reported having ever performed BSE in the past year. The likelihood to perform BSE was associated with older age $(>40)$, well-educated (having at least a high school education), and having a family history of cancer. This chapter indicated that HBM conceptualization was supported, that is when the women showed higher perceived benefits and self-efficacy, and low perceived barriers were more likely to perform BSE. In contrast to the HBM postulate, cues to action were negatively associated with the likelihood 
to perform BSE. Further, the study indicated that perceived severity and susceptibility did not predict BSE performance.

To gain a deeper understanding on factors encourage women to perform an early presentation and their lived experiences, in Chapter 3, we conducted semi-structured interviews among breast cancer survivor in Surabaya, Indonesia. Our respondents were mostly diagnosed with an early stage of breast cancer (Stage I and II), married, employed, having a university education, a good family income, and no family history of breast cancer. Most respondents received their first medical consultation between one day to three months after noticing the first symptom, and it took between one day to one month later to obtain the diagnosis. We found that breast cancer early presentation was determined by internal factors including the understanding of the nature of breast cancer, perceived behavioral control or self-efficacy to perform BSE, previous health-related experience which associated with perceived risk of breast cancer, and positive and negative evaluation about BSE; and external factors, namely: normative expectation from significant others, competing priorities, instrumental support, accessibility and comfortability of health providers, and financial issues.

Further, in Chapter 4 we explore the potential beliefs that underlie BSE motivation among women who never or rarely $(\leq 3)$ performed BSE in the previous year in Surabaya, Indonesia, using focused group discussions. In addition, we also explore the effective approach work best to improve breast awareness in the women's social network. Our finding indicated that underlying beliefs that contributed to BSE motivation among our respondents were: the understanding about breast cancer and BSE, perceived outcome evaluation of performing BSE, perceived vulnerability and severity of breast cancer, subjective norms, perceived behavioral control, and intention. Further, we found that the potential breast consultation agents for married participants were their husband, and those who were 
unmarried preferred to discuss issues with their families, particularly their mother. Face-toface meetings that encompassed both oral and written information, and delivered by a trusted source, i.e., healthcare professionals, were mentioned as the effective channel for breast cancer education. Community organization or activities, e.g., PKK (Indonesia: Pembinaan Kesejahteraan Keluarga, English: Women's Family Welfare Movement), POSYANDU (Indonesia: Pos Pelayanan Terpadu, English: Integrated Service Post), religious communities, were also mentioned as the resources to support such intervention.

Finally, we conducted a quantitative study to confirm and assess the psychosocial factors of BSE practice among women in Surabaya, Indonesia from our previous quantitative and qualitative studies in Chapter 5. Our respondents were mostly well-educated, employed, having a good family income, no history of breast cancer in their family, and having health insurance. Most women (72.5\%) expressed intention to perform BSE, however, only $7.8 \%$ and $2.9 \%$ performed BSE per week and per month, respectively, in the past year. Our finding suggested that intention to perform BSE was determined by perceived behavioral control and attitudes towards BSE, while BSE performance was determined by understanding of the nature of breast cancer and attitude towards BSE. Additionally, we found that several changeable psychosocial variables i.e., perceived benefits and barriers, and subjective norms were failed to explain any unique variances of both intention and BSE behavior. However, these variables were significantly associated with intention and/or BSE behavior in the bivariate correlation analysis.

In the general discussion in Chapter 6, the main findings are summarized, discussed, and critically appraised. The following practical implications of the findings are proposed:

1. Encouraging a tailored and theoretically based intervention to promote BSE and breast awareness in the Indonesian context by involving various relevant stakeholders, i.e., husband/family/close friend, healthcare provider, health policymakers, PKK and 
POSYANDU. Concerning determinants of behavior at risk explored, suggestions for intervention should convey the message to improve understanding of the nature of breast cancer and BSE, incorporate strategies to promote women's perceived benefits and positive attitudes towards BSE, comprehend methods to improve women's self-efficacy and skill to perform BSE and train relevant strategies to overcome the barriers to perform such. Additionally, the education should incorporate methods to increase knowledge and attitudes in the women's social network (i.e., husband, family, and close friend) to support women's BSE behavior. Lastly, breast cancer education could employ a face-to-face meeting equipped with visual media, and involving healthcare professionals as spokeperson, which can be incorporated in PKK/POSYANDU monthly meetings.

2. Improving patients-healthcare provider relationship by promoting a two-way consultation style where there is more room for the questions the patients may have and an opportunity to ask further information about their disease and treatment plan. Thus, allowing exploration and facilitation of patients' worries and concerns, which in turn promotes health-seeking behavior. 


\section{Ringkasan}

Kanker payudara merupakan salah satu masalah kesehatan masyarakat di Indonesia. Hal ini dikarenakan tingginya angka kejadian kanker payudara dan sebagian besar pasien didiagnosis pada stadium lanjut sehingga berdampak pada jumlah angka kematian yang cukup tinggi. Oleh karena itu, diagnosis dini diikuti dengan pengobatan tepat waktu dianggap sebagai landasan penting untuk pengendalian kanker payudara. Penggunaan mamografi sebagai metode skrining kanker payudara berbasis populasi nampak kurang efektif untuk diterapkan di Indonesia. Hal ini disebabkan karena adanya keterbatasan sumber daya kesehatan, selain itu mamografi dianggap sebagai metode yang kurang efektif untuk mendeteksi kanker payudara pada wanita usia muda sebagai kelompok usia yang paling banyak didiagnosis di Indonesia. Praktik pemeriksaan payudara sendiri (SADARI) yang diikuti dengan pemeriksaan medis segera setelah terdeteksi adanya kelainan pada payudara dapat berfungsi sebagai metode skrining untuk mendeteksi kanker payudara pada tahap awal. Namun demikian, praktik SADARI di kalangan wanita Indonesia masih cukup rendah. Disertasi ini bertujuan untuk menginvestigasi determinan psikososial SADARI pada wanita di Surabaya, Indonesia, sehingga pada akhirnya dapat memberikan input bagi pengembangan intervensi untuk meningkatkan perilaku deteksi dini kanker payudara.

Secara spesifik, tujuan disertasi ini adalah: 1) untuk mengeksplorasi determinan psikososial potensial perilaku SADARI, dan 2) untuk mengkonfirmasi dan mengukur determinan psikososial SADARI pada wanita di Surabaya, Indonesia. Untuk mencapai tujuan ini, kami melakukan empat studi empiris - menggunakan metodologi kuantitatif dan kualitatif - yang akan dirangkum di bawah ini.

Bab 2 merupakan studi cross-sectional untuk mengukur hubungan komponen Health Belief Model (HBM) dengan perilaku SADARI pada wanita di Surabaya, Indonesia. Kami 
menemukan bahwa 44,4\% dari total 1.967 responden pernah melakukan SADARI dalam satu tahun terakhir. Kemungkinan untuk melakukan SADARI dikaitkan dengan usia yang lebih tua ( $>40$ tahun), berpendidikan tinggi (memiliki pendidikan setidaknya sekolah menengah), dan memiliki keluarga dengan riwayat kanker. Bab ini menunjukkan bahwa konsep HBM dapat memprediksi perilaku SADARI, yaitu ketika seseorang berpikir bahwa melakukan SADARI cukup bermanfaat (perceived benefits) dan memiliki keyakinan diri (self-efficacy) yang cukup tinggi untuk melakukannya, serta menilai hambatan untuk melakukan SADARI (perceived barriers) cukup rendah, maka ia akan lebih mungkin untuk melakukan SADARI. Akan tetapi, berbeda dengan postulat HBM, isyarat untuk bertindak (cues to action) berhubungan negatif dengan kemungkinan untuk melakukan SADARI. Selanjutnya, penelitian ini juga menunjukkan bahwa persepsi atas keparahan penyakit (perceived severity) dan persepsi bahwa ia rentan untuk menderita penyakit (perceived susceptability) tidak memprediksi perilaku SADARI.

Untuk memperoleh pemahaman yang lebih mendalam tentang faktor-faktor yang mendorong perempuan untuk melakukan presentasi awal (yaitu meliputi melakukan deteksi dini kanker payudara dan segera melakukan konsultasi medis ketika ada keluhan pada payudara), di Bab 3, kami melakukan wawancara semi-terstruktur pada penyintas kanker payudara di Surabaya, Indonesia. Responden kami sebagian besar didiagnosis dengan kanker payudara stadium awal (Stadium I dan II), menikah, bekerja, memiliki pendidikan universitas, pendapatan keluarga yang baik, dan tidak ada riwayat keluarga kanker payudara. Sebagian besar responden melakukan konsultasi medis pertama mereka antara satu hari sampai tiga bulan setelah mengalami gejala pertama, dan membutuhkan waktu antara satu hari sampai satu bulan kemudian untuk memperoleh diagnosis. Kami menemukan bahwa presentasi dini kanker payudara ditentukan oleh faktor internal termasuk pemahaman tentang kanker payudara, persepsi kontrol perilaku (perceived behavioral control) atau keyakinan diri 
untuk melakukan SADARI, pengalaman terkait kesehatan sebelumnya yang terkait dengan persepsi risiko, dan sikap atau evaluasi positif dan negatif tentang SADARI; dan faktor eksternal, yaitu: ekspektasi normatif dari orang-orang terdekat, adanya prioritas kegiatan lain, dukungan instrumental, aksesibilitas dan kenyamanan penyedia layanan kesehatan, dan masalah keuangan.

Selanjutnya, dalam Bab 4 kami mengeksplorasi keyakinan potensial yang mendasari motivasi perilaku SADARI di antara wanita yang tidak pernah atau jarang $(\leq 3)$ melakukan SADARI pada tahun sebelumnya di Surabaya, Indonesia, dengan menggunakan Focused Group Discussion (FGD). Selain itu, kami juga mengeksplorasi pendekatan yang paling efektif untuk meningkatkan breast awareness di lingkungan tempat tinggal mereka. Temuan kami menunjukkan bahwa keyakinan mendasar yang berkontribusi terhadap motivasi melakukan SADARI di antara responden kami adalah: pemahaman tentang kanker payudara dan SADARI, sikap terhadap SADARI, persepsi kerentanan dan keparahan kanker payudara, norma subjektif, persepsi kontrol perilaku, dan niat. Selanjutnya, kami menemukan bahwa responden mendiskusikan permasalahan payudara mereka dengan suami mereka - apabila sudah menikah, dan wanita yang belum menikah lebih suka mendiskusikan topik tersebut dengan keluarga, terutama ibu. Responden menyebutkan bahwa pertemuan tatap muka yang mencakup informasi lisan dan tertulis, dan disampaikan oleh sumber tepercaya, yaitu profesional kesehatan merupakan saluran yang efektif untuk pendidikan kanker payudara. Organisasi atau kegiatan kemasyarakatan, misalnya PKK (Pembinaan Kesejahteraan Keluarga), POSYANDU (Pos Pelayanan Terpadu), komunitas keagamaan, juga disebutkan sebagai sumber daya yang dapat dipergunakan untuk mendukung intervensi tersebut.

Pada studi terakhir, kami melakukan penelitian kuantitatif untuk mengkonfirmasi dan mengukur faktor psikososial perilaku SADARI pada wanita di Surabaya, Indonesia berdasarkan hasil dari penelitian kuantitatif dan kualitatif kami sebelumnya di Bab 5 . 
Sebagian besar responden kami berpendidikan tinggi, bekerja, memiliki pendapatan keluarga yang baik, tidak memiliki riwayat kanker payudara dalam keluarga, dan memiliki asuransi kesehatan. Sebagian besar wanita (72,5\%) menyatakan niat untuk melakukan SADARI, namun hanya $7,8 \%$ dan 2,9\% yang melakukan SADARI per minggu dan per bulan dalam satu tahun terakhir. Temuan kami menunjukkan bahwa niat untuk melakukan SADARI ditentukan oleh persepsi kontrol perilaku dan sikap terhadap SADARI, sedangkan perilaku SADARI ditentukan oleh pengetahuan terkait kanker payudara dan sikap terhadap perilaku SADARI. Selain itu, kami menemukan bahwa beberapa variabel psikososial yang dapat diubah yaitu, persepsi manfaat (perceived benefits) dan hambatan (perceived barriers) dalam melakukan SADARI, dan norma subjektif bukan merupakan varian unik dari niat dan perilaku BSE. Namun, variabel-variabel tersebut secara signifikan memiliki hubungan dengan niat dan/atau perilaku SADARI dalam analisis korelasi bivariat.

Dalam pembahasan umum di Bab 6, temuan-temuan utama dirangkum, didiskusikan, dan dinilai secara kritis. Berikut beberapa implikasi praktis dari temuan:

1. Mendorong intervensi yang disesuaikan dengan karakteristik populasi dan berbasis teori untuk mempromosikan perilaku SADARI dan breast awareness dalam konteks Indonesia dengan melibatkan berbagai pemangku kepentingan terkait, yaitu suami/keluarga/teman dekat, penyedia layanan kesehatan dan pembuat kebijakan kesehatan, PKK, dan POSYANDU. Sesuai dengan temuan terkait determinan perilaku beresiko, target intervensi sebaiknya meliputi upaya untuk meningkatkan pengetahuan terkait kanker payudara dan perilaku SADARI, menyusun strategi untuk meningkatkan persepsi kebermanfaatan (perceived benefits) melakukan SADARI dan sikap positif terhadap perilaku SADARI, memahami metode untuk meningkatkan keyakinan diri dan keterampilan melakukan SADARI dan melatih strategi yang relevan untuk mengatasi hambatan untuk melakukan perilaku tersebut. Selain itu, intervensi yang dilakukan 
perlu melibatkan metode untuk meningkatkan pengetahuan dan sikap terkait kanker payudara dan SADARI pada jaringan sosial yang dimiliki oleh para wanita (yaitu: suami, keluarga, dan teman dekat) untuk mendukung perilaku SADARI. Terakhir, edukasi kanker payudara dapat dilakukan melalui tatap muka yang dilengkapi dengan media visual, dan melibatkan tenaga kesehatan sebagai narasumber, yang dapat dilaksanakan dalam pertemuan bulanan PKK/POSYANDU.

2. Meningkatkan hubungan pasien-penyedia layanan kesehatan dengan mempromosikan pola komunikasi dua arah. Hal ini memungkinkan adanya lebih banyak ruang untuk pertanyaan yang mungkin dimiliki pasien dan kesempatan untuk menanyakan informasi lebih lanjut tentang penyakit dan rencana pengobatan yang akan mereka terima. Dengan demikian, memungkinkan adanya eksplorasi dan fasilitasi kekhawatiran yang dirasakan oleh pasien, yang pada gilirannya akan mendorong perilaku pengobatan (health-seeking behavior). 


\section{Impact paragraph}

The overall aim of this dissertation is to understand relevant and changeable determinants of BSE behavior in the Indonesian context. Thus, this dissertation provides a need assessment a primary step to initiate the development of future tailored breast awareness education to stimulate regular BSE and other screening behaviors among Indonesian women. Particularly, this dissertation provides practical recommendations aimed to guide the development of breast cancer education. First, to effectively plan, develop, implement and evaluate breast education, a joint collaboration of relevant key stakeholders identified in this dissertation is needed: The intervention should include the empowerment of women's direct social networks i.e., spouse, family, friends, PKK (Indonesia: Pembinaan Kesejahteraan Keluarga, English: Women's Family Welfare Movement) or POSYANDU (Indonesia: Pos Pelayanan Terpadu, English: Integrated Service Post), and involving healthcare providers, health policymakers, and behavior change experts.

Second, this dissertation proposes a logic model to analyze health and quality of life problems and their causes and to decide on priorities, which is generated using the PRECEDE (Predisposing, Reinforcing and Enabling Constructs in Ecosystem Diagnosis and Evaluation) model. This logic model provides a guideline for future breast education by targeting behaviors at risk, including:

1. Individual factors: intervening the women failure to identify breast cancer symptoms, to overcome personal and environmental barriers of BSE, not to wait and see if symptoms resolve, to perform a medical examination prior to noticing any symptom, to overcome personal and environmental barriers of the medical examination after onset symptom, not to contract a non-medical treatment, and to perform the medical treatment after diagnosis. 
2. Environmental factors:

a. Targeting women's husband/family/close friend/colleagues to work on reducing lack of social support to perform BSE, lack of social and instrumental support for medical examination after onset symptom, and lack of social and instrumental support to perform the medical treatment after onset symptom.

b. Targeting healthcare providers and policymakers to work on providing accessible information about breast cancer diagnosis pathways, promoting patients-health care providers communication, training PKK/POSYANDU members about breast cancer and BSE, and eliminating the lack of: information about breast cancer, recommendations to perform breast cancer test to symptomatic women, accessible breast cancer diagnosis facilities and recommendation to perform medical treatment following a breast cancer diagnosis.

c. Targeting PKK or POSYANDU to work on providing information about breast cancer and BSE and promoting social support to perform BSE.

Further, future breast education may translate the findings into practical application by incorporating the psychosocial determinants which are found to be relevant and changeable into intervention messages. Therefore, breast education in the Indonesian context should focus on promoting breast cancer literacy and BSE information by focusing on strategies to stimulate understanding of BSE benefits and positive attitudes towards BSE. The education should also encompass methods to improve women's self-efficacy/PBC and skill to perform $\mathrm{BSE}$, for example by providing video on how to perform BSE, and the women are asked to practice it and discussed whether they had performed it correctly. Moreover, relevant strategies to overcome the barriers to perform such should also be incorporated. For example, the women are asked to list potential barriers to performing BSE and related and trained 
effective strategies to overcome them. Finally, a sustainable breast cancer early detection intervention may be promoted by fostering a theoretically and culturally-based intervention program, with the ultimate aim to reduce breast cancer mortality in Indonesia.

To disseminate the knowledge in this dissertation, conference and scientific publications in high-impact journals have been used. A popular article for laypeople was also published at The Conversation Indonesia, which was further circulated among national online news portals, such as Kompas.com. Further, the findings were communicated to PKK Kota Surabaya, and further will be disseminated to the Health Office of Kota Surabaya. 


\section{Acknowledgement}

My $\mathrm{PhD}$ trajectory is a dream comes true, an amazing journey that I deeply value both in my academic and personal life. I would like to express my gratitude and sincerely thank all of the people who inspire and kindly guide and support me during my $\mathrm{PhD}$ journey.

Prof Rob Ruiter, I sincerely thank you for your ongoing support during my $\mathrm{PhD}$. I am more than grateful and proud to have you supervise my work. You always encourage me to learn something new and to improve my critical and analytical thinking. Your strong passion, commitment, and intellect you put into your work have inspired me, especially your emphasis on how our work can be translated into practical application to promote the betterment of society. You're always kind and cared for my well-being, especially in this COVID-19 outbreak where I struggling the work with my other role as a mother of four.

Dr. Karlijn Massar, I am deeply grateful to have you as my supervisor. You were always patient with me, especially in the initial stage where I just started my PhD. You encouraged and guided me to build confidence and grow as an independent researcher and a writer. Under your supervision, I found myself enjoying each of research process, taking the challenges, and eager to learn and experience something new. You also help me with everything under your control to make sure I have sufficient funding to continue my $\mathrm{PhD}$. You are indeed a great supervisor and mentor. Thank you for your endless support and for making sure I could complete my PhD without constraints.

Dr. Rahkman Ardi, a supervisor and a best friend. I cannot be more grateful to have you in this $\mathrm{PhD}$ journey. You are at the forefront of social psychology researcher and your compassion, intellect and humbleness have been an inspiration to me. You always encourage 
me to build my confidence in research, writing, and presenting my work. You helped me to secure research funding so I could finish my project without constraints. Thank you for always listening and motivating me and being a part of my progress as a researcher and as a person.

I thank my friends and colleagues at the Department of Work and Social Psychology, FPN. Mariella, thank you for your help during my PhD. My PhD colleagues; Sandra, Eka, Tari, Bona, Sumit, and Untung, wishing you a successful future. Rosine and Darta, thank you for organizing $\mathrm{PhD}$ meetings for us.

Dr. Gill ten Hoor, my PBC tutor back in 2011, the one who recommend me for a $\mathrm{PhD}$ position and also one of my thesis assessment committee. Thank you for helping me to experience this amazing $\mathrm{PhD}$ journey. Moreover, we valued your lecture on Intervention Mapping for our students in 2018.

I am grateful for the support I received from the Deans of Faculty of Psychology, Universitas Airlangga, from the first time I initiated until finally finished my $\mathrm{PhD}$ trajectory: Prof Seger Handoyo, Prof Nurul Hartini, and Prof Suryanto. The Vice Deans, Mas Ilham and Ayok, thank you for arranging financial support for some part of my study. I am thankful for the support from my colleagues at the Faculty of Psychology, Universitas Airlangga, particularly my colleagues in the (ex-)department of clinical psychology and mental health. Mas Sam and Mbak Wiwin, I highly appreciate your time and thoughtful discussion in statistics and qualitative research methods. Mbak Mima - my lunch, shopping, conference, and workshop buddy, thank you for sharing every up and down in campus and personal life. Late $\mathrm{Bu}$ 
Hamidah and Mbak Ira, thanks for believing my dream in the first place, I always appreciate it.

My regards go to the participants of the project, Reach to Recovery Surabaya,

Wisnuwardhana cancer foundations, PKK Kota Surabaya, Oncology hospital Surabaya, dr.

Bob J. Octavianus, Sp.B (FICS) and Ny. Siti Nuriya Zam Zam Sigit. My research team: Bibi, Vania, Sari, Giska, Sukma, Nina, Nanda, Anya, and Siska, you were amazing, girls! Mas Tino and Merle, it was a great experience to work one of my chapter with you.

Friends I met during this PhD journey, Mas Nael, Mbak Astin, Bu Carla, and PPI Maastricht thank you for being a great accompany when I visited Maastricht. Friends which turn out to be family I first met during my master study and always provided a great deal of support when I visited Maastricht: Johan and Ratna Brandse, Ilse Cox, Mas Wisnu and Mbak Yuli. I am grateful to know each of you, thank you for being part of my journey.

Finally, I would like to deeply thank my beloved family. Ayah, you are truly my backbone, your continued support enables me to stand where I am today. My fantastic four, Bima, Indra, Zahra, and Fatimah, you are the reason and my energy. Bapak and Mami, your endless support, prayers, and wisdom help me navigate through life. My big brother and sisters, Mas Iwan, Mbak Pipit, and Mbak Ririn, thank you so much for your support and prayers. And in the loving memories of my Father and Mother-in-law, thank you for your genuine support and prayer for me, especially when you were taking care of my children when I was away for Maastricht. I cannot be more grateful to have this loving and caring family. With all of my heart, thank you. 


\section{Curriculum Vitae}

Triana Kesuma (Anna) Dewi was born on January 1983, in Jombang, East Java, Indonesia. She earned a Bachelor's Degree in Psychology (Clinical Psychology major) from the Faculty of Psychology, Universitas Airlangga, Indonesia in 2005. Following her graduation, she worked as a lecturer in the same faculty. She moved to the Netherlands with her husband and their children to pursue a further degree and earned a Master degree in Health and Social Psychology from Maastricht University in 2012. After receiving her master degree, she returned to her work in the Faculty of Psychology, Universitas Airlangga. In 2018, she enrolled as a doctoral candidate back at Maastricht University, under the Department of Work and Social Psychology. Her research interests are mainly in health and social psychology area, particularly behavior change in health context, psychosocial determinants of health (risk) behavior, health-related quality of life, and psycho-oncology.

\section{Publication in this Dissertation}

Dewi, T. K., Massar, K., Ruiter, R. A., \& Leonardi, T. (2019). Determinants of breast selfexamination practice among women in Surabaya, Indonesia: an application of the health belief model. BMC Public Health, 19(1), 1-8.

Dewi, T. K., Massar, K., Ardi, R., \& Ruiter, R. A. (2020). Determinants of early breast cancer presentation: a qualitative exploration among female survivors in Indonesia. Psychology \& Health, 1-14.

Dewi, T. K., Ruiter, R. A., Ardi, R., \& Massar, K. (2021). The role of psychosocial variables in breast self-examination practice: Results from focused group discussions in Surabaya, Indonesia. Manuscript submitted for publication.

Dewi, T. K., Ruiter, R. A., Diering, M., Ardi, R., \& Massar, K. (2021). Breast selfexamination as a route to early detection in a lower middle-income country: Assessing psychosocial determinants among women in Surabaya, Indonesia. Manuscript submitted for publication. 


\section{Other Publications}

Dewi, T.K., Peters, M.L., \& Margono, B.P. (2014). The effect of religiosity mediated by acceptance on quality of life: A study on Muslim patients with cancer in palliative care. GSTF Journal of Law and Social Science, 2(2), 102-107.

Hartini, N., Ariana, A. D., Dewi, T. K., \& Kurniawan, A. (2017). Improving urban environment through public commitment toward the implementation of clean and healthy living behaviors. Psychology Research and Behavior Management, 10, 79.

Dewi, T. K., \& Zein, R. A. (2017). Predicting intention to perform breast self-examination: application of the theory of reasoned action. Asian Pacific Journal of Cancer Prevention: APJCP, 18(11), 2945.

Dewi, T. K. (2018). Validation of the Indonesian version of Champion's Health Belief Model Scale for breast self-examination. Psychology Research and Behavior Management, 11, 433. 